\title{
THE CUSTOMARY OF THE ROYAL CONVENT \\ OF LAS HUELGAS OF BURGOS: \\ FEMALE LITURGY, FEMALE SCRIBES
}

\author{
David Catalunya \\ Universität Würzburg \\ david.catalunya@gmail.com \\ orcid.org/oooo-0002-1847-0137
}

\begin{abstract}
This article explores the medieval customary of the royal convent of Las Huelgas of Burgos, a hitherto unpublished document of critical importance for the knowledge of one of the most emblematic institutions of medieval Castile. The manuscript, compiled by female scribes at some time between 1390 and I406, represents the first concrete evidence of the Las Huelgas nuns' ability to write and compile codices. The article discusses aspects of monastic topography, the distribution of liturgical duties between nuns and clerics, and the anniversary celebrations of members of the royalty. An extensive appendix provides an edition of the most representative chapters of the customary.
\end{abstract}

\section{Keywords}

Las Huelgas, Female monasticism, Cistercian order, Customary, Liturgy.

\section{Resumen}

Este artículo analiza el ordinario medieval del Real Monasterio de Las Huelgas de Burgos, un documento que hasta ahora había permanecido inédito. El manuscrito, compilado en algún momento entre 1390 y 1406 por escribas femeninos, representa la primera evidencia concreta de la habilidad de las monjas del monasterio regio para escribir y compilar códices. El estudio aborda aspectos de topografía monástica, distribución funciones litúrgicas entre monjas y clérigos, y la celebración de aniversarios de miembros de la realeza. Un extenso apéndice presenta la edición parcial de los capítulos más representativos del costumario.

\section{Palabras clave}

Las Huelgas, Monacato femenino, Orden cisterciense, Ordinario, Liturgia. 
Founded in the II8os by King Alfonso VIII of Castile and his queen Leonor of Plantagenet, the royal abbey of Las Huelgas occupies a prominent place in the history of the female branch of the Cistercian Order. Although the convent of Las Huelgas, like many other female communities, began to adopt Cistercian practices independently of any men's house, its symbolic designation as a special daughter of Cîteaux in II99 deeply influenced the Order's relationship with women's religious communities. In the decades and centuries to come, however, relations between Las Huelgas and the Cistercian Order went through especially conflictive periods.

Las Huelgas was much more than just a nunnery. In many respects it can be regarded as an extension of the Royal House of Castile. Located only fifteen minutes' walking distance from Burgos Cathedral, Las Huelgas was the place regularly chosen by the monarchy to perform the most extravagant royal ceremonies and its monastic complex even included a royal palace. The chronicles state that the nuns themselves officiated public ceremonies, such as the coronation of Alfonso XI and his queen in $13322^{2}$ As a major scenario for the exhibition of power and for political propaganda, the royal abbey was placed among the wealthiest and most prestigious institutions in the entire kingdom. And as such, it enjoyed many special privileges and an extraordinary institutional independence, even from the Cistercian Order. The convent and its abbess were not under episcopal authority but rather reported directly to the Pope, and it is precisely in the intensive diplomacy with the Holy See that one most clearly observes the perseverance of the community in maintaining its autonomy and institutional independence. The documentation preserved in the monastic archives includes a significant number of papal bulls that confirm the privileges and particular customs of the monastery (Lizoain, 1985). These repeated and insistent confirmations should be viewed in connection with the disputes carried on by the community, not only with local bishops, but also with the Cistercian Order. In the thirteenth century the community of Las Huelgas took a rebellious attitude against the abbot of Cîteaux's attempts at control and taxation. It refused to obey the Order's mandates by claiming royal protection and the Pope's recognition of its special customs. The opposition of Las Huelgas led the abbot of Cîteaux to decide to visit the nunnery, and the conflict reached its most critical point

I See Berman 1999; Berman 2000; Baury, 2012.

${ }^{2}$ For a detailed account of the royal ceremonies carried out at Las Huelgas, see Catalunya, 2018. 
when the community refused to receive him. Despite this fiercely desired independence, however, the Las Huelgas convent continued defining itself as Cistercian, and adopted (or rather adapted) most of the Order's liturgical practice.

More than eighty years ago, in the introductory study of his monumental edition of the Las Huelgas music codex, Higini Anglès briefly mentioned a manuscript kept in the monastic library, which he referred to as the "consueta" (customary) of the royal convent in Burgos. ${ }^{3}$ Despite the critical importance of this source to a knowledge of the daily life and liturgical practice of one of the most emblematic institutions of medieval Castile, quite surprisingly the document remained unpublished and unexplored by subsequent scholarship. I recently had the opportunity to examine the original manuscript at the archives of Las Huelgas, and I am currently preparing a critical edition with an introductory study of the complete customary. ${ }^{4}$ The aim of this short article is to report some of my preliminary observations without expanding on their implications for the contextualization of the polyphonic manuscript of Las Huelgas and the history of the institution, aspects that I will examine extensively in forthcoming publications. Appendix I provides a partial edition of selected chapters of the customary.

\section{THE CODEX}

MS 6 of the Biblioteca del Monasterio de Las Huelgas (hereinafter Huelgas 6) is a codex relatively large in size $(370 \times 270 \mathrm{~mm})$ written in the vernacular Castilian, of which 79 folios have survived until the present time.' According to references made in the text to members of the royalty, we can establish the compilation date of the manuscript quite precisely, between 1390 and $1406 .^{6}$ The main body

3 Anglès, I93I, I, p. IIo. The manuscript containing the customary is Burgos, Biblioteca del Monasterio de Las Huelgas, MS 6. In this article I will refer to it using the abbreviation Huelgas 6.

${ }^{4}$ My most sincere thanks to Patrimonio Nacional, and especially to María Jesús Herrero Sanz, curator of Las Huelgas, who made it possible for me to consult the manuscripts in the monastery's archives.

5 The codex has an original foliation (by Scribe B) in red roman numerals on the right side of the upper margin of each recto. Written above it is a modern foliation in Arabic numerals, in pencil. In this article, I will cite folios from the manuscript by referring to its modern foliation.

${ }^{6}$ See the section on anniversary celebrations below. Anglès, however, stated (incorrectly) that the codex dates from the late thirteenth of early fourteenth century. 
of the manuscript originally consisted of 84 folios arranged into seven senions (that is, gatherings of six bifolios). The first senion (original folios i-xii) has been lost. The seven senions were filled by one principal scribe (Scribe A) who worked in collaboration with another scribe who wrote the chapter headings in red ink (Rubricator A). Later, a secondary scribe (Scribe B) added three folios at the beginning of the codex, on which he compiled a table of contents for all seven senions, and annexed two consecutive bifolios at the end of the codex, on which he copied commentaries to the Rule of St Benedict. Scribe B also corrected the text and the rubrics of certain chapters in the main body of the manuscript. The fact that many other secondary hands contributed with further corrections throughout the entire manuscript suggests that the codex was actually in use for some time after its compilation.

In material terms, Huelgas 6 offers a great contrast to the richly illuminated codices that filled the armarium of the royal abbey. The parchment is of relatively poor quality. The ruling of the pages in a two-column page-layout appears at times to have been done quite carelessly, and the principal hand is similarly irregular, with noticeable variations in size and changes in pen and ink. The script is particularly inelegant and clearly pertains to a non-professional scribe. ${ }^{7}$ On certain pages, however, the main scribe amuses himself with attempts to finesse the writing by including some calligraphic adornments in the letters' descenders and ascenders. The manuscript generally lacks decoration, and the very few initials that include pen-work decoration look like the trials of an inexperienced hand.

At the textual level, the manuscript contains scribal errors that are most certainly due to a lack of attention, such as consecutive repetitions of sentences (homeoteleuton errors), omission of words, polar errors and misspellings. Moreover, whenever the scribe felt insecure about the name of a Mass, chant, or any further detail, he quite recurrently left a blank space within the text. ${ }^{8}$ The scribe's orthographic practice is much more inconsistent than we would expect from any other codex of this period. ${ }^{9}$ Punctuation and capitalization are equally inconsist-

7 Unlike Scribe A, however, the writing of Scribe B has a more 'professional' look.

${ }^{8}$ Some of these blank spaces were later filled in by a secondary hand, although many remained blank.

9 The scribe is specially inconsistent in the use of ç/s/z/c (e.g. conçede, concede, consede), i/y (e.g. sy, si, ssy, ssi), double/simple consonants (s/ss, f/ff, r/rr), and in the use or omission of the h. 
ent. At times, the lack of these devices becomes critical to the extent that it is difficult to determine where one sentence ends and the next begins. ${ }^{\text {I0 }}$

Once Scribe A had the bulk of the text copied, Rubricator A inserted the chapter headings in red ink in the blank spaces left by Scribe A for that purpose. In contrast to the principal scribe, the rubricator does not copy the chapter headings from an exemplar, but rather deduces them based on the content of (only) the first lines of each chapter. For this reason, the headings quite often do not fit the content of the full chapter. Occasionally, the rubricator even seems to have understood the content of a chapter incorrectly, perhaps due to having read it too fast. ${ }^{\text {II }}$

Despite the fact that Rubricator A applied a consecutive numbering to all chapters throughout the entire manuscript, Chapters [I]-78 and 79-I42 constitute two different and distinct texts. This division is evident from the content of the chapters themselves and was also noticed by Scribe B, who described the content of the codex in the incipit of the index by distinguishing a book entitled Quatro órdenes del áureo numero from "other treatises and ceremonial that belong to the Cistercian Order". ${ }^{12}$ The Quatro órdenes (Chapters [I]-78) is an extensive manual whose purpose was to assist the cantora in determining the calendar of moveable feasts of the liturgical year. It provided not only a table (now lost) and the instructions necessary for such complex calculations, but also included many other directions of liturgical nature, such as the order of Masses or the texts and chants to be performed on a given day or season. ${ }^{\mathrm{I}}$ Immediately following Chapter 78 , there is a portion of text lacking a heading and a chapter number,

Io My edition in Appendix I normalizes the punctuation and capitalization according to modern Spanish practice. I have also added accentuation according to modern practice with a view to resolving certain ambiguities (for example "el" as an article or "él" as a pronoun).

II See, for example, Chapter 80 in Appendix I. Another example of 'fast rubrication' is found on $\mathrm{f} .64 \mathrm{v}$, where the rubricator mechanically completed the capital letters ' $S$ ' (for "[S]ant") in a list, and continued writing ' $S$ ' for words that were to have had a different initial letter ("[L]as ochauas", rubricated as "Sas ochauas").

I2 "Aquí se escomiença la tabla delos capítulos que se contienen en este libro, e contiene se enél 'Quatro órdenes del áureo número' e otros tractados e cerimonial que pertenesçen ala orden de Çistel [...]”. Huelgas 6, f. Ir.

${ }^{13}$ Those directions clearly follow the customs of Las Huelgas, as shown by the fact that the text mentions specific liturgical practices, such as the royal anniversary celebrations or the distribution of Masses between clerics and nuns. 
which must be a colophon to the Quatro órdenes, given that it merely describes the content of that particular portion of the codex. ${ }^{\text {I4 }}$

Chapters 79-I42, in turn, constitute a textual unit distinct from the Quatro órdenes. ${ }^{15}$ Scribe B identified that section of the codex as "other treatises and ceremonial"; I will refer to those chapters (79-I42) as the 'customary' of Las Huelgas.

Table I. Content of manuscript Huelgas 6

\begin{tabular}{|c|l|l|l|}
\hline fol. & \multicolumn{1}{|c|}{ Content } & \multicolumn{1}{|c|}{ Scribe } & Codicological structure \\
\hline $1 \mathrm{r}-3 \mathrm{v}$ & $\begin{array}{l}\text { Table of contents of the codex } \\
\text { up to f. 75v. }\end{array}$ & Scribe B. & Three single folios. \\
\hline 4r-53v & $\begin{array}{l}\text { Quatro órdenes del áureo } \\
\text { numero. } \\
\text { Chapters [1]-78. }\end{array}$ & $\begin{array}{l}\text { Scribe A, Rubricator A; } \\
\text { with corrections by } \\
\text { Scribe B. }\end{array}$ & $\begin{array}{l}\text { Six senions (originally } \\
\text { seven; the first has been } \\
\text { lost). }\end{array}$ \\
\hline 53v-75v & $\begin{array}{l}\text { Customary of Las Huelgas } \\
\text { Chapters 79-142. }\end{array}$ & Scribe A, Rubricator A. & One bifolio. \\
\hline $77 \mathrm{r}-78 \mathrm{v}$ & $\begin{array}{l}\text { Rules for fasting on Fridays; } \\
\text { commentary on the Rule de } \\
\text { St Benedict. }\end{array}$ & Scribe B. & One bifolio. \\
\hline $79 \mathrm{r}-80 \mathrm{v}$ & $\begin{array}{l}\text { Clean copy of the same } \\
\text { commentary on the Rule de } \\
\text { St Benedict. }\end{array}$ & Scribe B. & \\
\hline
\end{tabular}

${ }^{14}$ "Eneste escripto ay escriptos auros números en quatro vezes [...]. E para catar el aure número cómmo vyniere enel anno que fuere presente, quien lo quisiere saber lo puede ffallar en vno ayuntando el aure número e la claue delos términos e la epacta e el concurrente e la indiçión. E [...] deue catar en qué día es para poner las estorias e las vigilias e las fiestas delos ssantos e cómmo lean los libros enel rrefitor e cómmo an de faser quando ouieren defunto e todas las otras cosas que son menester del ordenamiento del coro por todo el anno. E quien lo quisiere catar, ffallar lo ha desta guysa commo está aquí escripto para lo catar en cada anno". Huelgas 6, fol. $53 \mathrm{r}-\mathrm{v}$.

${ }^{15}$ No incipit or general heading marks the beginning of this new section of the codex. Nevertheless, Rubricator A stops writing the Roman numerals I to IIII (corresponding to the four sections of the Quatro órdenes) on the top margin of each leaf from Chapter 79 onwards. 


\section{THE CUSTOMARY}

A substantial portion of the Las Huelgas customary is based on an official text of the Cistercian Order composed in the twelfth century and known as Ecclesiastica officia. ${ }^{16}$ The Las Huelgas customary, however, shows the great extent to which this official text was adapted to the needs, customs and liturgical practice of the Castilian abbey. Not all chapters of the Ecclesiastica officia (hereinafter EO) are represented in the Las Huelgas customary (hereinafter $H C$ ) and, vice versa, some chapters of $H C$ have no exact concordance in $E O$. Still, even those chapters that can be considered 'concordant' with the official text show a great deal of variants, interpolations, omissions and adaptation. Only a few chapters located at the end of the compilation were intended to be literal translations of $E O$ from Latin to the vernacular Castilian without applying any modification to the content of the text.

Obviously, most of the variants and omissions found in $H C$ resulted from a process whereby the official statutes of the Cistercian Order were adapted to the monastic structure and liturgical practice of a female community. As we will see in the next section, the entire customary was drafted from the nuns' perspective and by the nuns themselves. Yet not all variants and omissions in $H C$ are genderrelated. The redactors and compilers of the Las Huelgas customary seem to have been primarily concerned with calendar issues. Unlike $E O, H C$ describes only a few special liturgies and rituals in detail. ${ }^{17}$ Instead, $H C$ continually focuses, on a more general level, on the chants, collects and lessons to be included in or excluded from the ecclesiastical offices, and especially on the order of Masses, depending on whether a movable feast fell on Sunday, or whether any deceased was to be interred on that day. Still, even at that general level, the Las Huelgas customary provides interesting clues about the daily life of the convent and the singularities of its liturgical practice.

The customary's prose is generally quite chaotic. It is characterized by frequent digressions and the mixing of topics. Although this is the general tendency throughout the entire customary, some chapters more that others can be

${ }^{16}$ Edited in Choisselet and Vernet, 1989. See also Berman, 2000.

${ }^{17} \mathrm{HC}$ lacks the $E O$ ordinal for Masses, offices and the cura infirmorum. The few rituals described in detail are those that take place in Lent (Ash Wednesday and the First Sunday of Lent) and Holy Week (Holy Thursday and Good Friday; the Palm Sunday ritual is omitted, although there is a literal translation of the $E O$ chapter devoted to this ritual at the end of the compilation). Funerary rituals are also described in some degree of detail. 
regarded as actual miscellany, in which very different subjects and seasons of the liturgical year are treated. The fact that some instructions are duplicated in more than one miscellany chapter suggests that $H U^{\text {s }}$ compiler worked with different exemplars that she did not collate properly. Those exemplars would include literal translations of the official $E O$ (perhaps as a first step, prior to their adaptation), ${ }^{18}$ adapted texts (some even dictated), ${ }^{19}$ miscellany chapters (possibly collected from different sources), obituary lists, ${ }^{20}$ and even pedagogical manuals. ${ }^{2 \mathrm{I}}$

Table 2 lists the chapters of the Las Huelgas customary as rubricated in the manuscript. As explained above, the chapter headings usually do not accurately reflect the content of the chapters themselves. The table's right column identifies the chapters' main subjects and their concordances with the EO. This gives an overview of the content and structure of the whole customary. We can thus recognize a first 'section', comprising Chapters 79 through I05, which matches groso modo the outline of the $E O$ up to its Chapter 49. It starts with a set of chapters devoted to the principal feasts from Advent to Pentecost and continues with various lists of solemnities and commemorations to be celebrated throughout the liturgical year. Therein, what follows in $H C$ is a miscellaneous assortment of chapters on diverse subjects (some with direct concordances in $E O)$, one following another without any apparent order. This second 'section' (Chapters 106-136) includes a group of chapters on funerary rites and anniversary celebrations (Chapters I26-I3I, I33). Finally, Chapters I37-I4I compose a third section with literal translations of the chapters of $E O$ devoted to the rituals of the Holy Week.

III. FEMALE LITURGY, FEMALE SCRIBES

The social structure of Las Huelgas consisted of Ioo nuns (the 'convent') and 40 girls, exclusively noblewomen, 40 freyras (at the service of the nuns and in charge of the girls' education), and over 50 clerics, chaplains, servants and officials who

I8 Some of those translations were indeed included at the end of the compilation.

19 The style of the prose in some chapters suggests an oral composition/adaptation of the text (see for example Chapter 8I), but the homeoteleuton errors in other chapters reveal a mechanical process of copying from a written exemplar.

${ }^{20}$ Perhaps Arqueológico 3 was one of the sources. See Appendix 2.

${ }^{21}$ See the interpolation of a pedagogical text on counting in Latin between Chapters 135 and 135. 


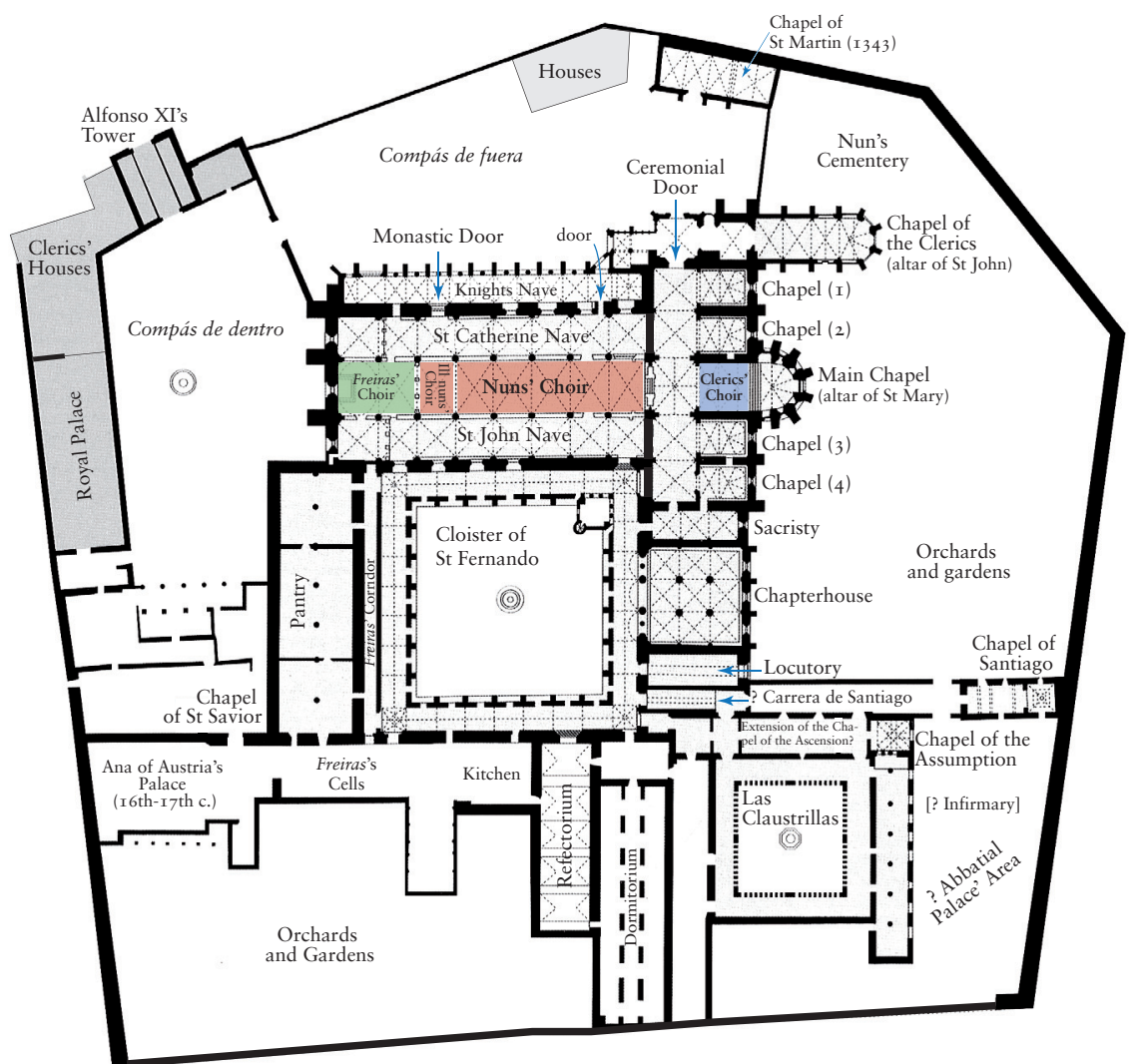

Fig. I. Las Huelgas

lived within the monastic compás (see Fig. I). The Choir of the Nuns was located in the central nave of the abbey church, while that of the clerics was in the presbytery. The church's High Altar (dedicated to St Mary) was in the presbytery too; the Choir of the Nuns had the altars of the Holly Cross and All Saints and the royal sepulchres. A wall with a wide grill-door and two ornamental oculi separated these two spaces (see Fig. 2). ${ }^{22}$ The chaplains of the monastery, however,

${ }^{22}$ The form and function of the grill and wall that separated the Choir of Nuns from the transept are discussed in Catalunya, 20I8. 


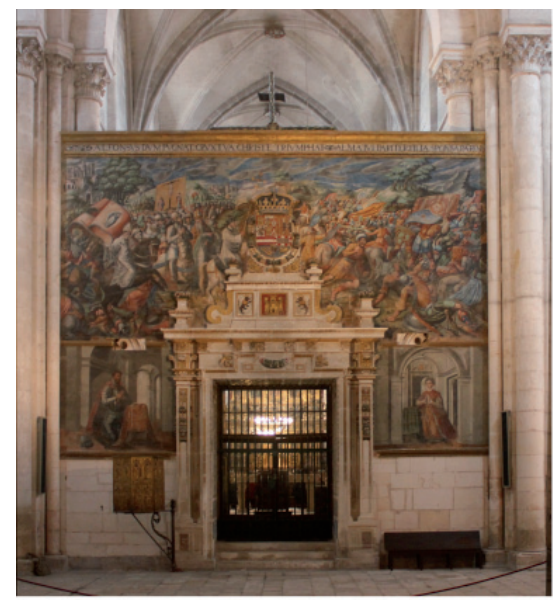

Current state

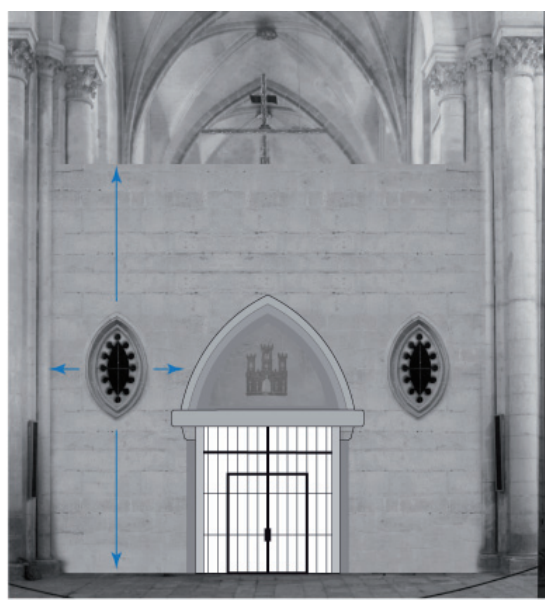

Hypothetical reconstruction of the wall's aspect in the thirteenth century

Fig. 2. Wall closing the Nuns' Choir. View from the presbytery

entered the Choir of the Nuns daily in order to pray for the deceased, ${ }^{23}$ and there are hints of the possible presence of the nuns in the church's presbytery as well.

As mentioned above, the Las Huelgas customary was drafted and compiled from the nuns' perspective and by the nuns themselves. This is especially evident in the use of verbs in first person plural, such as "quando tenemos cuerpo en coro [...] desimos colecta" (when we have a body in the choir [...] we say a collect). ${ }^{24}$ Yet it is in the rubrication process that the gender of the scribal hands is most

clearly seen, given that the rubricator 'spontaneously' uses the female voice where

${ }^{23}$ Evidence of the permeability of the Choir of the Nuns is found in the testament of Señora Infanta Blanca (I32I), whose sepulchre was (and still is) located in the nuns' choir. In her testament she ordered that the chaplains, upon finishing their daily mass, should go to her sepulchre, which was located in the Choir of Nuns, and say a responsory with its collect: "cada uno destos dichos capellanes, acabada su misa cada día, salga sobre la mi sepultura e diga un responso con su colleta” (Castro Garrido, 1987, doc. 364, p. 332).

${ }^{24}$ Chapter III. See Appendix I. 
the main text speaks in first person. ${ }^{25}$ Chapter 128 begins "Este es el deubdo que auemos a conplir" (This is the duty we have to fulfil) and the rubricator entitles "De las cosas que somos tenudas a desir..." (The things we have [feminine verb-ending] to say...). I believe this is the clearest indication that both Scribe A and Rubricator A were actually female scribes, that is, members of the learned community of Las Huelgas.

At this point, I must emphasize that the books of the best material and scribal quality at Las Huelgas were not produced at the monastic scriptorium; instead, they were donations or were commissioned to other scriptoria. ${ }^{26}$ Therefore, Huelgas 6 is a priceless testimony that sheds light not only on the liturgical practices of the convent, but also on the material and human conditions of its scriptorium. Despite the collection of beautifully miniated codices, everything indicates that the scriptorium at the monastery had only limited resources and that its scribes were cultivated but not 'professional'. The cultural level of these nuns appears to be reflected in Alfonso X's Cantiga $285,{ }^{27}$ which tells of a noble nun who had "gran clerecía", a term that, according to Las siete partidas, referred to persons learned in Latin and Greek and lettered in various areas of knowledge.

The Las Huelgas customary also employs the third person plural to refer to the liturgical actions performed by the nuns. ${ }^{29}$ Most of the time it gives simple directions such as: "el sábado digan la misa dela vigilia" (on Saturday they shall say the Mass of the Vigil). ${ }^{30}$ On other occasions the context makes clear that such directions about the celebration of Masses are indeed addressed to the nuns rather than to the clerics of the monastery:

${ }^{25}$ Note that, as explained above, Rubricator A does not copy the chapter headings from an exemplar, but infers them from the chapter's first sentences.

${ }^{26}$ See Herrero González and Cortés Santi, I988, pp. I2I-I22. To cite further examples, the famous twelfth-century illuminated antiphonary of Las Huelgas was brought from Portugal by the Infanta Blanca (Ferreira, 2002, p. 269 n. 8), and the Las Huelgas martyrology Arqueológico 3 was most likely produced in the royal scriptorium of Alfonso X (see Appendix 2).

${ }^{27}$ For a text edition of this cantiga, see Mattmann, 1989 , p. 85.

${ }^{28}$ For more on the term clerecía, see Juárez Blanquer, I991-92.

${ }^{29}$ Here the use of the third person plural (either subjunctive - e.g. digan - or present tense - disen -) has an impersonal nature comparable to the Latin passive voice (dicitur).

${ }^{30}$ Chapter 79 . 
e ssaliendo de cabillo digan la missa dela vigilia. E acabada la misa tusten la tabla e, sy non, prediquen, e después tangan a terçia e digan la misa del ochauario [...] a missa de cuerpo presente, la que ofiçiare la missa comiençe los Quirios. ${ }^{3 \mathrm{I}}$ and leaving the chapter house, they shall say the Mass of the Vigil. And after the Mass they shall strike the table and preach, and thereafter they sha11 ring the bells for Terce and say the Mass of the Octave [...] at the Mass held in the presence of the body, she who officiates the Mass must begin the Kyries.

The customary distinguishes three levels at which the nuns participated in the liturgy of the Mass. When the nuns were expected to celebrate a given Mass on their own, the text either reads simply "digan misa" (they shall say Mass) or specifies that the Mass is to be held by "el conuento" or "en conuento". When the nuns were expected to perform the chants in a Mass held by the clerics of the monastery, the customary employs the expressions "oficien la" or "comiençen la" (they shall officiate it, or, they shall begin it). ${ }^{33}$ If they were to attend a Mass held by the clerics without officiating it, the customary employs the expressions "van oyr misa" or "oyan misa" (they go to hear Mass, or, they shall hear Mass). ${ }^{34}$ Any Mass that was not to be held by the nuns is almost systematically accompanied by the expression "digan la los clérigos"; lacking this specification, it is generally understood that the nuns were the celebrants. ${ }^{35}$ This dichotomy in the distribu-

${ }^{31}$ Chapter 106. A similar direction is given in Chapter IO2: "E quando missa en conuento es çelebrada e después alguna missa acaesçiere de desir, la cantora comiençe los Quirios de amas missas, mas el día de Nabidat, a la primera missa e ala de terça comiençen los do es el vytatorio. E dessa guisa fagan enla Quaresma la Pasqua. Enlas fiestas que labramos, amas las misas; mas quando ouiere defunto, sienpre los comiençen la cantora".

${ }^{32}$ For example: "digan en conuento missa de Sant Iohan" (Chap. II2). The term conuento (convent) appears to refer to the community of nuns exclusively (excluding the clerics and chaplains of the monastery).

33 "vistan se las cogullas e tangan dela missa e oficien la" (Chap. I08); "e tangan a misa los clérigos, e vaya el conuento al coro e comiençe la, mas pora la prefeçia primera, e digan las segund está ordenado enlos libros. E des que fueren acabadas digan la ledanía, mas non digan 'Ut gente' a ninguna ledanía, e luego digan los Quirios e la Gloria [e des]que dixeren 'Et in terra pax', tangan las canpanas fasta que sea acabado 'Domine deus res'. Después digan 'Dominus uobiscum' e la collecta 'Praesta [domine] quaesumus'” (Chap. 94).

34 "En la vigilia de Çinquagesma, des que ssalieren de cabillo, tusten la tabla e fagan signo de tercia e pedriquen; e acabada la pedricación, tangan tercia, oyan misa de Santa María” (Chap. I08); "acabado cabillo tustan la tabla e tannen al signo de terçia e van a oyr misa" (Chap. 94).

${ }^{35}$ To give three significant instances of the Masses assigned to the clerics: "si el ssábado ouiere missa de vn ministro, digan la los clérigos" (Chap. II3); "E sy ouiere comemoraçión que aya ofiçio 
tion of Masses between clerics and nuns causes one to suspect that the Masses held by the convent of nuns excluded the participation of any priest or cleric. To quote one example:

la misa dela fiesta digan la los clérigos the feast Mass shall be said by the clee la de la dominica diga la el conuen- rics and that of the Sunday shall be to (Chap. 84). said by the convent.

This raises a critical question. Were the nuns of Las Huelgas able to hold Mass without the assistance of a priest? It is of common knowledge that, according to canon law, only ordained priests were allowed to administer the sacrament of Eucharist. But the Las Huelgas customary states that "the abbess can say Mass". ${ }^{36}$ My guess is that here the term 'Mass' is used with some flexibility; in other words, 'conventual Masses' at Las Huelgas were most likely liturgical ceremonies without the Eucharist. ${ }^{37}$ Two twelfth-century Italian manuscripts bear witness to communion services led by female celebrants that imply the use of previously consecrated bread elements. ${ }^{38}$ Could this also have been the case in Las Huelgas? Unfortunately, this is a difficult question to answer; the customary does not provide any specific information about the liturgy of conventual Masses. Even the Masses in which the clerics were supposed to participate are buried in obscurity.

Chapter 88 addresses the Masses and rituals of Maundy Thursday without mentioning any male actor at all, either priest or cleric (see Table 4). The Tenebrae ceremony carried out by the sachristana (in the Choir of the Nuns, we might suppose) suggests that the nuns were the protagonists of the liturgy on that day. But the text lacks a detailed description of the solemn Mass that took place afterwards. It says only that the nuns who are ill ("las dela enfermería") and the

enel gradal, digan la los clérigos" (Chap. I23); "Este día [vigilia de Çinquagesma], acabado cabillo tustan la tabla e tannen al signo de terçia e van [a] oyr misa, e digan los clérigos la missa de Ssanta María e esté el conuento enel coro fasta que sea acabada (Chap. 94).

36 "Quando la abbadesa ffuere en camino o viniere en verano antes de terçia e en ynuierno, después de terçia ffasta la nona puede oyr missa o puede la desir" (Chap. 134).

${ }^{37}$ These liturgical ceremonies labelled 'Mass' possibly included a preaching by the abbes, a practice contrary to canon law but documented in Burgos since the thirteenth century. As early as I2IO, Pope Innocent wrote to the bishop of Burgos to denounce the abbesses' custom of preaching publically, hearing confession and giving blessing to their own nuns (Escrivá, 1944, pp. I5O-I5I).

${ }^{38}$ These orders lack the words of institution, and the prayers ask God's blessing on the participants rather than the bread and wine; in any other respect, they are extremely close to the most common written Mass liturgies. Chazelle, 20I2, pp. 223-224, citing Leclercq, I98I and Wilmart, I929. 
choir nuns are to take communion together, and that once they have closed up the (remaining) Body of God (to be consumed on the morrow, Good Friday) they shall finish the Mass. The customary omits the description of any part of the liturgy carried out by the clerics in the presbytery. Chapter 89, in contrast, does mention very briefly the presence of a priest in the Good Friday liturgy, although the summary given of his intervention is minimal (see Table 5).

Perhaps the most interesting example of the extent to which the Las Huelgas customary was drafted from the nun's perspective is the description of the Ash Wednesday liturgy in Chapter 86 (see Table 3). The text describes in great detail the liturgy performed by the cantora, the choir nuns and the nuns who were ill. Only the parts of the ceremony that $E O$ situates in the presbytery are left out of the Las Huelgas customary: the Blessing of Ashes on the main altar and the Imposition of Ashes on the altar step. This suggests that the clerics of the monastery had their own ordinale and, therefore, the compiler of the customary did not find it necessary to include an exhaustive account of the parts of the liturgy performed by the clerics. In any case, Chapter 86 offers one detail of great interest regarding the interaction between nuns and clerics. After the Blessing of Ashes (on the High Altar in the presbytery, we might suppose), the cantora begins the introit of the Mass (Exaudi nos domine) and, when she sings the versicle, "they shall open the door" ${ }^{39}$ Since the opening of "the door" occurs just before the Imposition of Ashes, we might suppose that it refers to the grill door that gives access to the presbytery from the Choir of Nuns (see Fig. 2). In turn, this would suggest that the nuns received the ashes, not in the Choir of Nuns, but in the presbytery. ${ }^{40}$

IV. FUNERARY RITUALS AND ANNIVERSARY CELEBRATIONS

Evidence that one of the convent's most important concerns revolved around the death is the fact that the nuns' funerary rituals are among the few ceremonies that the Las Huelgas customary describes in detail (Chapters 126 and I33).

39 "E acabada la bendiçión dela çeniza, comiençe la cantora 'Exaudi nos domine' e, encommençando el vielso, abran la puerta. [...] E quando ouieren tomada la çeniza comiençen 'In nuctemur"” (Chap. 86).

${ }^{40}$ Could the presence of the nuns in the presbytery perhaps be extensible to holy communion as well? This would contradict the traditional idea that the nuns received communion through a closed grill. 
Chapter 126 is especially interesting because of the allusions to the topography of the monastic complex it provides. According to the customary, the body of a deceased nun was to be washed in the "cabildo delas fynadas" (literally, 'the chapterhouse of the deceased nuns'), a space that certainly made part of (or was near) the infirmary. While the body was being washed, the convent sat in the "carrera de Santiago" and prayed the psalter until they received the body (see Fig. I). ${ }^{4 \mathrm{I}}$ Then, the convent accompanied the body from the carrera de Santiago to the abbey church. This strengthens Eduardo Carrero Santamaría's hypothesis that the monastic infirmary of Las Huelgas was adjacent to the cloister of Las Claustrillas, and that the Chapel of the Assumption served as the chapel of the infirmary and abbatial palace (Carreo Santamaría, 2008 and 20I4). Elsewhere, the customary also mentions the abbatial palace, but unfortunately it does not provide a clue to its exact location. ${ }^{42}$

Another aspect of capital importance at Las Huelgas was the celebration of death anniversaries. As is well known, the founders of the royal abbey aimed to make Las Huelgas the funerary pantheon of the royal dynasty. Despite King Alfonso VIII's efforts, however, the Castilian kings reigning after him preferred to be interred elsewhere. Unlike the French monarchy, whose dynastic pantheon had been installed in the monastic church of Saint Denis since the twelfth century, the Castilian kings did not have only one royal pantheon; in the words of Raquel Alonso Álvarez, they preferred to have their tombs mark a territory that was continually expanding (Alonso Álvarez, 2012, pp. 222-223). In fact, the only monarchs interred in Las Huelgas are Alfonso VIII and his queen, Leonor, his son King Enrique I, and his daughter Queen Berenguela, the queen consort who succeeded Enrique I. ${ }^{43}$ All of the other royal personages interred in Las Huelgas were infantes. ${ }^{44}$

${ }^{41}$ The "carrera de Santiago" could be the passageway (now exterior) that runs between the cloister and the Chapel of Santiago. The passageway parallel to the so-called locutory would appear to be too narrow for the convent sitting in two choirs ("assienten se e rresen el psalterio a vielsos del vn coro e del otro"). Perhaps this exterior passageway was not always outside?

${ }^{42}$ "Otrosí, sy alguna comulgare en casa dela abbadesa, por la puerta dela cama lyeuen el Cuerpo de Dios" (Si alguna monja comulga en casa de la abadesa, lleven el Cuerpo de Dión por la puerta de la cama). Cap. CXXIII.

${ }^{43}$ Fernando III's queen, Beatriz of Swabia, was initially interred in Las Huelgas until Alfonso X had her remains transferred to Seville in 1279 .

${ }^{44}$ Infante was a royal title comparable to that of prince or princess, given to sons, daughters, brothers and sisters of kings). For a list of the 32 sepulchres preserved in Las Huelgas, see GómezMoreno, I946, pp. I08 and 2I-38; Yarza Luaces and Mancini, 2005, p. 57. 
At Las Huelgas, the anniversary of the death of Alfonso VIII was celebrated each year on 6 October with the greatest solemnity, and was attended by monks, nuns and clerics from all over Burgos and the surrounding areas. On this day, the abbey church of Las Huelgas was opened to the townsfolk so that they could visit the sepulchres of the kings, ${ }^{45}$ and the ringing of bells, either at Vespers or at Mass, was proscribed (Chap. I08). In addition to the anniversary Mass, on the Tuesday prior to Ash Wednesday the community celebrated another Mass in honour of Alfonso VIII. ${ }^{46}$ Moreover, the nuns included prayers for Alfonso VIII in the offices every day, except for certain specific feast days. ${ }^{47}$

But there were many other anniversary celebrations that perpetuated the memory of members of the royal family with great ceremonies. The testament of the Infanta Blanca of Portugal (I32I), Señora of Las Huelgas, reveals that the monks and nuns of at least six other monasteries in or near Burgos regularly attended the anniversaries of the infantes and the kings at Las Huelgas. ${ }^{48}$ Chapters I28 to 130 of the Las Huelgas customary provide the list of death anniversaries celebrated annually. ${ }^{49}$ This anniversary list was segmented into three chapters (Chapter I28 lists the anniversaries to be celebrated from October to January; Chapter 129, from March to May; Chapter I30, from July to October), although it is unclear what the purpose of this segmentation could have been.

The list specifies the length of the offices to be celebrated in commemoration of each person. We can thus distinguish among three different categories of celebrations according to the number of psalms to be prayed. The kings and the queens of Castile were always commemorated with the performance of one full psalter. The Infanta Blanca of Portugal (who was a major funder, protector and señora of Las Huelgas) and the Infanta Berenguela (daughter of King Fernando III) were also commemorated with one full psalter. The infantes Fernando, Pedro and Constanza (all three of them interred in Las Huelgas) were commem-

${ }^{45}$ In 1253 Pope Innocent IV offered one year of indulgence to the faithful who visited the sepulchres of the monarchs in Las Huelgas on the anniversaries of their death. Document edited in Lizoain, 1985, doc. 439, p. 233.

46 "el martes antes del miércoles dela cenisa, digan missa del Rrey Bueno" (Chap. Io8).

47 "La vigilia de Nabidat [...] nin a matines nin alas oras suelten al Rrey Bueno" (Chap. 80).

48 "Otrosí, mando que den cadanno a los conuentos de Burgos: al de los Frayres Menores trezientos maravedís, al de los Predigadores, trezientos maravedís, a las duennas de Sancta Clara, trezientos maravedís, a las de Renuzo, trezientos maravedís, al de la Trinidat, trezientos maravedíes, a los de Sant Agostin, dozientos maravedís, e uengan cadanno al mi aniuersario fazer al monesterio de Las Huelgas así commo suelen uenir a los aniuersarios de los reyes e de los infantes". Document edited in Castro Garrido, 1987, doc. 364, pp. 322-333: p. 332.

49 For a comparison of this list with the obituary in Arqueológico 3, see Appendix 2. 
orated with 50 psalms; all other infantes and noblemen, with 7 psalms. Seven was also the number of psalms to be performed in the anniversary celebrations of the abbesses (see Chap. I3I).

Table 6 lists the names in the order in which they appear in the customary. Of the personages identified in the second column, those who were interred in Las Huelgas are marked with an asterisk. Without counting the duplication of the Infanta Blanca, the customary cites 34 persons for whom an anniversary is to be celebrated annually. ${ }^{50}$ The monastery preserves 29 sepulchres of persons belonging to the royal family until I390, of which only I7 or I8 are represented in the customary (marked with an asterisk on Table 6). At least II members of the royal family who are interred in Las Huelgas are missing from the customary. ${ }^{5 \mathrm{I}}$ On the other hand, of the 35 persons listed in the customary, at least $\mathrm{I} 3$ or I4 were certainly not buried in the monastery. Only three of the persons listed in the customary, María de Almenar, Moriel and his wife Elvira, were not relatives of the royal family to the first degree, although they were major donors and benefactors of the monastery.

The Castilian kings mentioned in the customary start with from Alfonso VIII († I2I4), founder of the monastery, and end with Juan I († 1390) (see Fig. 3). In fact, the latter provides the latest datable personage in the customary. The fact that his successor, Enrique III ( $\dagger \mathrm{I} 4 \mathrm{O} 6$ ), is not mentioned, suggests that the customary was written between 1390 and $1406 .^{52}$ Kings Alfonso X and Alfonso XI

so There are two entries for Infanta Blanca in the customary. See the footnote to entry 2 in Table 6.

${ }^{51}$ These include four newborns and two underage children:

King Enrique I, son of Alfonso VIII ( $†$ I2I7, underage child) (represented in Arqueológico 3);

Infante Sancho, son of Alfonso VIII († II8I, newborn);

Infanta Sancha, daughter of Alfonso VIII ( $\dagger$ II $84-5$ ?, newborn);

Infanta Mafalda, daughter of Alfonso VIII († I204?, newborn);

Infanta Leonor, daughter of Alfonso VIII (newborn);

Infanta Constanza, daughter of Alfonso VIII, nun of Las Huelgas ( $†$ I243) (represented in Arqueológico 3);

Infante Fernando de Navarra, cousin of Alfonso VIII, son of Sancho VI of Navarra ( $\dagger$ I208);

Fernando, bastard son of Alfonso X ( $\dagger$ ? underage?);

Infanta María of Aragon, wife of the Infante Pedro of Castile ( $\dagger$ I333);

Sancho, bastard son of Alfonso XI ( $†$ ca. I343, underage);

Queen Leonor of Aragon, wife of Alfonso IV of Aragon, daughter of Fernando IV of Castile († 1359 ).

52 Other persons from the last quarter of the century unambiguously recorded in the customary are the Infanta Blanca ( $†$ 1375), "daughter of the Infante Pedro", and King Enrique II († 1379), "son of King Alfonso" (references 32 and 24 in Table 6). 


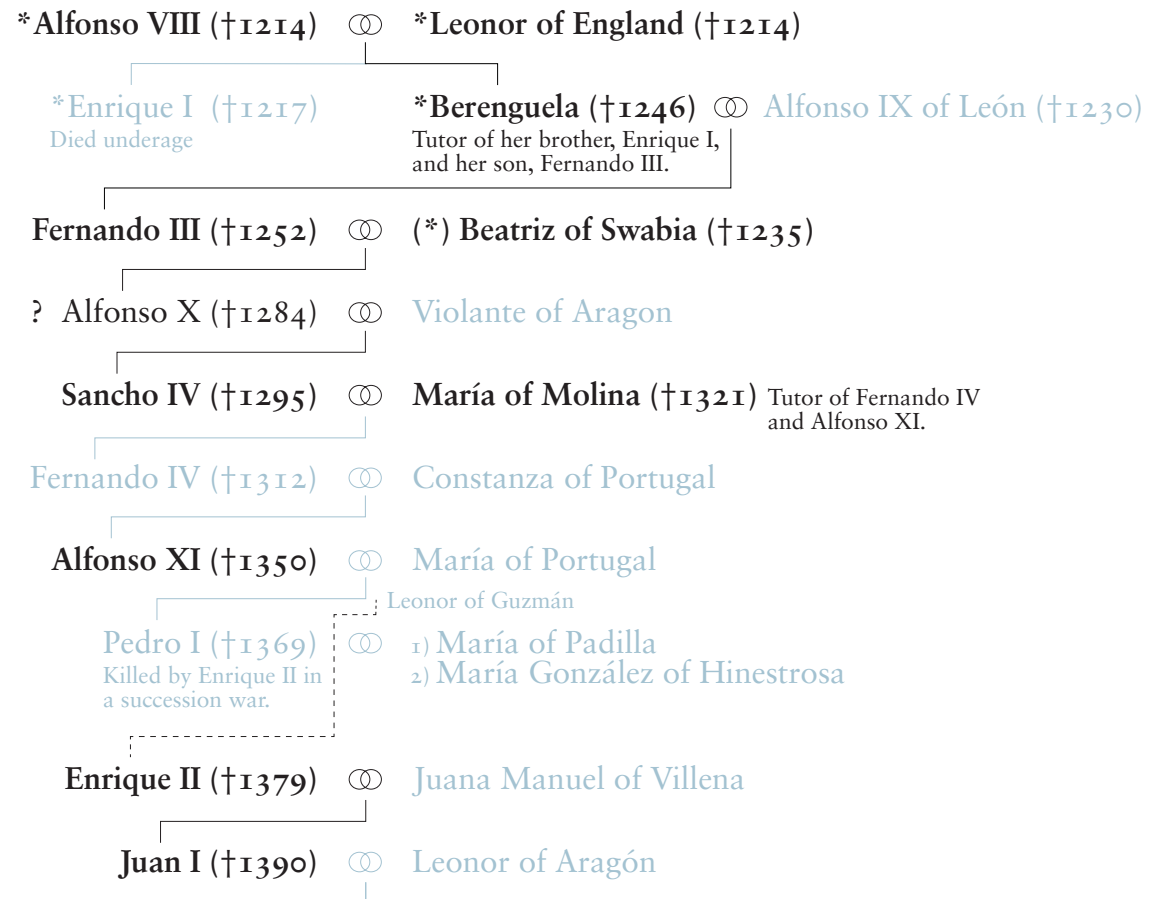

Fig. 3. Kings and queens mentioned in the Las Huelgas customary

were likely merged into a single record as a result of a copying error and the confusion of the date of their death. ${ }^{33}$ Such an error is not surprising given the fact that the Infanta Blanca is mentioned twice and the Infante Fernando lacks a date. Nonetheless, the customary fails to mention Enrique I († I217), Fernando IV († I3I2) and Pedro I († 1369). This requires further explanation on a case-by-case basis.

I. Enrique I, interred in Las Huelgas, son of Alfonso VIII, died at I3 years of age after having reigned only three years under the tutelage of his aunt,

53 See the footnotes to reference 20 in Table 6 . Indeed, due to the proximity of the dates of their deaths, Alfonso XI's entry would have followed that of Alfonso X. The scribe might have committed a homeoteleuton error. But the fact that Alfonso X does not appear in the obituary of Arqueológico 3 is certainly intriguing. There is no apparent reason why Alfonso X should have been excluded from the anniversary list. 
the queen consort Berenguela, who is represented in the customary with one full psalter. ${ }^{54}$ Enrique I's name, however, is found in the obituary of Arqueológico 3, which suggests that the celebration of his anniversaries was discontinued at some point during the fourteenth century. ${ }^{55}$

2. As for Fernando IV, the Las Huelgas documentation shows how the weakness of this king, concerned above all with imposing and maintaining social order in the kingdom, prevented him from supporting the royal monastery. Throughout this period, the documentation records only two legates of importance from the royal family, those made by the Infanta Isabel and by the Infante Pedro (the sister and the brother of Fernando IV). ${ }^{56}$ The Infante Pedro, who made a major donation and is interred in the monastery, is indeed represented in the customary. The Infanta Isabel, on the contrary, does not appear to be represented in the customary, perhaps because she specified that her endowment of income was to be used to perpetuate the anniversaries of her father, King Sancho IV, and to have the nuns pray for the life and health of her brother Fernando IV; the document is silent with respect to the celebration of anniversaries for Fernando IV or for the Infanta Isabel herself after their death. ${ }^{57}$ This shows to what extent the anniversary ceremonies were treated as business agreements between the monastery and the funder.

3. Pedro I 'the Cruel' was assassinated by his stepbrother, Enrique II of Castile, bastard son of Alfonso XI, after a civil war in which all the Castilian nobility had turned against the king. Pedro I was even excommunicated by the pope, who had taken sides with Enrique II in the civil war. Before doing away with Pedro I, Enrique II had himself crowned at Las Huelgas in an attempt to legitimize his reign and, as mentioned above, in I37I he endowed the monastery with income and goods. ${ }^{58}$ It therefore seems obvious that Enrique II prohibited the nuns of Las Huelgas from celebrating

${ }^{54}$ The other underage children of Alfonso VIII, interred in Las Huelgas, are not mentioned in the customary.

"Arqueológico 3 is datable to the last third of the thirteenth century, with additions made in the early fourteenth century. See Appendix 2.

${ }^{56}$ See the diplomatic collection from that period in Garrido, 1987.

57 Document edited in Araceli, 1987, doc. 215, pp. 34-36.

${ }^{8}$ The document, an endowment of income and goods, clearly specifies that one of Enrique's aims was to compensate Las Huelgas for having held his coronation ceremony. Edited in Peña Pérez, I990, doc. 297 , p. 296. 
the anniversary of Pedro I, with a view to discrediting his step brother completely and strengthening his own legitimacy. ${ }^{59}$

The fact that anniversary ceremonies were treated as business agreements between the monastery and the person who funded them is also suggested by the formulation "este es el 'deubdo' que auemos a conplir" ("this is the 'debt' we have to pay", or "this is the duty we have to fulfil") found at the beginning of Chapter I28, referring to the number of psalms to be performed for each of the listed anniversaries (Fig. 4). The term deubdo, or deubda, is indeed related to monetary issues (Alfonso X referred to the tithe as "diezmo que es la debda de Nestro Señor").

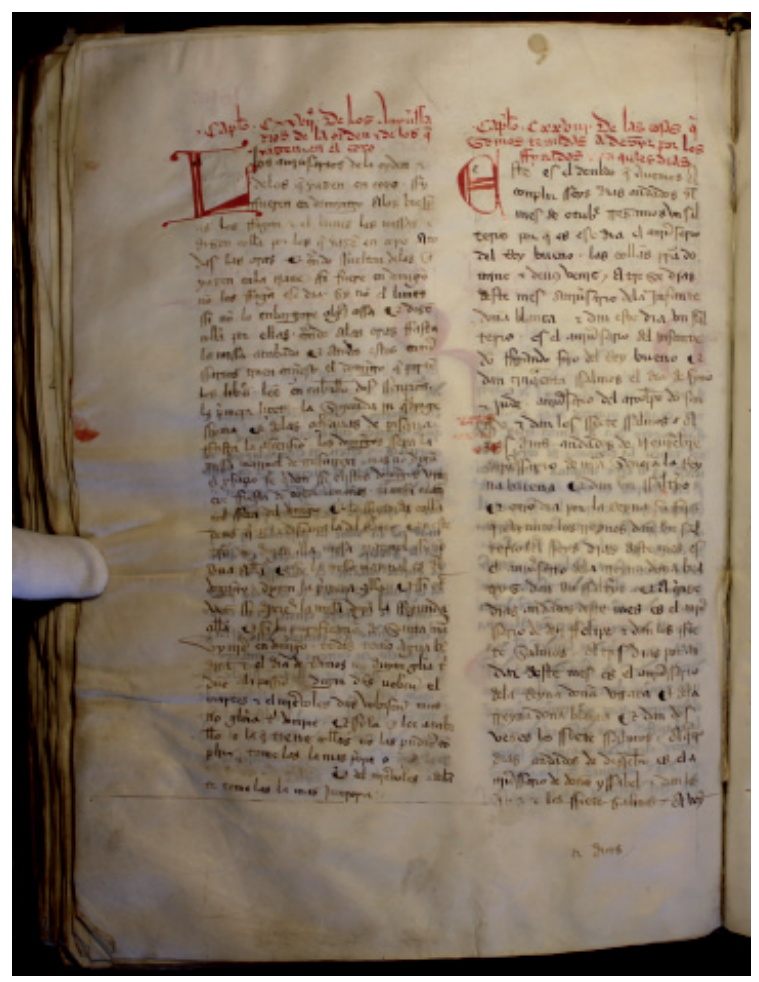

Fig. 4. Huelgas 6, fol. 69v. () Patrimonio Nacional. With permission

${ }^{59}$ Historians surmise that, after usurping the throne from Pedro I, Enrique obliterated books, documents and any other evidence favouring Pedro I, and that the servants of the new king were responsible for proclaiming the cruelties of the assassinated monarch. 
BIBLIOGRAPHY

Alonso Álvarez, R., 20I2: "Enterramientos regios y panteones dinásticos en los monasterios medievales castellano-leoneses", in García, J. A. et all. (eds.), Monasterios y monarcas: fundación, presencia y memoria regia en monasterios hispanos medievales, Aguilar de Campo: Fundación Santa María la Real, pp. 2OI-223.

Anglès, H., 1931: El Còdex Musical de Las Huelgas, 3 vols., Barcelona: Biblioteca de Catalunya.

Arco y Garay, R. del, 1954: Sepulcros de la Casa Real de Castilla, Madrid: CSIC.

Baury, G., 2012: Les religieuses de Castille. Patronage aristocratique et ordre ciestercien. XIIe-XIIIe siècles, Rennes: Presses Universitaires de Rennes.

Berman, C. H., I999: "Were There Twelfth-Century Cistercian Nuns?", Church History 68/4, pp. 824-864.

- 2000: The Cistercian Evolution: The Invention of a Religious Order in TwelfthCentury Europe, Philadelphia: University of Pennsylvania Press.

Carrero Santamaría, E., 2008: "Monjas y conventos en el siglo XIV. Arquitectura e imagen, usos y devociones", en El 'Libro de buen amor': Texto y contextos, eds. G. Serés, D. Rico y O. Sanz, Bellaterra, pp. 207-235.

— 20I4: "Epigrafía y liturgia estacional entre el locutorio y el pasaje a la enfermería de la abadía de Santa María la Real de las Huelgas, en Burgos", Territorio, Sociedad y Poder 9, pp. II5-I32.

Castro Garrido, A., 1987: Documentación del monasterio de Las Huelgas de Burgos (I307-I32I), Fuentes medievales castellano-leonesas 34, Burgos.

Catalunya, D., 2018: Music, Space and Ceremony at Las Huelgas of Burgos, c. I200I350, Lucca: LIM (forthcoming).

Chazelle, C., 20I2: "The Eucharist in Early Medieval Europe", in Levy, I. Ch. et all. (eds.), A Companion to the Eucharist in the Middle Ages, London: Brill, pp. 205-249.

Choisselet, D. and Vernet, P. (eds.), 1989: Les 'Ecclesiastica Officia' cisterciens du XIIe siècle, Documentation cisterciene 22, Reiningue: Abbaye d'Oelenberg.

Crónica de Alfonso XI: Rosell, Cayetano (ed.), Crónicas de los Reyes de Castilla. Desde Don Alfonso el Sabio hasta los Católicos Don Fernando y Doña Isabel, 3 vols., Biblioteca de autotes españoles, Madrid: M. Rivadeneyra, I875 (reprinted edition: Atlas, 1953).

Domínguez Bordona, J., I933: Manuscritos con pinturas, 2 vols., Madrid.

Escrivá, J. M., 1944: La Abadesa de Las Huelgas, Madrid: Luz. 
Fernández Fernández, L., 20IO-II: "El MS. 8322 de la Bibliothèque de l'Arsenal y su relación con las tablas alfonsíes. Hipótesis de trabajo", Alcanate: Revista de estudios alfonsies 7, pp. 235-267.

Ferreira, M. P., 2002: "Early Cistercian Polyphony: A Newly-Discovered Source", Lusitania Sacra I3-I4, pp. 267-313.

Gómez-Moreno, M., 1946: El panteón real de Las Huelgas de Burgos, Madrid: CSIC.

Gutiérrez, C. J., 20I4: "Señoras y abadesas en torno al códice de Las Huelgas", in Nagore, M. and Sánchez, V. (eds.), Allegro cum laude. Estudios en homenaje a Emilio Casares, Madrid: ICCMU, pp. 273-282.

Herrero González, S. and Cortés Santi, J., 1988: Códices miniados en el Real Monasterio de Las Huelgas, Barcelona: Patrimonio Nacional.

Janini, J., I962: "Manuscritos latinos del Museo Arqueológico Nacional de Madrid", Hispania Sacra I5, pp. 224-225.

—, 1977: Manuscritos litúrgicos de las bibliotecas de España. I Castilla y Navarra, Aldecoa.

and Serrano, J., 1969: Manuscritos litúrgicos de la Biblioteca Nacional, Madrid: Dirección General de Archivos y Bibliotecas.

Juárez Blanquer, A., I99I-92: "La voz 'clerecía' (y sus correspondencias) en la 'Primera Partida", Boletín de la Academia de BuenasLetras de Barcelona 43, pp. 4I-49.

Leclercq, J., I98I: "Eucharistic Celebrations Without Priests in the Middle Ages", Worship, 55, pp. 160-168.

Lizoain, J. M. (ed.), 1985: Documentación del monasterio de Las Huelgas de Burgos (I23I-I262), Fuentes medievales castellano-leonesas 3I, Burgos.

- (ed.), 1987: Documentación del monasterio de Las Huelgas de Burgos (1263I283), Fuentes medievales castellano-leonesas 32, Burgos.

— and Castro Garrido, A. (eds.), 1987: Documentación del monasterio de Las Huelgas de Burgos (1284-1306), Fuentes medievales castellano-leonesas 33, Burgos.

Mattmann, W. (ed.), 1989: Alfonso X O Sabio, Cantigas de Santa María, 3 vols., Coimbra (1964; reed., Madrid, I989).

Montero Torres, A. R., I987: "Calendario —o martirologio— cisterciense, y regla de San Benito, del real monasterio de Santa María de Las Huelgas de Burgos, que se conserva en el Museo Arqueológico Nacional de Madrid”, Cistercium 173, pp. 433-447.

Monteverde, J. L., I949: "El Museo de telas medievales del Real Monasterio de Las Huelgas", Boletín de la Comisión Provincial de Monumentos 28/ı09, pp. 233-249, p. 245 . 
Peña Pérez, F. J., 1990: Documentación del monasterio de Las Huelgas de Burgos (1349-1376), Fuentes medievales castellano-leonesas 37, Burgos.

Revilla Vielva, R., 1934: "Un códice latino de Burgos", Anuario del Cuerpo facultativo de Archiveros, Bibliotecarios y Arqueólogos I, pp. 2II-22I.

Wilmart, A., I929: "Prières pour la communion en deux psautiers du Mont-Cassin", Ephemerides liturgicae 45, pp. 320-328.

Yarza Luaces, J. and Mancini, M. (eds.), 2005: Vestiduras Ricas: el monasterio de Las Huelgas y su época, Madrid: Patrimonio Nacional. 
Table 2. The Las Huelgas customary. List of chapters, as rubricated by Rubricator A.

The selected chapters edited in Appendix I are marked with an asterisk

\begin{tabular}{|c|c|c|c|}
\hline fol. & Chap. & Rubric & Content/Remarks \\
\hline $53 \mathrm{v}$ & $79 *$ & $\begin{array}{l}\text { Dela ffiesta de Ssant Andrés, quando viniere } \\
\text { en la primera dominica de Abyento, cómmo } \\
\text { an de ffazer. }\end{array}$ & Advent. Few elements from $E O 1$. \\
\hline $53 v$ & $80 *$ & $\begin{array}{l}\text { De cómmo en la vigilia de Nauidat de } \\
\text { Nuestro Sennor non tienen de desyr oras de } \\
\text { Santa María. }\end{array}$ & $\begin{array}{l}\text { Nativity of the Lord and its Vigil. } \\
\text { Few elements from } E O 3 \text { and } 4 .\end{array}$ \\
\hline $54 \mathrm{r}$ & $81 *$ & $\begin{array}{l}\text { Del día de Sant Esteuan e de las ochauas de } \\
\text { de Nauidat commo an de dezyr las misas e } \\
\text { las Epistolas e los Euangelios. }\end{array}$ & $\begin{array}{l}\text { Octave of the Nativity. } \\
\text { EO 5, with discrepancies. }\end{array}$ \\
\hline $54 \mathrm{r}$ & $82 *$ & $\begin{array}{l}\text { De la vigilia de Anno Nuevo, cómmo an de } \\
\text { ordenar este día las misas e las otras cosas, e } \\
\text { qual canpana an de tanner. }\end{array}$ & $\begin{array}{l}\text { New Year's Day (Circumcision) and } \\
\text { its Vigil (St Sylvester). } \\
\text { Few elements from EO } 7 \text { and } 8 .\end{array}$ \\
\hline $54 \mathrm{v}$ & 83 & $\begin{array}{l}\text { De la vigilia de los Tres Reyes. Cómmo e en } \\
\text { qué manera an de ordenar las missas. }\end{array}$ & Magi (Epiphany) and its Vigil. EO 9. \\
\hline $54 \mathrm{v}$ & $84 *$ & $\begin{array}{l}\text { De las antifanas que an de dezir a } \\
\text { Benedictus e a Magnificat quando cantan el } \\
\text { estoria 'Domine ne in ira tua'. }\end{array}$ & Mix of $E O 6,10$ and 42. \\
\hline $55 \mathrm{r}$ & 85 & $\begin{array}{l}\text { Sy alguna ffiesta en que non labramos } \\
\text { vynyere en la dominica de la Ssetuagésyma. }\end{array}$ & $\begin{array}{l}\text { Septuagesima Sunday. } \\
\text { Few elements from } E O 11 .\end{array}$ \\
\hline $55 \mathrm{r}$ & $86^{*}$ & $\begin{array}{l}\text { Del Miércoles de la Cenyza. Cómo e en qué } \\
\text { manera han de ffazer todas las cosas que en } \\
\text { este día vinyeren. }\end{array}$ & Ash Wednesday (ritual). EO 13. \\
\hline $55 \mathrm{v}$ & $87 *$ & $\begin{array}{l}\text { De cómo an de leer en cabildo dos } \\
\text { ssentencias en la dominica de 'Ecce nunc } \\
\text { tempus'. }\end{array}$ & First Sunday of Lent (ritual). EO 15. \\
\hline $56 \mathrm{r}$ & $88 *$ & $\begin{array}{l}\text { De la fiesta de Sant Benito o de Sancta } \\
\text { María[, si] vyniere en la dominica que dizen } \\
\text { 'Isti sunt dies', que son quinze días ante de } \\
\text { Pascua. }\end{array}$ & $\begin{array}{l}\text { Two weeks before Easter, and Holy } \\
\text { Thursday (ritual). EO 16, 18-21. } \\
\text { (EO 17, omitted here, found in } \\
\text { HC 137) }\end{array}$ \\
\hline $56 \mathrm{v}$ & $89 *$ & $\begin{array}{l}\text { De cómo an de dezir las oras e las otras } \\
\text { cosas en Vyernes Santo de la Cruz. }\end{array}$ & $\begin{array}{l}\text { Good Friday (ritual). EO } 22 \\
(H C 140) .\end{array}$ \\
\hline $56 \mathrm{v}$ & 90 & $\begin{array}{l}\text { De la Ssemana Ssanta de Pascua de } \\
\text { Resurreción e de las sus ochauas. }\end{array}$ & Holly Week. EO 25. \\
\hline $57 \mathrm{r}$ & 91 & $\begin{array}{l}\text { De cómo an de ordenar las missas e las otras } \\
\text { oras en la dominica de Quasy modo. }\end{array}$ & Quasimodo Sunday. EO 26. \\
\hline $57 \mathrm{r}$ & 92 & $\begin{array}{l}\text { Cómmo an de leer el Apocalipssy a la mesa } \\
\text { en la dominica de 'Dignus es domine'. }\end{array}$ & Easter Week. EO 27. \\
\hline $57 \mathrm{~V}$ & 93 & De las ledanías antes de la Ascensión. & Ascension Day. EO 29 \\
\hline
\end{tabular}




\begin{tabular}{|c|c|c|c|}
\hline $57 \mathrm{v}$ & $94 *$ & $\begin{array}{l}\text { De la vigilia de Çinquagesma e de cómo se } \\
\text { han de regir en este día. }\end{array}$ & $\begin{array}{l}\text { Vigil and Octave of Pentecost and } \\
\text { Ember Days. } E O[30,] 31 .\end{array}$ \\
\hline $58 \mathrm{r}$ & 95 & $\begin{array}{l}\text { Commo an de arder quatro lanparas e an de } \\
\text { dezyr oras de Santa María e an de fablar en } \\
\text { el cabildo e an de tomar agua bendita en el } \\
\text { día de la Santa Trinidat. }\end{array}$ & Trinity and Corpus Christi. \\
\hline $58 \mathrm{v}$ & 96 & $\begin{array}{l}\text { De la primera dominica después de la } \\
\text { Trinidat en la qual se ha de poner la estoria } \\
\text { de 'Deus omnium'. }\end{array}$ & First Sunday after Trinity. \\
\hline $58 \mathrm{v}$ & 97 & $\begin{array}{l}\text { De las quatro estorias, cómmo se an de } \\
\text { poner. }\end{array}$ & $\begin{array}{l}\text { Miscellany. Calendar for diverse } \\
\text { historiae (EO 39); anniversaries } \\
\text { (fol. 59r contains a reference to the } \\
\text { "abadesas que enterran en cabillo"). }\end{array}$ \\
\hline $59 v$ & 98 & $\begin{array}{l}\text { De la dominica que viene después de la } \\
\text { Trinidat e cómo an de dezyr la ystoria de } \\
\text { 'Deus omnium'. }\end{array}$ & Calendar for diverse historiae. \\
\hline $59 \mathrm{v}$ & 99 & $\begin{array}{l}\text { De las fiestas en que non labramos e que } \\
\text { vynieren en domingo. }\end{array}$ & $\begin{array}{l}\text { Non-working feast days that fall on } \\
\text { Sunday. } E O 34 \text {. }\end{array}$ \\
\hline $60 \mathrm{r}$ & 100 & $\begin{array}{l}\text { De las fiestas en que labramos e vynieren en } \\
\text { domingo. }\end{array}$ & $\begin{array}{l}\text { Working feast days that fall on } \\
\text { Sunday. EO } 35 .\end{array}$ \\
\hline $60 \mathrm{r}$ & 101 & $\begin{array}{l}\text { De los domingos en los quales non vyene } \\
\text { ffiesta ninguna de doze leciones. }\end{array}$ & $\begin{array}{l}\text { Sundays without the feast of twelve } \\
\text { lessons. EO } 36 .\end{array}$ \\
\hline $60 v$ & $102 *$ & $\begin{array}{l}\text { Quando la Fiesta de Santa María Asunción o } \\
\text { Santa María Natiuitas vynieren en jueues. }\end{array}$ & Miscellany (calendar issues). \\
\hline $60 v$ & 103 & $\begin{array}{l}\text { De las fiestas en que non labramos, sy } \\
\text { uynyeren en las ochauas de Pascua o enel } \\
\text { día de la Ascensyón o en la Septuagésima. }\end{array}$ & $\begin{array}{l}\text { Non-working feast days that fall } \\
\text { on the Octave of Easter, Ascension } \\
\text { or Septuagesima (EO 43) and an } \\
\text { extended section on further calendar } \\
\text { matters. }\end{array}$ \\
\hline $64 v$ & $104 *$ & $\begin{array}{l}\text { De los santos que tienen doze leciones e que } \\
\text { non les dan sy non vna missa. }\end{array}$ & $\begin{array}{l}\text { Feasts of twelve lessons and one } \\
\text { Mass. EO } 49 .\end{array}$ \\
\hline $64 v$ & $105^{*}$ & Quales santos an doze leçiones e dos missas. & $\begin{array}{l}\text { Feasts of twelve lessons and two } \\
\text { Masses. EO } 60 .\end{array}$ \\
\hline $65 \mathrm{r}$ & $106^{*}$ & $\begin{array}{l}\text { Sy la fiesta de Sant Pedro vynyere enel } \\
\text { jueues de las ochauas del Cuerpo de Dios. }\end{array}$ & Miscellany (calendar issues). \\
\hline $65 \mathrm{r}$ & $107 *$ & $\begin{array}{l}\text { De la collecta 'Concede nos ffamulos', en } \\
\text { quales días es a dexir. }\end{array}$ & $\begin{array}{l}\text { Miscellany (two chapters merged } \\
\text { in one). Diverse collects and } \\
\text { anniversaries; Masses and calendar } \\
\text { matters. }\end{array}$ \\
\hline $65 \mathrm{v}$ & $108^{*}$ & De Ia vigilia de Çynquagesma. & Miscellany. \\
\hline $66 \mathrm{r}$ & $109 *$ & $\begin{array}{l}\text { Del vielso ‘Any recurso', en quales días se } \\
\text { deue desyr. }\end{array}$ & Miscellany. \\
\hline $66 \mathrm{r}$ & $110^{*}$ & $\begin{array}{l}\text { De la fiesta de Sant Johan, e de Sant yago, e } \\
\text { de Sant Pedro, sy vynyeren en domingo. }\end{array}$ & Miscellany. \\
\hline
\end{tabular}




\begin{tabular}{|c|c|c|c|}
\hline $66 \mathrm{r}$ & $111 *$ & $\begin{array}{l}\text { De quando touieren cuerpo presente en coro, } \\
\text { cómmo an de aser. }\end{array}$ & Miscellany. \\
\hline $66 \mathrm{v}$ & $112 *$ & Del ochauario de Sant Iohan Bba $<$ utista $>$. & Octave of St John. \\
\hline $67 \mathrm{r}$ & $113 *$ & $\begin{array}{l}\text { De cómmo an de desyr misa de Santa } \\
\text { María en todos los sábbados que no fueren } \\
\text { enbargados. }\end{array}$ & The Mass of St Mary on Sundays. \\
\hline $67 \mathrm{r}$ & $114 *$ & $\begin{array}{l}\text { De cómo se a de dessyr las missas por todo } \\
\text { el anno. }\end{array}$ & Weekly distribution of masses. \\
\hline $67 \mathrm{r}$ & $115^{*}$ & $\begin{array}{l}\text { De los Sábbados del Abiento e de } \\
\text { Setuagésima e Çinquagésima e Sexagésima. }\end{array}$ & Feasts on Pentecost. \\
\hline $67 v$ & $116^{*}$ & $\begin{array}{l}\text { De cómmo non an de desyr en el día de Sant } \\
\text { Iohan a laudes 'Any recurso'. }\end{array}$ & The hymn-stanza 'Anni recurso'. \\
\hline $67 v$ & $117 *$ & $\begin{array}{l}\text { En quales días an de desyr 'Gloria in } \\
\text { excelsis' e 'Ite missa est'. }\end{array}$ & Gloria. EO 63. \\
\hline $67 v$ & $118^{*}$ & En quales días an de desyr 'Credo'. & Credo. EO 65. \\
\hline $67 \mathrm{v}$ & 119 & $\begin{array}{l}\text { De cómmo an desir los prephacios, e en } \\
\text { quales días. }\end{array}$ & Prefaces. \\
\hline $68 \mathrm{r}$ & 120 & $\begin{array}{l}\text { En quales días an de acender alas oras } \\
\text { quatro lanparas. }\end{array}$ & $\begin{array}{l}\text { Miscellany. Four lamps (EO 67) and } \\
\text { further calendar issues. }\end{array}$ \\
\hline $68 \mathrm{r}$ & 121 & $\begin{array}{l}\text { En quales días non an de desir la collecta } \\
\text { 'Eclesie tue'. }\end{array}$ & $\begin{array}{l}\text { Miscellany. Collects and calendar } \\
\text { issues. }\end{array}$ \\
\hline $68 \mathrm{v}$ & 122 & Como an de cumplir la leue culpa. & $\begin{array}{l}\text { Miscellany. Penance and calendar } \\
\text { issues. }\end{array}$ \\
\hline $68 v$ & 123 & $\begin{array}{l}\text { De la fiesta del Cuerpo de Dios, sy vynuere } \\
\text { enel día de Sant Iohan. }\end{array}$ & Corpus Christi and its Octave. \\
\hline $68 v$ & 124 & En quáles ffiestas non labran las ffreylas. & $\begin{array}{l}\text { Non-working feast days for the } \\
\text { freyras. }\end{array}$ \\
\hline $69 \mathrm{r}$ & $125^{*}$ & $\begin{array}{l}\text { De cómmo sse an de partir los tiempos en } \\
\text { cada vn anno. }\end{array}$ & Miscellany. \\
\hline $69 \mathrm{r}$ & $126^{*}$ & $\begin{array}{l}\text { De cómmo an de vannar el cuerpo después } \\
\text { que fuere ffinado, e de cómmo se an de } \\
\text { regir. }\end{array}$ & $\begin{array}{l}\text { Bathing of the body after death } \\
\text { (ritual). } \\
\text { EO } 94.21-94.25 \text {. }\end{array}$ \\
\hline $69 v$ & $127 *$ & $\begin{array}{l}\text { De los anyuerssarios de la orden e de los } \\
\text { que yasen en el coro. }\end{array}$ & Miscellany. \\
\hline $69 v$ & $128 *$ & $\begin{array}{l}\text { De las cosas que somos tenudas a desir por } \\
\text { los ffinados e en quales días. }\end{array}$ & Anniversary list. \\
\hline $70 \mathrm{r}$ & $129 *$ & $\begin{array}{l}\text { A quantos días de cada vn mes ffasen } \\
\text { aniuersario por los sennores ffinados. }\end{array}$ & \\
\hline $70 \mathrm{r}$ & $130 *$ & $\begin{array}{l}\text { De los anyuersarios que fasen por ssenores e } \\
\text { sennoras finados. }\end{array}$ & \\
\hline $70 \mathrm{v}$ & $131 *$ & $\begin{array}{l}\text { Delos siete psalmos de los anyuersarios de } \\
\text { las abbadessas. }\end{array}$ & $\begin{array}{l}\text { Computation of the psalms to be } \\
\text { prayed on the anniversaries thought } \\
\text { the entire year. }\end{array}$ \\
\hline
\end{tabular}




\begin{tabular}{|c|c|c|c|}
\hline $70 \mathrm{v}$ & 132 & $\begin{array}{l}\text { De la ffiesta de Sant Gregorio e de Sant } \\
\text { Anbrosyo sy vinieren en sábbado. }\end{array}$ & $\begin{array}{l}\text { St Gregory and St Ambrose on } \\
\text { Saturday. }\end{array}$ \\
\hline $70 \mathrm{v}$ & $133^{*}$ & $\begin{array}{l}\text { De lo que a de ffaser el conuento quando } \\
\text { alguna se quisyere ffinar. }\end{array}$ & $\begin{array}{l}\text { How to proceed when a nun dies. } \\
E O 94 \text {. }\end{array}$ \\
\hline $71 \mathrm{r}$ & $134 *$ & $\begin{array}{l}\text { En quales tienpos pueden tomar bendición } \\
\text { las monjas quando fueren de camino. }\end{array}$ & Trips. EO 88. \\
\hline $72 \mathrm{r}$ & - & - & $\begin{array}{l}\text { Interpolation. Pedagogical text on } \\
\text { how to count in Latin. }\end{array}$ \\
\hline $72 \mathrm{r}$ & $135^{*}$ & $\begin{array}{l}\text { Del tiempo que ay de la Setuagésima ffasta } \\
\text { la Pascua, cómmo se an de ordenar. }\end{array}$ & $\begin{array}{l}\text { Masses and tracts, from Septuagesima } \\
\text { to Easter. }\end{array}$ \\
\hline $72 \mathrm{r}$ & $136^{*}$ & $\begin{array}{l}\text { De los Kyrios e la Gloria e los Ssanctus } \\
\text { e Agnus ffestivales, en quales días son a } \\
\text { desyr. }\end{array}$ & Kyrie, Gloria, Sanctus, Agnus. EO 62. \\
\hline $72 \mathrm{r}$ & $137 *$ & $\begin{array}{l}\text { De commo ha de bendesyr el agua el abbat o } \\
\text { el conffessor el día de Ramos. }\end{array}$ & Literal translation of $E O 17$. \\
\hline $73 r$ & $138 *$ & De la Passión del día de Ramos. & Literal translation of $E O 18$. \\
\hline $73 r$ & $139 *$ & $\begin{array}{l}\text { Del Jueves de la Cena, cómmo an de aser } \\
\text { en este día. }\end{array}$ & Literal translation of $E O 21$. \\
\hline $73 r$ & 140 & Del Viernes Ssanto de la Crus. & Literal translation of $E O 22$. \\
\hline $74 \mathrm{r}$ & 141 & Del Sábbado de las vygilia de Pascua. & Literal translation of EO 23. \\
\hline $75 r$ & 142 & $\begin{array}{l}\text { De cómo e en qué manuera sse an de poner } \\
\text { las katendas ..... (erased) }\end{array}$ & Literal translation of $E O 39$. \\
\hline $75 \mathrm{r}$ & - & $\begin{array}{l}\text { Quomodo legantur libri in refectario a } \\
\text { Pentecoste usque ad kalendas novembris. }\end{array}$ & $\begin{array}{l}\text { EO } 41 \text { (in Latin), added by a third } \\
\text { hand. }\end{array}$ \\
\hline
\end{tabular}


Table 3. Ash Wednesday

\begin{tabular}{|c|c|}
\hline EO 13 & $D C 86$ \\
\hline $\begin{array}{l}\text { 1. Feria quarta in capite ieiunii dicta } \\
\text { prima exeant in claustrum, et altaris } \\
\text { ministri ut in ceteris diebus se ad } \\
\text { celebrandam missam preparent. } \\
\text { 2. Tunc sacerdote, alba cum stola et } \\
\text { manipula. et ministro suo alba et } \\
\text { manipula induto, signoque pulsato } \\
\text { fratres in claustra se discalcient, } \\
\text { atque in eodem calciamenta dimittentes } \\
\text { loco, ecclesiam intrent: et in ordine suo } \\
\text { versis vultibus ad altare stent. } \\
\text { 3. Altaris itaque ebdomadarii in vestiario } \\
\text { se discalciantes in chorum veniant. } \\
\text { 4. Post hec cantor incipiat antiphonam: } \\
\text { 'Exurge domine'. } \\
\text { 5. Quam dum incipit, vertant vultus ad } \\
\text { invicem. } \\
\text { 6. Et subsequatur versus: 'Deus auribus' } \\
\text { et 'Gloria patri'. } \\
\text { 7. Deinde ebdomadarius misse dicat } \\
\text { versiculum 'Ostende nobis domine'. }\end{array}$ & $\begin{array}{l}\text { E desque fuere acabado dos veses } \\
\text { 'Exurge', digan el domadario dela } \\
\text { missa el vielso 'Ostende nobis'. } \\
\text { Respondan 'Salutare' } \\
\text { e ffagan presçes sobre las formas. } \\
\text { Diga la cantora 'Quirieleyson' e 'Pater } \\
\text { noster'. Digan 'Et ne nos inducas' e } \\
\text { rrespondan 'Set libera nos' e comiençe la } \\
\text { cantora 'Deus misereatur' e digan le a } \\
\text { vielsos e 'Gloria patri'. } \\
\text { Este ofiçio fagan las dela enfermería asy } \\
\text { como las de coro con sus presçes. } \\
\text { Después digan 'Et veniat super nos', } \\
\text { 'Dominus uobiscum', 'Oremus', } \\
\text { 'Concede nobis domine', } \\
\text { e leuantense e estén tornadas al altar } \\
\text { ffasta el comienço dela missa. }\end{array}$ \\
\hline
\end{tabular}


cantetur antiphona 'Exaudi nos

domine', et alie ut in libris habentur.

11. 'Exaudi nos domine' incepta, abbas stola deposita veniens ante gradum, el sub illo flexis genibus ab ebdomadario misse prius ipse sacros accipiat cineres.

12. Quibus acceplis erigens se resumpla stola stet supra gradum, et versus ad chorum super singulorum capita mittat cineres benedictos, incipiens a ministris altaris, omnibus flectentibus genua in terra.

13. $[\ldots]$

21. Inchoata vero antiphona

'Immutemur', sacerdos et minister calcient se:

et signo pulsato accedant ad missam celebrandam. $[\ldots]$
E acabada la bendiçión dela çeniza, comiençe la cantora 'Exaudi nos domine' (introit)

e, encommençando el vielso, abran la puerta.

E a esta 'Gloria' non se enclynen. [Después de] 'Exaudi nos', comiençen 'Justa vestibulum'.

E quando ouieren tomada la çeniza comiençen 'Immutemur' a $<$ ntifana $>$.

Estonçe tangan a misa. $[\ldots]$ 
Table 4. Maundy Thursday

\begin{tabular}{|c|c|}
\hline$E O 20$ and 21 & HC 88 \\
\hline 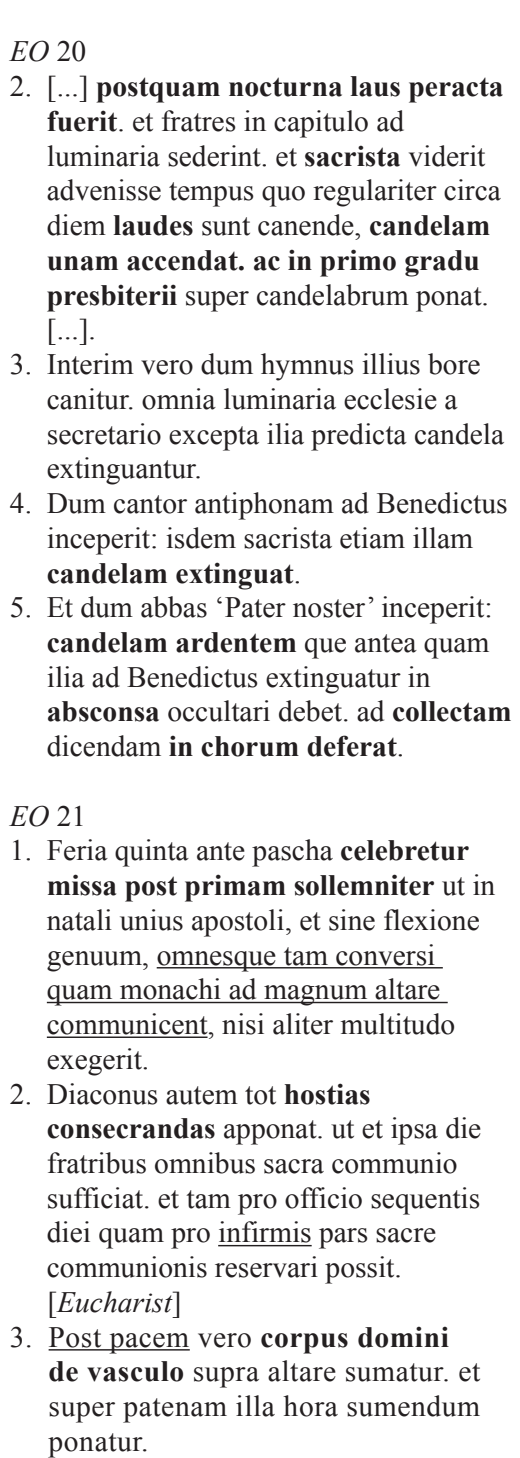 & $\begin{array}{l}\text { e quando començare la antifana de } \\
\text { Benedictus, amate la } \\
\text { e lieue otra açendida e ascondida, } \\
\text { e quando dixeren la collecta, ssaquen la } \\
\text { candela. }\end{array}$ \\
\hline
\end{tabular}


4. Linteum etiam mox de eodem vasculo auferatur, aliudque a sacrista ilia bora presentatum in eo ponatur, illoque mutato ab eodem secretario, mox abbas vel qui cantat missam partem sacre communionis in crastinum servandam in vasculo anlenotato honorifice recondat, et tune linteum velus in palena diligenter excussum super piscinam comburatur, cineresque eius in eam proiciantur.

5. Et sciendum quod hac die missa privata non sit ab aliquo cantanda nisi pro conversis communicandis ubi multitudo exegerit: et ipsa missa de die sit.

6. Missa tamen de Sancta Maria ad quam nullus hac die communicet, et cotidiana pro defunctis cantabitur.
E desque ouieren el Cuerpo de Dios ençerrado, acaben la missa. E este día toman pas las de coro e las dela enfermería en vno e comulgan. E la que diere el libro ala abbadesa enclyne se, e la que tomare pas con ella faga presçes, e quantos días tomaren pas con ella. E desque ouieren tomado pas, dé el libro alas freiras dela enfermería [e] después alas de coro. $[\ldots]$ 
Table 5. Good Friday

\begin{tabular}{|c|c|}
\hline $\begin{array}{c}\text { HC } \mathbf{1 4 0} \\
\text { (literal translation of } \\
\text { EO Chapters 22.18 and 22.24-36) }\end{array}$ & $\begin{array}{c}\text { HC } 89 \\
\text { (ritual adapted) }\end{array}$ \\
\hline $\begin{array}{l}\text { E en tanto que este ofiçio fasen, el } \\
\text { prior aconpannante a él, el ssachristan } \\
\text { o otro frayre qual él llamare por signo, } \\
\text { presente otra crus con rreuerençia a } \\
\text { adorar ffuera del coro ala conpann<í>a e } \\
\text { alos huespedes, ssi ý fueren. E después } \\
\text { que todos ouieren adorado, aquellos } \\
\text { que tyenen la crus leuante[n] sse e } \\
\text { comiençen el antifana 'Super omnia } \\
\text { ligna' e luego tome venia el conuento } \\
\text { contra ella, mas los monjes luego tomen } \\
\text { la crus en su logar ssobre el altar. E } \\
\text { estonçe, el abbad e el diácono tomen } \\
\text { lo que dexaron e vengan al altar con } \\
\text { el subdiácono assy commo antes eran } \\
\text { descalços los pies e fagan la oraçión e } \\
\text { assy dygan la confesión. E esto fecho, } \\
\text { ponga el diácono el corporal ssobre el } \\
\text { altar que ya primera mente deue sser } \\
\text { puesto ssobrel ministerio del ssachristán. } \\
\text { Mas el abbad al altar el Corpus Domini } \\
\text { con el vaso en que es, pongal cerca } \\
\text { del corporal. E quando el subdiácono } \\
\text { ordenare el calis con el vino buelto con } \\
\text { el agua, ofrescal ssobre el altar segundo } \\
\text { suele ala missa. El abbad primera } \\
\text { mente tome el ençenso e, abierto el el } \\
\text { vaso, laue los dedos e saque la Santa } \\
\text { comunión del vaso e pongalo ssobre } \\
\text { el corporal. Estonçe, nin el Corpus } \\
\text { Domini nin el calis leuantado, diga } \\
\text { lyuiana bos: 'Oremus preceptis' } \\
\text { 'Salutaribus moniti’ e 'Libera nos }\end{array}$ & $\begin{array}{l}\text { Otras cruses aya para las flacas e para } \\
\text { las que vynieren a oyr missa, } \\
\text { e los que touieren la cruz comiençen } \\
\text { 'Super omnia ligna' [e] el conuento } \\
\text { después diga en media bos. }\end{array}$ \\
\hline
\end{tabular}


quaesumus domine' e [...] dicente: 'Per eundem dominum nostrum', e ponga el corpus domini en tres partes, e diga después baxa bos: 'Per omnia secula seculorum'; e assí todos rrespondientes: 'Amen'. La una parte enel calis ninguna cossa diçiente, pero el diácono, ffecha la purificaçión e lauadas las manos, esté con el subdiácono do suele estar alas collectas fasta que sse deua a llegar al comulgar. 'Pax domini' non sea dicho nin ssea dado, nin venia ssea tomada de conuento, nin 'Agnus dei' non ssea cantado dessi el abbad e los ministros comulguen. E en tanto los frayres oyan, sus ffases [sean] tornadas al altar, e después quelos ministros comulgaren, ssalga el conuento e calçen sus pies de sus çapatos; mas [agua] caliente ssea proueida del clau $<$ str $>$ ero en la claustra [para que] quien quisiere pueda lauar sus pies. [...] mas non diga 'Pax domini'

nin 'Agnus dei'.

Quando fuere todo acabado, vayan a cabillo [a] lauar se los pies las que quisieren. [...] 


\section{Table 6.}

\section{Obituary in Huelgas 6 (Chapters I28-I30).}

The identified persons interred in Las Huelgas are marked with an asterisk

\begin{tabular}{|c|c|c|c|}
\hline Name given in $\mathrm{HC}$ & Identification & Anniversary & Office \\
\hline 1. Rey Bueno & * King Alfonso VIII († 1214, 6 October) & 6 October & 1 full psalter \\
\hline $\begin{array}{l}\text { 2. Infante donna } \\
\text { Blanca }\end{array}$ & $\begin{array}{l}* \text { Infanta Blanca of Portugal }(\dagger 1321,15-25 \\
\text { April). }{ }^{1}\end{array}$ & $\begin{array}{l}13 \text { "deste mes" } \\
\text { [i.e., October }]^{2}\end{array}$ & 1 full psalter \\
\hline $\begin{array}{l}\text { 3. Infante don } \\
\text { Ffernando, fijo del } \\
\text { Rey Bueno }\end{array}$ & $\begin{array}{l}* \text { Infante Fernando († 1211, } 14 \text { October), } \\
\text { son of Alfonso VIII }\end{array}$ & [date missing] & 50 psalms \\
\hline $\begin{array}{l}\text { 4. Arçobispo don } \\
\text { San[cho] }\end{array}$ & $\begin{array}{l}\text { (*) Infante Sancho, son of Fernando III of } \\
\text { Castile and León, archbishop-elect of Toledo } \\
(\dagger 1261,27 \text { October). }\end{array}$ & $\begin{array}{l}\text { St Simon } \\
\text { and Jude } \\
{[28 \text { Octover] }}\end{array}$ & 7 psalms \\
\hline 5. Reyna Buena & $\begin{array}{l}* \text { Queen Leonor }(\dagger 1214,31 \text { October), wife } \\
\text { of Alfonso VIII, founder of the Las Huelgas } \\
\text { Monastery }\end{array}$ & 3 November & 1 full psalter \\
\hline $\begin{array}{l}\text { 6. Reyna su fija, que } \\
\text { ayuntó los rreynos }\end{array}$ & $\begin{array}{l}\text { * Queen Berenguela of Castile }(\dagger 1246,8 \\
\text { November), daughter of Alfonso VIII and } \\
\text { Leonor, wife of Alfonso IX de León. She } \\
\text { managed the heirs of the kingdom of León } \\
\text { to waive their right to the throne in favour } \\
\text { of her son Fernando III and thus united the } \\
\text { kingdoms of Castile and León. }\end{array}$ & $\begin{array}{l}4 \text { November } \\
\text { ("otro día") }\end{array}$ & 1 full psalter \\
\hline
\end{tabular}

'The entry "Infante donna Blanca" appears twice in $H C$ (see entry 35 below).

2 This date is certainly mistaken: it reads "the thirteenth day of 'this' month", referring to the month previously mentioned in $H C$, but this entry is likely misplaced. The date found in the second entry for Infanta Blanca (entry 35 below in this table) seems to be closer to the day of her death. She must have died shortly before 25 April, since it was on this day that her testament was opened and read publically. Castro Garrido, 1987, doc. 366, pp. 335-337.

${ }_{3}$ The final resting place of the remains of the Infante Sancho of Castile is contested territory. Arco y Garay, 1954, claims that the remains of the infante-archbishop are currently found in the chancel of the Toledo Cathedral, together with the sepulchre of King Sancho IV, whose tomb was discovered intact during the archaeological excavations carried out in the cathedral in 1947. Nonetheless, Las Huelgas also has a sepulchre which, according to the tradition of the monastery, contains the remains of the Infante Sancho of Castile. Gómez-Moreno, 1946, holds that this sepulchre had first been placed in the pórtico of the church and was subsequently transferred inside the church of the monastery and reused for the interment of someone else. Arco y Garay, however, considers it improbable that a sarcophagus in which someone had already been buried would be reused for an archbishop of Toledo. In the I940's, when the sepulchres of the Las Huelgas Monastery were examined, this sepulchre was found to hold the skeleton of a young adult, which would be consistent with the age of the Infante Sancho upon his death at age 28. The fact that the skull of the deceased was turned towards the church's altar also suggests that the person buried in Las Huelgas was a prelate. 


\begin{tabular}{|c|c|c|c|}
\hline $\begin{array}{l}\text { 7. Rreyna dona } \\
\text { Beatrys }\end{array}$ & $\begin{array}{l}(*) \text { Queen Beatriz ( } \dagger 1235,5 \text { November), } \\
\text { wife of Fernando III. She was interred in } \\
\text { Las Huelgas until she was transferred to the } \\
\text { Seville Cathedral in } 1279 \text { by order of her } \\
\text { son Alfonso X. }\end{array}$ & 6 November & 1 full psalter \\
\hline 8. don Ffelipe & $\begin{array}{l}\text { Infante Felipe of Castile }(\dagger 1274,28 \\
\text { November), son of Fernando III, brother of } \\
\text { Alfonso X, archbishop elect of Seville }\end{array}$ & 15 November & 7 psalms \\
\hline $\begin{array}{l}\text { 9. Reyna donna } \\
\text { Vrraca; }\end{array}$ & $\begin{array}{l}\text { Queen Urraca († 1220, } 30 \text { November), } \\
\text { daughter of Alfonso VIII, infanta of Castile } \\
\text { and queen consort of Portugal by virtue of } \\
\text { her marriage to Alfonso II of Portugal; }\end{array}$ & $\begin{array}{l}28 \text { November } \\
\text { ("3 días por } \\
\text { andar") }\end{array}$ & $2 \times 7$ psalms \\
\hline $\begin{array}{l}\text { 10. Rreyna donna } \\
\text { Blanca }\end{array}$ & $\begin{array}{l}\text { Queen Blanca († 1252, } 29 \text { November), } \\
\text { daughter of Alfonso VIII, infanta of Castile } \\
\text { and queen consort of France by virtue of her } \\
\text { marriage to King Luis VIII. }\end{array}$ & & \\
\hline 11. donna Yssabel & $\begin{array}{l}\text { * Isabel de Molina ( } † 1292) \text {, daughter of } \\
\text { Alfonso Fernández, bastard son of Alfonso } \\
\text { X. }\end{array}$ & 4 December & 7 psalms \\
\hline $\begin{array}{l}\text { 12. donna María de } \\
\text { Almenar }\end{array}$ & $\begin{array}{l}\text { * María de Almenar († 1196), daughter of } \\
\text { the count of Urgel Armengol. She donated } \\
\text { the main altar to the Las Huelgas convent. }\end{array}$ & 20 December & 7 psalms \\
\hline 13. Infante Ssanta & $\begin{array}{l}* \text { Infanta Berenguela ( } \uparrow 1288 / 90) \text {, daughter } \\
\text { of Fernando III, sister of Alfonso X, señora } \\
\text { of Las Huelgas. }\end{array}$ & 1 [January] & 1 full psalter \\
\hline $\begin{array}{l}\text { 14. don Moryel; } \\
\text { 15. ssu muger }\end{array}$ & $\begin{array}{l}(*) \text { Moriel and his wife Elvira (1230s-40s). } \\
\text { Benefactors, together with their son (who } \\
\text { requested burial in Las Huelgas). They } \\
\text { donated lands, income and goods to the } \\
\text { monastery. }\end{array}$ & 20 January & $2 \times 7$ psalms \\
\hline
\end{tabular}

${ }^{4}$ For more on this person, see Monteverde, 1949, pp. 233-249, p. 245.

5 On the problem of the dating of Infanta Berengela's death, see Lizoain and Castro Garrido, I987, p. I25 n I.

${ }_{6}$ Moriel and his wife are mentioned a number of times throughout the Las Huelgas documentation covering the I23Os and the I24Os. In one of the documents, the Abbess Inés Laínez sets rental income aside to ensure that two priests sing masses for the souls of Moriel and Elvira, who had given the monastery one thousand maravedís for such purpose (Lizoain, 1985, doc. 355, pp. I39-I4O). In another document, dated I245, the couple's son, Gonzalo Moriel, requests interment in the monastery, stipulating that, after his death, the abbess was to take a portion of the goods he had inherited from his mother, Elvira (Lizoain, 1985, doc. 354, pp. 138-139). For other documents concerning donations and other transactions carried out by Elvira, Moriel's widow, all dated I240, see Lizoain, 1985, doc. 316, pp. 94-95; doc. 317, pP. 95-96; doc. 320, pp. 98-99; doc. 321, pp. 99-100. A certain "Domus Moriel" signs as "maius merius in Castella" in documents of Fernando III dated I237 (Lizoain, 1985, doc. 289, pp. 63-63; doc. 292, pp. 66-68). 


\begin{tabular}{|l|l|l|l|}
\hline $\begin{array}{l}\text { 16. Alfonso, ffijo } \\
\text { del infante don } \\
\text { Fernando }\end{array}$ & $\begin{array}{l}\text { * Alfonso de la Cerda († 1333), son of the } \\
\text { Infante Fernando de la Cerda, heir to the } \\
\text { Crown of Castile. }\end{array}$ & 13 January & 7 psalms \\
\hline $\begin{array}{l}\text { 17. don Manuel, } \\
\text { ffijo de don } \\
\text { Fernando rrey de } \\
\text { Castiella et de León }\end{array}$ & $\begin{array}{l}\text { * Infante Manuel († 1283, 25 December), } \\
\text { son of Fernando III of Castile and León. }\end{array}$ & 15 January & $\begin{array}{l}\text { [info } \\
\text { missing] }\end{array}$ \\
\hline $\begin{array}{l}\text { 18. Infante don } \\
\text { Alfonso, fijo de } \\
\text { don Alfonso Rey de } \\
\text { León }\end{array}$ & $\begin{array}{l}\text { Infante Alfonso de Molina († 1272, 6 } \\
\text { January), son of King Alfonso IX of León, } \\
\text { brother of Fernando III of Castile and León. }\end{array}$ & January & $\begin{array}{l}\text { [info } \\
\text { missing] }\end{array}$ \\
\hline $\begin{array}{l}\text { 19. Infante don } \\
\text { Alffonso }\end{array}$ & $\begin{array}{l}\text { * Infante Alfonso of Aragon († 1260, 23 } \\
\text { March), son of James I of Aragon and } \\
\text { Leonor of Castile (daughter of Alfonso VIII } \\
\text { of Castile). }\end{array}$ & 11 March & 7 psalms \\
\hline $\begin{array}{l}\text { 20. Rey don } \\
\text { Alfonso, que fynó } \\
\text { en día de Viernes de } \\
\text { la Crus. }\end{array}$ & $\begin{array}{l}\text { ? King Alfonso X († 1284, 4 April, Tuesday } \\
\text { of Holy Week). } \\
\text { ? King Alfonso XI († 1350, 26 March, Good } \\
\text { Friday). }\end{array}$ & 5 April & 1 full psalter \\
\hline $\begin{array}{l}\text { 21. Rey don Sancho } \\
\text { King Sancho IV († 1295, 25 April). }\end{array}$ & $\begin{array}{l}\text { 27 April } \\
\text { ““4 días por } \\
\text { andar") }\end{array}$ & 1 full psalter \\
\hline $\begin{array}{l}\text { 22. Infante Fradique } \\
\text { ffijo de Fernando } \\
\text { Rey de Castiella et } \\
\text { León }\end{array}$ & $\begin{array}{l}\text { Infante Fadrique († 1277), son of Fernando } \\
\text { III of Castile and León, executed by order of } \\
\text { his brother Alfonso X for conspiring against } \\
\text { after the death of Alfonso X’s first-born son. }\end{array}$ & May & 7 psalms \\
\hline
\end{tabular}

7 The date 23 March 1260 appears in an inscription on his sepulchre. The sepulchre itself, however, is dated 1263 (Arco y Garay, 1945).

8 "King don Alfonso, who died on Good Friday", Huelgas 6, f. 7or.

${ }^{9}$ In principle, this would seem to be the correct identification, since the date of death of Alfonso X differs by only one day from the date given in $H C$. Alfonso X, however, died on the Tuesday of Holy Week and not on Good Friday as stated in $H C$. This may have been confused with the date of the death of Alfonso XI, who, according to the Crónica de Alfonso XI, died on Good Friday, but in March (see the note below). Yet, the fact that Alfonso X does not appear in the obituary of Arqueológico 3 is certainly intriguing.

Io According to the Crónica de Alfonso XI, he died on March 27, Good Friday, in I350. But that year, Good Friday was on March 26, not March 27 as affirmed in the Crónica: "And he died on Friday of the Holy Week [...] which was the twenty seventh day of March in the Holy Week before Easter in the year of our Lord Jesus Christ thirteen hundred and fifty" (Et finó viernes de la semana sancta $[. .$.$] que fue a veinte et siete dias de Marzo en la semana sancta antes de Pascua en el ańo del$ nascimiento do nuestro Señor Jesu-Christo de mili et trecientos et cincuenta ańos). Crónica, p. 39i.

II According to certain sources, the remains of the Infante Fadrique of Castile were transferred to the Las Huelgas Monastery after the demolition of the convent of the Santísima Trinidad in Burgos in the nineteenth century. Among the sepulchres located in the pórtico of the monastery of 


\begin{tabular}{|c|c|c|c|}
\hline $\begin{array}{l}\text { 23. Rey don } \\
\text { Fernando el Ssanto }\end{array}$ & $\begin{array}{l}\text { King Fernando III of Castile and León, 'the } \\
\text { Saint' († 1252, } 30 \text { May). }\end{array}$ & $\begin{array}{l}28 \text { May } \\
\text { (“4 días por } \\
\text { andar") }\end{array}$ & 1 full psalter \\
\hline $\begin{array}{l}\text { 24. Rrey don } \\
\text { Enrrique ffijo del } \\
\text { Rrey don Alfonso }\end{array}$ & $\begin{array}{l}\text { King Enrique II of Castile ( } \dagger 1379,29 \text { May), } \\
\text { House of Trastamara, son out of wedlock of } \\
\text { Alfonso XI. }\end{array}$ & $\begin{array}{l}30 \text { May } \\
\text { ("2 días por } \\
\text { andar") }\end{array}$ & 1 full psalter \\
\hline $\begin{array}{l}\text { 25. Reyna de } \\
\text { Aragón ffija del Rey } \\
\text { Bueno }\end{array}$ & $\begin{array}{l}\text { * Queen Leonor of Aragon ( } \dagger 1244), \\
\text { daughter of Alfonso VIII, queen consort of } \\
\text { Aragon by virtue of her marriage to King } \\
\text { James I de Aragón. }\end{array}$ & $\begin{array}{l}23 \text { July } \\
\text { ("9 días por } \\
\text { andar") }\end{array}$ & $\begin{array}{l}15+7 \\
\text { psalms }\end{array}$ \\
\hline $\begin{array}{l}\text { 26. Infante don } \\
\text { Pedro }\end{array}$ & $\begin{array}{l}\text { * Infante Pedro ( } † 1319,25 \text { June; buried in } \\
\text { Las Huelgas on } 25 \text { August), son of Sancho } \\
\text { IV, killed in the 'Disaster of La Vega de } \\
\text { Granada'. }\end{array}$ & 28 July & 50 psalms \\
\hline $\begin{array}{l}\text { 27. Infante don } \\
\text { Iohan }\end{array}$ & $\begin{array}{l}\text { Infante Juan ( } † 1319,25 \text { June; buried in the } \\
\text { Cathedral of Burgos), son of Alfonso X, } \\
\text { killed in the 'Disaster of La Vega de } \\
\text { Granada'. }\end{array}$ & $\begin{array}{l}29 \text { July } \\
\text { ("otro día") }\end{array}$ & 7 psalms \\
\hline $\begin{array}{l}\text { 28. donna Costança } \\
\text { ffija de don Alfonso } \\
\text { Rey de Castiella et } \\
\text { de León }\end{array}$ & $\begin{array}{l}\text { * Infanta Constanza ( } \uparrow 1280,23 \text { July), } \\
\text { daughter of Alfonso X, nun of Las Huelgas, } \\
\text { died at age } 21 .\end{array}$ & $\begin{array}{l}23 \text { July } \\
\text { ("9 días por } \\
\text { andar") }\end{array}$ & 50 psalms \\
\hline $\begin{array}{l}\text { 29. Reyna donna } \\
\text { María }\end{array}$ & $\begin{array}{l}\text { Queen María de Molina († 1321, } 1 \text { July), } \\
\text { wife of Sancho IV and tutor of Fernando IV } \\
\text { and Alfonso XI, buried in Las Huelgas de } \\
\text { Valladolid. }\end{array}$ & $\begin{array}{l}\text { "Otro día de } \\
\text { ssant pablo" }\end{array}$ & 7 psalms \\
\hline $\begin{array}{l}\text { 30. Infante don } \\
\text { Fernando, ffijo } \\
\text { heredero de don } \\
\text { Alfonso Rrey de } \\
\text { Castiella et de León }\end{array}$ & $\begin{array}{l}* \text { Infante Fernando de la Cerda }(\dagger 1275,25 \\
\text { July), first born son of Alfonso X and heir to } \\
\text { the throne of Castile until his death, which } \\
\text { caused a succession crisis. }\end{array}$ & $\begin{array}{l}28 \text { August } \\
\text { (“4 días por } \\
\text { andar”) }\end{array}$ & 7 psalms \\
\hline $\begin{array}{l}\text { 31. Infante don } \\
\text { Enrique fijo de don } \\
\text { Ffernando Rrey de } \\
\text { Castiella et de León }\end{array}$ & $\begin{array}{l}\text { Infante Enrique ( } † 1303,11 \text { August), son of } \\
\text { Fernando III. }\end{array}$ & 11 August & 7 psalms \\
\hline $\begin{array}{l}\text { 32. infante donna } \\
\text { blanca ffija del } \\
\text { infante don pedro }\end{array}$ & $\begin{array}{l}\text { * Infanta Blanca († 1375), daughter of } \\
\text { Infante Pedro, señora of Las Huelgas. }\end{array}$ & 2 September & 7 psalms \\
\hline
\end{tabular}

Las Huelgas of Burgos, there is one that was assumed to be that of the Infante Fadrique, given that it was decorated with arms similar to those used by the infante at a certain stage of his life. The sepulchre contains the remains of a man dressed in clothing the quality of which rivals that of the kings interred there, although Gómez-Moreno, 1946, does not believe that the sepulchre or the remains deposited therein are those of the Infante Fadrique of Castile. 


\begin{tabular}{|l|l|l|l|}
\hline $\begin{array}{l}\text { 33. Infante donna } \\
\text { Constança ffija del } \\
\text { rrey de León }\end{array}$ & $\begin{array}{l}\text { * Infanta Constanza, daughter of Alfonso IX } \\
\text { de León, }(\dagger 1242,7 \text { September) }\end{array}$ & 7 September & 7 psalms \\
\hline 34. Rrey don $\mathrm{Jn}^{\circ}$ & $\begin{array}{l}\text { King Juan I of Castile, crowned in Las } \\
\text { Huelgas in 1379 }(\dagger 1390,9 \text { October). }\end{array}$ & October & 1 full psalter \\
\hline $\begin{array}{l}\text { 35. Infante donna } \\
\text { Blanca }\end{array}$ & $\begin{array}{l}\text { * Infanta Blanca of Portugal }(\dagger 1321,15-25 \\
\text { April). [duplication of reference 2 above in } \\
\text { this table] }\end{array}$ & $\begin{array}{l}\text { Quasimodo } \\
\text { Sunday } \\
\text { [the Sunday } \\
\text { after Easter } \\
\text { Sunday] }\end{array}$ & 1 full psalter \\
\hline
\end{tabular}

${ }^{12}$ The death of Juan I was kept secret for several days by Cardinal Pedro Tenorio, who claimed that he was injured until everything relating to the regency of Enrique III, underage at the time, had been arranged. This could explain the lack of a specific date for his anniversary celebration in $H C$. His body was transferred to the city of Toledo, where he was laid to rest in the Chapel of the New Kings of the Toledo Cathedral, where he remains today. 
Appendix I.

The Las Huelgas Customary. Selected chapters

\section{f. 53v Chapter 79. Capítulo LXXIX. Dela ffiesta de Ssant Andrés, quando viniere en la primera dominica de Abyento, cómmo an de ffazer.}

La primera dominica de Abiento, sy fuere Ssant Andrés, ffagan le el lunes, e las ochauas el domingo, mas el sábado digan la misa dela vigilia[.] Sy [Ssant Andrés] fuere lunes, el domingo la misa matynal sserá dela vigilia, e sy ouiere defunto, digan tres missas. Esta dominica toman agua bendita las dela enfermería e non fablan en cabillo. Otrosy, el día de Rramos toman agua bendita las dela enfrmerya, e el día dela Trenidat e todas las ffiestas que an quatro lánparas dela orden e ffueren en domingo. Mas las ffiestas que las an de graçia quatro lánparas, non toman agua bendita. Todo el Abiento digan ala conpleta 'Quem terra pontus' sy non las fiestas. Sy las biesperas del ssábado fueren dela dominica, digan 'Quem terra pontus'. Enesta dominica comiençe el Libro de Ysayas e cuente la cantora quántos días sson de lauor ffasta las homelías para que digan en coro e todo lo lean ${ }^{\mathrm{I}}$ ala messa. Sy en estas dominicas ouiere ffiestas que ouiere vna misa, la misa matinal sserá ssuya e comemoración a laudes a amas las biesperas. Mas sy Ssanta María Conçeçió ffuere en ssábbado, las biesperas serán suyas e comemoración | 2nd col. dela dominica. E sy ffuere en domingo, ffagan le el lunes. Otrosí, cada día digan la collecta dela dominica ala misa, sy non los días dela tenpora. E ordene la cantora en manera que lean ala messa las omelías de Ssan Bernardo antes que comiençe las del Abiento. Sy podiere ser, digan tres veses la missa dela dominica enla semana: el martes e el jueves e el viernes. Otrosy, el aniuersario de donna Yssabel ffagan le enel día que viniere mas non en domingo. La dominica de 'Ecce aparebit' ffagan las quatro tenporas. E ssy Santo Thome ffuere en jueues, el martes antes digan 'Legimus secundum moysen' e los responsorios e las antifanas del martes después[.] Las homelías 'Esurientes in[plevit]' e 'Anoquinto', algunas veses non las disen por la fyesta de Ssanto Thome. Mas la antifana 'Nolite tymere' digan la a çinco días antes de Nabidat. E sy Ssanto Thome ffuere en ssábbado, la mysa matynal sserá del Abiento e la collecta dela ffiesta e 'Deus qui tribus pueris'. Este día quando missa de quatro tempora vjniere en ssábado que ssea fiesta, a amas las missas digan los Quirios do es el vytatorio por el Benedictus. Otrossy, sy Sancta María de 'O sapiençie' non vyniere en las quatro tenporas, digan la missa 'Rrorate çely' como los sábbados.

\footnotetext{
${ }^{I}$ e todo lo lean] ms reads: e todo lo al lean lo.
} 
Chapter 80. Capítulo LXXX. De cómmo en la vigilia de Nauidat de Nuestro Sennor non tienen de desyr oras de Santa María.

[En] la vigilia de Nabidat, acabados matynes, non digan de Santa María, más digan de fynados, e acabada prima non digan 'Salve rregyna' nin a matines, nin alas oras suelten al Rrey Bueno, [mas] digan misa asy commo día de domingo e non digan sy non vna collecta sy non ssy ouiere defunto. Sy este día ffuere en

f. 54r domingo, será el vytatorio 'Le- | -uate capita uestra', e las ocho leçiones e los rresponsos sserán dela estoria, e la homelía [será] 'Cum esse[t] desponsata' con sus $\mathrm{r}<$ espons $>$ os, e el duodeçimo, 'Nascetur nobis'. Acabado el Euangelio, [digan] la collecta 'Deus qui nos in [blank] rredençionis', e a todas horas digan Alleluya e los uersetes dela vigilia. E a sexta e a nona, los capítolos dela dominica pasada e las collectas, e a laudes e ffagan comemoraçión dela dominica 'Aue Maria', e la misa matinal sserá dela dominica ssola con su collecta e non digan la collecta dela vigilia. La missa de terçia sserá dela vigilia con ssu prefaçio. Sy esta uigilia uiniere en domingo e ouiere defunto, digan tres misas, la segunda de requiem, e a todas tres digan collecta por él. Otrosy, sy este día non fuere domingo, acabada prima, vayan las de coro e las dela enfermería todas en vno en su orden a cabillo. Deste día fasta otro día delos Tres Reys, non digan oras de Ssanta María. El día de Nabidat, acabado el Euangelio delos matines digan la missa de 'Dominus dixit', e acabada esta missa tangan a laudes la canpana del coro. Acabados laudes digan la missa de 'Lux fulgebit', e acabada la collecta dela missa digan collecta de Ssanta Anastasia e 'A domo tua' atodas' las tres missas. Sy este día ouiere defunto, enterren le, mas non le digan misa el conuento; quien quisiere, digan la rresada, más digan collecta por él a todas tres missas. Acabada esta missa, tangan a signo de prima. Quien este día non pudiere comulgar, comulgue otro día ala misa de terçia. Este día lean ala messa las homelías, e desque fueren acabadas, comiençen enla quarta leçión e acaben las quando pudieren.

\section{Chapter 8I. Capítulos LXXXI. Del día de Sant Esteuan e de las ochauas de de Nauidat commo an de dezyr las misas e las Epístolas e los Euangelios.}

2nd col. El día de SsantEsteuan, todas las ochauas e la Nabidat, la ${ }^{6} \mid$ misa matinal será 'Puer natus' e la collecta dela fiesta e la Epístola 'Aparuit gratia' e el Euangelio 'Exit heditum'. El día de Ssant Juan, ' la misa matinal será 'Puer natus' e la Epístola 'Aparuit begninitas', el Euangelio 'Pastores loquebantur' e assy lo digan. Estos

2 Santa María] ms reads: Santa María nin de los finados. The rubricator obviously did not understand the meaning of the first sentence of the chapter.

${ }^{3}$ la] 'a' added by a third hand.

${ }^{4}$ capítolos] different hand on top of erasure.

5 atodas] ms reads: e atodas.

${ }^{6}$ la] ms reads: e la.

7 Ssant] ms reads: ssant ssant. 
quatro días que non labran, asy el día de SantEsteuan[, si] non sse pudiere desir por alguna cosa que aviere, digan lo el día de Ssant Juan. E assí lo ffagan estos quatro días. Otro día de Santo Thome, digan maytines 'Nasçiturus' e los $r<$ espons>os 'In principio'. Non ssalga ninguna de matynes nin la que leyere ala mesa. Este día será la missa 'Puer natus' asy como el día de domingo. La Epístola 'Aparuit gratia', el Euanguelio 'Exit heditum', e sy fuere domingo, digan 'Cupientes' e la homelía e la missa matinal será 'Dum medium sylençium’ e [la] collecta dela Nabidat e delos ssantos. Enestas ochauas, si oujere defunto, digan tres missas; e sy alguna destas fiestas fuere en domingo, la missa matinal será 'Dum medium silençium', e a laudes primero ffagan comemoraçión dela dominica [e] después dela Nabidat e delos santos[.] Sy se pudiere dezir dominica infra entre Nabidat e Anno Nueuo, digan a biesperas la antifana 'Illuxit nobis'. Sy Nabidat ffuere en domingo, el viernes adelante lean ala messa 'Cupientes' e las biesperas dirán la antifana 'Inprinçipio'. E sy este día ouiere defunto, digan tres misas.

Chapter 82. Capítulo LXXXII. De la vigilia de Anno Nuevo, cómmo an de ordenar este día las misas e las otras cosas, e qual canpana an de tanner.

[Enla] Vigilia de Anno Nueuo, tangan la canpana dela claustra alas biesperas, e ssy fuere domingo, primero ffagan comemoraçión del santo[, e] después dela dominica, e después delos santos. E sy fuere domino, la missa matinal sserá 'Dum medium silençium'. Este día, sy oujere defunto, digan tres misas | e ffablan en cabillo[.] Alas biesperas ffagan el aniuersario de la ${ }^{8}$ Infante Ssanta e digan 'Praesta domine qaesumus' e 'Fidelium deus'. E alos maitines comiençan las Epístolas de Sant Pablo enel libro banco fasta 'Greçis abarbaris', e quantas dominicas passaren después de Nabidat dasta los Tres Reys, comiençen los $\mathrm{r}<$ espons $>$ os 'In principio' e lo[s] otros que siguen, que estos dizen entre ssemana por estoria. Mas sy dominica ouiere después de Anno Nuevo fasta los Tres Rreys, digan la antifana ${ }^{10}$ alas biesperas 'Inprinçipio', por que este anno es dominica infra fynque la que es después de Nabidat.

\section{Chapter 84. Capítulo LXXXIIII. De las antifanas que an de dezir a Benedictus} e a Magnificat quando cantan el estoria 'Domine ne in ira tua'.

De las antifanas que son a dezir quando cantan 'Domine ne in ira tua', que las digan a Magnificat e al Benedictus antes de la Setuagésima e antes del Abiento: 'Fratres confortamini' e 'Loquere domine' e las otras que son a dezir. E sy algunas bynieren demás, ssean dexadas, e ssy de menos, la postremera ssea tornada quantas vezes fuere menester. Después delos Tres Reys, la primera dominica cantan 'In

${ }^{8}$ la] different hand top of erasure.

9 quaesumus] ms reads: q $\mathrm{s}$.

Io la an $<$ tifa $>$ na] marginal addition.

${ }^{\text {II }}$ ne] interlinear addition by a third hand. 
exçelso trono' e otras dos dominicas cantan 'Omnis terra' e otras dos 'Adorate'. $\mathrm{E}$ algunas veses, por que ay poco espaçio antes de la Setuagésima, ponen estas quatro dominicas en quinze días. E sy el día quelas ouieren a poner fuere fiesta de dose leçiones, pongan la otro día avn que ssea fiesta de comemoraçión e que tenga misa. E la misa dela fiesta digan la los clérigos e la de la dominica diga la el conuento. E pueden se poner estas dos dominicas vn día en po de otro a vn que ssea ssábbado, e alas byesperas non digan la a<ntifana> por la Setuagésima e otro tiempo puede ser que aurá grande espaçio, e quando ouiere çinco ssemanas del día que cantan 'In exçelso trono' fasta la Setuagésima, las tres ssemanas postremeras dirán 'Adorate' e la postremera ssemana tornarán la postremera a<ntifana $>$ e collecta ala misa e la Epístola e el Euangelio postremeto. [...]

f. 55r Chapter 86. Capítulo LXXXVI. Del Miércoles de la Cenyza. Cómo e en qué manera han de ffazer todas las cosas que en este día vinyeren.

f. 55v El Miércoles, acabada prima, estén | en leçión e tanga la ssachristana la canpana dela claustra e descalçense enla claustra e las dela enfermería en cabillo, e vaya el conuento al coro e comiençe 'Exurge domine' conel vielso e 'Gloria'. E quando le començare, estén tornadas vnas a otras. E desque fuere acabado dos veses 'Exurge', $\operatorname{diga}^{\mathrm{I} 2}$ el domadario dela missa el vielso 'Ostende nobis'. Respondan 'Salutare' e ffagan presçes sobre las formas. Diga la cantora 'Quirieleyson' e 'Pater noster'. Digan 'Et ne ${ }^{13}$ nos inducas' e rrespondan 'Set libera nos' e comiençe la cantora 'Deus misereatur' e digan le a vielsos e 'Gloria patri'. Este ofiçio fagan las dela enfermería asy como las de coro con sus presçes. Después digan 'Et veniat super nos', 'Dominus uobiscum', 'Oremus', 'Concede no[bi]s domine', e leuantense e estén tornadas al altar ffasta el comienço dela missa. E acabada la bendiçión dela çeniza, comiençe la cantora 'Exaudi nos domine' e, encommençando el vielso, abran la puerta. E a esta 'Gloria' non se enclynen[. Después de] 'Exaudi nos' comiençen 'Justa vestibulum'. E quando ouieren tomada la çeniza comiençen 'In nuctemur' (i.e. Immutemur) $a<n$ tifana $>.{ }^{14}$ Estonçe tangan a misa. [...]

\section{Chapter 87. Capítulo LXXXVII. De cómmo an de leer en cabildo dos ssenten-} cias an la dominica de 'Ecce nunc tempus'.

A la dominica de 'Ecce nunc tempus' leerán en cabillo dos ssentencias: la primera 'Licet', después 'In quadragesime'; e, desque ouieren acabado de leer, diga la cantora [qué] libros a de partir, e quando los diere a cada vna, tomen los con amas las manos enclynando se e deles la abbadesa que rresen 'Miserere miserere deus' con 'Gloria' toda la Quaresma, mas primero ffagan las bysytadoras. E este día cubran los altares e las cruzes e sy la cruz fuere menester de tomar para comulgar

${ }^{12}$ diga] ms reads: digan.

${ }^{13}$ et ne] ms reads: ene

${ }^{14}$ 'In nuctemur' a<ntifana>] inserted by a third hand in a blank space. 
o para unçión o para defunto, lyeuen la descubierta ffasta que la tornen al altar e la cortina que ponen enla eglesia, tiren la | los ssábados a biesperas fasta otro día a cunpleta, e así lo fagan enlas fiestas e por defunto fasta que sea enterrado. Et el anno que vyniere visiesto non ffagan [blank] ese día que es, más fagan le otro día e la leyenda que leen en vn día lean lo el otro; más non lean la luna el vn día que el otro, que si dixeren el vn día luna prima digan el otro segunda. E quando asy vyniere el mes de enero e de febrero e de março, enestos tres meses digan luna t'sesima. E quando Ssant Mathe viniere en ssábbado el anno que es visiesto, ese día le fagan [blank] [.] En la quaresma caten el breue el día de fiesta entre nona e biesperas, [más] los domingos después de nona caten el breue.

Chapter 88. Capítulo LXXXVIII. De la fiesta de Sant Benito o de Sancta María[, si] vyniere en la dominica que dizen 'Isti sunt dies', que son quinze días ante de Pascua.

Los quinze días antes de Pasqua, ssy el sabbado de 'Isti sunt' ffuere Ssant Benito o Santa María, las biesperas sserán dela fiesta e commemoraçión dela dominica. Et quando asy viniere, ese anno non dirán el responso 'Multiplicati' a biesperas e a conpleta, dirán 'Christe qui lux es', mas si Ssant Gregorio e Ssant Anbrosio ffuere eneste ssábbado, las biesperas serán dela dominica e comemoraçión dela fiesta e la cunpleta 'Cruz fidelis'. E ese domingo non dirán 'Gloria' ala missa fasta el día de Pasqua nin a biesperas, mas tornen le. Mas sy enestos días ouiere fiesta, a la su misa digan 'Gloria'. E este día comiençen el Libro de Geremías en coro e ala messa, e ssy la vigilia de Ramos fuere Ssant Benito o Santa María, las biesperas serán de Rramos e comemoraçión dela fiesta e ala cunpleta dirán 'Crus fidelis'. E deste día fasta el miércoles delas ochauas, alas biesperas non ffagan fiesta de dose leçiones, más sy fiesta de comemoraçión ouiere, fasta el jueues dela çena fagan la. E sy Sant Benito o Santa María fuere | esta ssemana [blank] de Pasqua, la una 2nd col. ffagan el jueues, la otra el ssábbado, e el día de Rramos ardan quatro lánparas e dos çirios a biesperas e non ffablan en cabillo e dizen oras de Santa María, e ala Passión [digan] 'Et cum spirito tuo' e 'Gloria tibi domine'. Mas el martes e el miércoles [digan] 'Dominus uobiscum' e non 'Gloria tibi domine'. Este día leen ala mesa todas las dose leçiones. El Jueues dela Çena a los maitines non digan de Santa María nin de ffinados, mas acabados los matynes, tangan a laudes ${ }^{15}$ e ponga la sanchristana vna candela antel altar, e quando començare la antifana de Benedictus, amate la e lieue otra açendida e ascondida, e quando dixeren la collecta, ssaquen la candela. Después tanga a prima, e desque fuere acabada, digan la missa de Santa María, e quando fuere acabada [the Mass of St Mary], tangan a misa [another mass] e digan la ssolepne e non sy no vna collecta. E desque ouieren el Cuerpo de Dios ençerrado, acaben la missa. E este día toman pas las de coro e las

${ }^{15}$ laudes] ms reads: lauades. 
dela enfermería en vno e comulgan. E la que diere el libro ala abbadesa enclyne se, e la que tomare pas con ella faga presçes, e quantos días tomaren pas con ella. $\mathrm{E}$ desque ouieren tomado pas, dé el libro alas freiras dela enfermería [e] después alas de coro. Este día e el miércoles en cabillo [disen] los siete psalmos por las almas e visten tres beses escapulario. E desque ouiere lauado los pobres dela cellerisa a cada vna sende dineros e ffynquen los inojos e den los alos pobres e besen les las manos. E quando ouieren comido, tanga la sanchristana a signo de biesperas la tabla, e después a biesperas, e digan las en mediana bos asy como suelen. Después de f. 56v comer ayuden a leuar el agua | las que an de servir, e quando viniere el abba <desa $>$ comiençen 'Dominus ihesus' e non se leuanten, e quantas pasaren ante la priora enclinense. E laue el abbad<desa> quatro monjas e quatro moças e quatro freyras; e quando fueren lauadas, laue el abbad<desa $>$ alas que ayudaren; después ellas ala abba $<$ desa $>$ e asy las otras, e quando vinieren a collaçión las más priora[s] del coro dela priora, lyeuen la candela ante la abba $<$ desa $>$ e quando ella vyniere todas se leuanten e la priora déle su logar e lean el euangelio [e] deste mandato non demanden lyçençia para beuer.

\section{Chapter 89. Capítulo LXXXIX. De cómo an de dezir las oras e las ${ }^{16}$ otras cosas en Vyernes Santo de la Cruz.}

El Uyernes dela Cryz alos matines comiença la cantora el ypno a todas las horas sy non a sexta e a nona, mas el jueues nin el ssábbado non lo comiençe. Este día entran las freyras enlas oras, e acabadas laudes vayan al dormitor e descalçen se e después tangan a prima e, des que fuere dicha, vayan [a] rezar el salterio cada vna en su orden. Quando fuere acabado, oyan el sermón. Después tangan a terçia e vayan a cabillo. Después de nona tangan a missa e digan la commo está ordenado enlos libros. A la Pasión non digan 'Gloria tibi'. E quando fuere acabada, digan las collectas, la primera en pie e las otras asentadas, e asy las otras. E después digan 'Agyos oteos', ${ }^{17}$ e quien los diere, fynque los inojos a 'Otheos', e el conuento a 'Ssantos deus'. E quando adoraren la cruz estén tornadas al altar e asienten se quien lo ouiere menester. Otras cruses aya para las flacas e para las que vynieren a oyr missa, e los que touieren la cruz comiençen 'Super omnia ligna' [e] el conuento después diga en media bos. Después diga el preste 'Oremus preceptis', mas non

2nd col. diga 'Pax domini' nin 'Agnus dei'. Quando fuere | todo acabado, vayan a cabillo [a] lauar se los pies las que quisieren. [...] digan la ledanía e los Quirios e la 'Gloria in excelsis deo', e quando dixeren 'Et in terra pax' tangan las campanas ffasta que digan 'Domine deus rrexcelestis'. E ese día non digan otra misa. [...]

${ }^{16}$ e las] ms reads: e que las. 
Chapter 94. Capítulo XCIIII. De la vigilia de Çinquagesma e de cómo se han f. 57v de regir en este día.

La vigilia de Çinquagesma, si fuere ffiesta de comemoraçión, fagan la comemoraçión alas biesperas e a laudes e collecta alla misa. Este día, acabado cabillo tustan la tabla e tannen al signo de terçia e van [a] oyr misa, e $\mathrm{e}^{18}$ digan los clérigos la missa de Ssanta María e esté el conuento enel coro fasta que sea acabada e después digan sexta e vayan al dormitor e tangan la canpana del coro e la del dormitor e tusten la tabla e tangan a signo de nona, e tangan a misa los clérigos, e vaya ${ }^{\mathrm{r} 9}$ el conuento al coro e comiençe la, mas pora la prefeçia primera, e digan las segund está ordenado enlos libros. E des que fueren acabadas digan la ledanía, mas non digan 'Ut gente' a ninguna ledanía, e luego digan los Quirios e la Gloria [e des]que dixeren 'Et in terra pax', tangan las canpanas fasta que sea acabado 'Domine deus res'. Después digan 'Dominus uobiscum' e la collecta 'Pra<esta $>$ [domine] q<uaesumu $>$ s' e 'P...' [blank]. E acabada la misa tangan a nona. El lunes otro día de Çinquagesma non salga ninguna de maitines nin la que lee a la mesa, e sy alguna estouiere fuera de coro que aya de tornar a coro ese día, tornen a matines día de Çinquagesma. [...]

Chapter 102. Capítulo CII. Quando la fiesta de Santa María Asunción o Santa f. 60v María Natiuitas vynieren en jueues.

Quando la ffiesta de Ssanta María Asunçión o Ssanta María Natyuitas viniere en jueues, el ssábbado adelante dirán alas biesperas 'Ascendente christus'[.] El domingo otra ves 'Asçendente christus' por que sson otro día[. En] las ochauas de Ssanta María Purificaçió, cada día disen 'Salue rregina', e [en] las ochauas delos Tres Rreys, digan cada día a Benedictus ${ }^{20}$ e a Magnificat 'Ab oriente'; e así la digan infra ssy non fuere las ochauas por que an todas las oras antifanas nueuas. E quando la vigilia de Ssant Mathe viniere enlas quatro temporas, la missa será del ayuno, e la ssegunda collecta suya e la missa desta vigilia digan la los clérigos. E quando missa en conuento es çelebrada e después alguna missa acaesçiere de desir, la cantora comiençe los Quirios de amas missas, mas el día de Nabidat, a la primera missa e ala de terça comiençen los do es el vytatorio. E dessa | guisa fagan 2nd col. enla Quaresma la Pasqua. Enlas fiestas que labramos, amas las misas; mas quando ouiere defunto, sienpre los comiençen la cantora.

Chapter 104. Capítulo CIIII. De los santos que tienen doze leçiones e que non f. 64v les dan sy non vna missa.

Sant Siluestre

Ochauas dela Epiphanía

${ }^{17}$ Agyos oteos] i.e.: Agios o Theos.

${ }^{18}$ e] $m s$ reads: e des que fuere acabado tangan a terçia e.

19 e vaya] inserted by a third hand in a blank space.

${ }^{20}$ Benedictus] ms reads: Benedictus magi. 
Ssant Antonio

Sant Fabián e Ssant Sabastián

Santa Ygnés

Sant Jullián

Santa Gadea

Sant Pedro de Quadra

Sant Pedro Mártir

Sant Pedro el obispo

Sant Juan e Sant Pablo

Las ochauas de Ssant Pedro delos Arcos

Santa Maryna

Sant Steuan el que cae en agosto

Santo Domingo

Ochauas de Santa M.

Sant Maurís

Sant Lambertj

Sant Ffrançiscv

Santa Sezilha

Sant Clemeynt

Santa Justa

2nd col. Chapter I05. Capítulo CV. Quales santos an doze leçiones e dos missas.

El día de Nabidat

El día de Anno Nueuo

El día delos Tres Rreys

El día de Pascua

El lunes e el martes e miércoles sigientes

El día dela asçensión

El día de çinquagesma

Los tres días sigientes

El día delos ynosçentes

El día de Santo Thome

El día de Sant Vyceynt

En todas las fiestas de Ssanta María

El día de Sant Giyllen el obispo

En la conuersión de Sant pablo

El día de Sant Mathe el apostol

En la fiesta de Sant Benito

En la fiesta de Sant Marchos euangelista

El día de Sant Rubert

El día de Sant Felipe e Ssantyago

El día de Sant Bernabé

El día de Santa Crus de mayo 
El día de Santa Crus de setienbre

En la Natiuitas

En la muerte de Sant Juan Bautista

El día de Sant Pedro e de Sant Pablo

El día de Santa Justa e Santa Rrufyna

El día de Santa Magdalena

El día de Santiago el apostol

El día de Sant Pedro ad Vincula

El día de Sant Llorençe

El día de Sant Bernardo

El día de Sant Bartolome apostol

El día de Sant Migel

El día de las Onse Mill Uirgines

El día de Sant Lucas euangelista

El día de Sant Symón e Jude

El día de Todos Santos

El día de Sant M.

El día de Santy Emundi

El día de Sant Andrés

El día de Sant Nicolas

El día de Santa Cataljna

El día de Santo Thome apostol

[E]l día de Ssant Anbrosio

Chapter 106. Capítulo CVI. Sy la fiesta de Sant Pedro vynyere enel jueues de las ochauas del Cuerpo de Dios.

sy el jueues delas ochauas del Cuerpo de Dios fuere Ssant Pedro, el miércoles antes

fagan las ochauas e ssaliendo de cabillo digan la missa dela vigilia. E acabada la misa tusten la tabla e, sy non, prediquen, e después tangan a terçia e digan la misa del ochauario; e alas biesperas, las antifanas delos psalmos de Ssant Pedro. E enla fiesta de 'Iuste Rrosyne', [a] amos los ofiçios digan 'Oferentur'; e a Sancta María Magdalena, amos los ofiçios, 'Gaudeamos'. [A] la fiesta delas Onse Mill Uirgenes, el primer ofiçio [será] 'Oferetur', e el de terçia, 'Gaudeamus'. E a Ssanta Cathelina, el primer officçio [será] 'Dilixisti', e el de terçia, 'Gaudeamus'[.] Del día de Çinquagesma fasta el miércoles delas biesperas non ${ }^{21}$ fagan commemoraçión nin digan la collecta ala misa de prima, mas ala misa delas ledanías e delas quatro temporas dela Trinidat non disen 'Gloria in exçelsis' nin 'Ite misa est', mas disen el prefaçio. E el viernes después delas ochauas de Açensión, digan la misa 'Nos autem gloriari'; sy non fuere santo que aya ofiçio gradal, e enel segundo logar digan la collecta dela Ascensión e alos quatro anniuersarios den ençenso e non digan

${ }^{21}$ non] ms reads: et non. 
rresponso al Cuerpo de Dios nin 'Miserere' nin 'Dominus'. Et si la dominica infra de Santa María delas Candelas fuere Santa Ágada, la missa de prima será delas ochauas con la menor Alleluya. Mas, sy dos misas sson a dezir aquel día fferial, amas las misas digan los quirios dela parte do es el uytatorio; mas a missa de cuerpo presente, la que ofiçiare la missa comiençe los Quirios. E estas son las collectas: [a] la misa en los días feriales, primero la collecta propia cuyo es el ofiçio, e 'Primo 2nd col. demus' e 'Oremus' | después la collecta 'Conçede nos famulos tuos' e 'Concede quaesumus' e 'Hesie tue' e 'Deus qui iustificas' e 'A domo tua' e 'Omnipotens [sempiterne] deus qui uiuorum dominaris', mas si alguna commemoraçión ay, digan la collecta antes que 'Consede nos famulos'.

\section{Chapter 107. Capítulo CVII. De la collecta 'Concede nos ffamulos', en quales días es a dexir.}

Conuien asaber que la collecta 'Concede nos ffamulos' es a dexir [a] la missa todos los días que non disen oras de Santa María enel coro. Otrosí, todas las vigilias de Ssanta María e vigilia de Çinquagesma e vigilia de Todos Ssantos e vigilia de Nabidat e dende fasta otro día delos Tres Reys, e el Jueues dela Çena e la vigilia de Pascua e dende fasta las ochauas de Pasqua sson a dezir estas collectas: 'Conçede q<uaesumu>s' [e] 'Omnipotens sempiterne deus qui uiuorum'. Mas ${ }^{22}$ todo el anno, todas las fiestas de dose leçiones son a dexar las dos collectas 'Conçede q<uaesumu $>\mathrm{s}$ ' [e] 'Omnipotens sempiterne deus qui uiuorum', mas ${ }^{23}$ todos los días dizen 'Gloria in excelsis'. E otrosí, deuedes saber que los ssábados dela quatro tenpora non se deue desir 'Dominus uobiscum' fasta acabado Benedictus, e des que ffuere acabado, digan 'Dominus uobiscum' e 'Deus qui tribus in veneris' e después digan 'Oremus'. E ssi fuere fiesta, digan la colecta del santo 'Concede nos ffamulos tuos', e si fuere en el treyntanario, digan 'it ${ }^{24}$ largitor' e non más. E otrosí, la collecta 'Eclesie tue' es a dexar enla vigilia de Nabidat, e el Jueves de la Çena, e enla vigilia de Pasqua e de Çinquagesma e enlos ssábados delas quatro tenporas [blank] de Ssanta Crus. E en los quatro ofiçios principales delos defuntos [blank]

f. 65v delos obispos e delos abbades, | la collecta es 'Praesta domine quaesumus', e non más. Enel mes de setienbre es el aniuersario prinçipal, e es la collecta 'Deus venie largitur' e, la segunda, 'Praesta domine quaesumus', e non más. E enel mes de otubre es el aniversario del Rey Bueno; la primera collecta [es] 'Praesta domine quaesumus', la segunda 'Deus venie largitur', e non más. E enel mes de nouienbre [es] el aniuersario de 'Fidelium deus' ${ }^{25}$ [e] la primera collecta es ${ }^{26}$ 'Fidelium

${ }^{22}$ Mas] E mas.

${ }^{23}$ mas] e mas.

${ }^{24}$ veniet] i.e. veniae.

${ }^{25}$ Fidelium deus] Error: the name of the deceased has been replaced by the incipit of the collect.

${ }^{26}$ es] ms reads: de. 
deus', e non más. Enese mesmo mes [es el] aniuersario ${ }^{27}$ dela Rreyna Buena, e la primera collecta [es] 'Praesta domine quaesumus' e la segunda 'In clina', e non más. A veynte días dese mesmo mes de nouienbre, aniuersario ${ }^{28}$ de nuestros padres e de nuestras madres, e la primera collecta 'Deus cui proprium', e non más. $\mathrm{E}$ delas fiestas en que viniere defunto, commo las digan. ${ }^{29} \mathrm{La}$ dominica primera de Abiento, si viniere defunto, digan tres misas; la segunda de rrequiem[, mas] sy comemoración ouiere, avn que ssean ochauas, antes fagan del Abiento. La dominica de 'Ecce apparebit' fagan [la] las quatro tenporas[, e] sy Santo Thome fuere en jueues, el martes antes digan 'Legimus secundum moysen'. E en todo Abiento digan a conpleta el ipno 'Quem terra pontus sidera' e enlas fiestas 'Christe qui lux es'[. En la] vigilia de Navidat, ssi fuere domingo e ouiere defunto, digan tres missas, la segunda de requiem. E el día de Sant Esteuan, la missa matinal será 'Puer natus', e la Epístola 'Aparuit gratia', e el Euangelio 'Exit editum'. E si este día non sse pudiere desir, digan lo el día de Sant Iohan, e la dominica infra de nabidat será 'Dum medium silençium', e la de terçia 'Puer natus' e | 'Aparuit gratia' 2nd col. e 'Exit editum' e alas biesperas digan el antifana [blank]. E ssi ennesta dominica ouiere defunto, digan tres missas e en todas las vigilias delos santos e del otauo día delas ochauas digan dos misas, si ouiere defunto. E la vigilia dela cruçifisión alas biesperas, tangan la canpana dela claustra. E el día de [ ] ${ }^{30}$ amas las missas sserá[n] 'Puer natus' sy non fuere domingo; essi fuere domingo, digan el an<tifo $>$ na 'In prinçipio' [e] alas biesperas fagan el aniuersario dela Infanta Santa: la primera collecta 'Praesta domine quaesumus', e la segunda 'Fidelium deus'. [En la] vigilia delos Tres Reys, sserá la misa 'Puer natus' e la[s] collecta[s] 'Corda nostra' e 'Deus qui ssalutis', e la Epístola 'Aparuit benignitas ${ }^{3 \mathrm{II}}$ e el Evangelio 'Defunto herode'. E el día de Sant Guillén alas biesperas fagan el aniuersario dela orden. E si otro día ouiere defunto, digan dos missas; e desta guissa se faga en todos los otros aniuersarios principales.

\section{Chapter 108. Capítulo CVIII. De la vigilia de Çynquagesma.}

[En] La vigilia de Çinquagesma, des que ssaliere[n] de cabillo, tusten la tabla e fagan signo de tercia e pedriquen; e acabada la pedricación, tangan tercia, oyan misa de Santa María, después tangan medio día, e acabado medio día vayan a ssesta, e la más [blank] primero. E después tusten la tabla e tangan signo de nona e vistan se las cogullas e tangan dela missa e oficien la. Así commo [enla] vigilia de Pasqua e enla quaresma enlos días feriales, canten el breue antes de terçia, e los días de

${ }^{27}$ aniuersario] ms reads: a eniuersario.

${ }^{28}$ aniuersario] ms reads: a aniuersario.

29 This sentence looks like the heading of another chapter, although it is neither rubricated nor highlighted.

${ }^{30}$ The name of the day is missing, and there is no blank space.

${ }^{31}$ benignitas] ms reads: begninitas. 
ffiesta acabada nona después de Pascua ffasta Santa Crus todo el verano le canten f. 66r al misto. Mas de Santa Crus | fasta la Çinquagesma, sienpre le cantan después de comer. E si acaesciere que tengan cuerpo en coro después de comer, acabados los ssiete ssalmos queden dos monjas conel cuerpo e vaya el conuento a cantar el breue e torne se luego al cuerpo. E al aniuersario del Rrey Bueno non doblen las campanas a biesperas nin ala missa. E el día de Anno Nueuo non disen 'Salue Regina' nin [blank] Rrey Bueno, e [non] fablan en cabillo e non disen 'Recordare'[. En] las ochauas dela Epiphania disen la misa del [blank] [e] non disen otra missa de requiem ninguna. E si el ssábbado antes del domingo de Quadraginta dies ffueren las ochauas de Santa María, todas las biesperas sserán de la comemoraçión de Ssanta María. E el martes antes del Miércoles dela Çenisa, digan missa del Rrey Bueno. E sy Ssanta María fuere el lunes después del día de Rramos, Sant Ambrosio será el jueues, ese día le fagan, e el sábado adelante, fagan de Ssanta María, e las biesperas del sábado sserán suyas, e comemorasión dela dominica. E si Ssanta María Conçeçió fuere en domingo, fagan la el lunes. E sy Sant Thome Apostol ffuere en ssábado, las biesperas sserán dela dominica. La vigilia de Nabidat disen oras de fynados [e] non sueltan al Rey Bueno. E la primera dominica del Abiento cantan en tres boses e non disen la oraçión del rey, nin sueltan al Rey Bueno, nin ffablan en cabillo, e entran todas al agua bendita e arden quatro lanparas.

\section{Chapter 109. Capítulo CIX. Del v<iel>so 'Any Recurso', en quales días se deue desyr.}

Deuedes saber que el día de Sant Jullián, non disen el 'Ani rrecurso', nin a Sant Rremissio, nin a Sant Rruberto, nin a Sant Pedro el Obispo, nin Translacio Sancti

2nd col. Benedicti, nin después de Pascua. Quando la Setuagésima | viniere dominica infra de Ssanta María, todo sea conplida miente dela Ssetuaginta, si non, la misa matinal, que sea de Santa María con tracto e con tres ministros. E quando tenemos cuerpo presente enel coro, antes que digan 'Deus cuy proprium' digan collecta por él. E si es día ferial, a biesperas e a matines fasen por él aniversario. Otrosí, ala v...ción ${ }^{32}$ deuen tanner la canpana del coro tres veses; e entre la vna e la otra, espaçio de vn 'Pater noster'.

\section{Chapter IIO. Capítulo CX. De la fiesta de Sant Johan, e de Sant yago, e de Sant Pedro, sy vynyeren en domingo.}

Si el día de Ssant Iohan e de Santiago o de Ssant Pedro ffueren en domingo, amas las missas serán suyas. Otrosí, deuedes saber [que] si en tiempo del verano tienen cuerpo enel coro, de que salieren de beueres non tusten la tabla nin tengan lauor nin leçión, mas vayan luego al cuerpo; e después de cena non tenga leçión fasta que comiençe a tanner collaçión; e por rescebir el cuerpo non se asienten en

32 unreadable. 
leçión sy non fuere tiempo en que lo an de tener. E [enla] vigilia de Santa María de setienbre, digan la missa 'Salue ssanta parens' e non tangan misto e digan la nona antes de comer, e alas biesperas fagan comemoración de Sant Adrián. todo el ochauario digan 'Natiuitas tua' ala Manificat.

\section{Chapter III. Capítulo CXI. De quando touieren cuerpo presente en coro, có-} mmo an de aser.

Deuedes ssaber que quando tenemos cuerpo en coro, después que es rresçebido fasta que ssea enterrado, a todas las oras e a la missa que ese día disen, desimos collecta, así después dela sepultura commo antes. Otrosí, enlas fiestas de dose leçiones o enlos domingos, si detouieren enlas ochauas de la Purificaçión o dela Asçensión de Santa María, cada día digan misa delas ochabas si non svbiniere ochtauario o fiesta de dose leçiones | que aya ssu missa. E ssi non acaesiere de desir misa de dominica que se non puede desir en su día, o si fuere de fiesta de dose leçiones que lo enbargare o si fuese pentecostes [blank] o si non ffuere costumbre de desir estonce missa de defuntos o ssy ouiere aniuersario de la orden, es a ssaber que sy Euençio ${ }^{33}$ Sancti Crucis vyniere en dominica entre las ochauas de asçensión, después de 'Benedicamus domino' alas laudes, ffagan primero comemoración alos $\mathrm{m}<$ arti $>$ res después dela dominica después de la Ascensión, e la missa de la dominica dexen la para el primero día que ouiere logar. E las ochtauas de la Asumpçión o dela Natiuidat o dela Purificaçión de Santa María, como está ordenado enlos libros, así lo digan. E si la fiesta de Ssant Bernardo vyniere enla dominica infra, todo ssea dela fiesta; mas la missa dela mannana será de Santa María e la missa dela dominica dexen la entre semana; mas el ssábado alas biesperas e a laudes e a las biesperas ffagan comemoración dela dominica después delas ochauas. Quando las ochauas de Sant Llorente vinieren en dominica infra, todo dela dominica infra alos laudes ffagan comemoraçión de Ssant Llorente después la collecta dela dominica e de Ssanta María e de Sant Mames; e la missa de tercia sserá de Santa María e las oras.

\section{Chapter II2. Capítulo CXII. Del ochauario de Sant Iohan Bbautista.}

Enel ochauario de Ssant Iohan Bbautista, el primero día después dela ffiesta digan missa de Sant Ihoan ssy non si ouiere presente o si ouieren | de desir missa de do- 2nd col. minica que non se pueda desir en su día. E ssi alguna destas dos cossas acaesçiere por que se non pueda desir missa de Ssant Iohan otro día dela ssu fiesta, digan la el quarto día dela su fiesta sinon si por auentura el quarto [día] acaesciere alguno delos dichos enbargos. E sy la missa de Sant Ihohan fuere dicha otro día dela ssu fiesta, [digan la] el ssegundo día en conuento. El quarto día dela su fiesta digan en conuento missa de defuntis si non fuere dicha en essa semana antes dela fiesta o si

${ }^{33}$ Euençio] i.e.: Inventio. 
non ffuere día de dominica. Al quarto día después dela fiesta, ssi missa de defuntis fuere dicha en esa semana antes dela ffiesta, o si non fuere día de dominica, ${ }^{34}$ digan en conuento missa de Sant Iohan a vn que sea dicha el ssegundo día ssy non si al quarto día fuere lunes, que si fuere lunes deuen desir missa de defuntys. Enpero es a entender [que] si antes de aquel día, el quarto día dela fiesta dicha ffuere la missa delas ochauas, vna ves primero se deue desir misa delas ochauas que delos fynados. Eso mismo que es dicho el segundo día e del quarto día delas ochauas de Ssant Juan deue ser guardado entre biesperas e ochauas de Ssant Pedro e de Sant Pablo. El quinto e séptimo día dela fiesta dellos digan missa dellos, si alguna rrasón delas ssobredichas non lo enbargare, commo dise delos otros días que son dela fiesta de Sant Iohan fasta el otauo día dela fiesta de Sant Pedro e de

f. 67r Sant Pablo, digan misa delos santos que son escriptos | en [el] libro[. Otrosí,] es a ssaber [que] destas ochauas [assy] que enla comemoraçión de Sant Pedro, dicho el 'Benedicamus' alas laudes, deuen faser comemoraçión luego de Ssant Juan [e] después de Sant Pedro. Otrosí, ala misa el día de Ssant Esteuan e de Ssant Juan e delos Ynoçentes ffagan comemoraçión cada día a laudes e a biesperas e a missa. E el octauo día digan la missa.

\section{Chapter II3. Capítulo CXIII. De cómmo an de desyr misa de Santa María en todos los sábbados que no fueren enbargados.}

La missa de Santa María. En todos los ssábbados digan misa de Santa Marya e dexen las collectas usadas con dos ministros. E si el ssábado ouiere missa de vn ministro, digan la los clérigos. Mas las vigilias e las ochavas de los Santos e el ssábbado dela Epifanía o dela asçensión e delos quatro aniuersarios dela orden e delos que yasen enel coro, e avn delos que yasen enla nave, sy non ouiere otro día para las faser, enestos ssábados ssobre dichos non digan missa de Ssanta María. Mas en todas las fiestas que vynieren en ssábbado, avnque sean de apostol, sserá la missa deIa mannana de Santa María. E si la ffiesta ouiere vigilia o sermón, o sy ouiere dos ofiçios commo es el día de Ssant Juan de gollaçio ${ }^{35}$ que es la misa de la mannana de Santa Sabjna e las Onze Mille Uirgines, enestos ${ }^{36}$ ssábados que son dichos que aya vigilia o sermón, non será la missa de Santa María.

\section{Chapter II4. Capítulo CXIIII. De cómo se a de dessyr las missas por todo el} anno.

Cómmo sson a desir las misas por todo el anno. Delas ochtavas de la Ephifania 2nd col. fasta la Quaresma: los lunes, misa dela orden; martes e jueves, missa de | la domi-

${ }^{34}$ dominica] ms reads: dominica - al quarto día después dela ffiesta, ssi missa de defuntis fuere dicha en essa semana antes dela ffiesta - el quarto día que es después dela fiesta. Homeoteleuton error.

${ }^{35}$ Ssant Juan de gollaçio] i.e.: San Juan Degollado.

${ }^{36}$ enestos] ms reads: E enestos. 
nica; miércoles, por los bien fechores; el Viernes, dela Crus; el sábado, de Santa María. E delas ochauas de Pasqua fasta la dominica antes dela Ascension: el lunes, misa dela orden; martes e jueves, dela dominica; miércoles, Resurrexi; viernes, de Ssanta Crus; el sábbado, de Santa María. Dela Trenidat ffasta el abiento: los lunes, missa dela orden; los martes, dela dominica; miércoles, por los ffamiliares; jueves, de Ssancti Spiritus; viernes, de Santa Crus; sábbado, de Ssanta María. Dela Trinidat ffasta el Abiento: los domingos, la missa dela mannana sserá dela Trenidat si non si ouiere ffiesta que aya misa. Enel Abiento: missa dela orden el lunes, e el martes dela dominica; miércoles, por los ffamiliares; jueves e viernes, dela dominica; el ssábbado, de Santa María. Enel Abiento non disen missa dela Crus. El viernes otro día de la Ascensión digan missa dela orden. El viernes después de las ochavas digan missa [blank] así commo la ssuelen desir los otros tiempos sy non ouiere missa de dominca o otra cossa.

\section{Chapter IIS. Capítulo CXV. De los Sábbados del Abiento e de Septuagesma e Çinquagesma e Quadragesma.}

Enlos ssábados del Abiento e dela Septuagesma e Çinquagesma e Quadragesma, si fiesta viniere las uiesperas, serán delas dominica e comemoración dela fiesta. Mas la Purificaçión de Ssanta María e la Anunçiaçión e Sant Benito e [la] fiesta en que non labremos, enel ssábado de Çinquagesma e delas ochauas ssean posadas desta rregla: las fiestas ayan llana mente sus biesperas e fagan comemoración dela | dominica en todos los otros ssábados; ${ }^{37}$ mas la fiesta de Ssant Math<e>, la ffiesta enel ssegundo día se deue ffaser, mas si Sant Mathe viniere en sábado, el primero día del visiesto le ffagan.

Chapter II6. Capítulo CVI. De commo non an de desyr en el día de Sant Iohan a laudes 'Any recurso'.

El día de Ssant Juan, a laudes non digan el $\mathrm{u}<\mathrm{iel}>$ so 'Any recurso' nin a [blank] disen enlas primeras biesperas. A Ssant Rremisio non le disen nin a Ssant Pedro Obispo, nin a Ssant Benito quando le ffasen después de Pasqua [blank] mas la rregla, el día que es la comiencen, a vn que non ffagan la fiesta.

\section{Chapter II7. Capítulo CXVII. En quales días an de desyr 'Gloria in excelsis' e} 'Ite missa est'.

En estos días digan 'Gloria in excelsis deo' e 'Ite missa est': enla vigilia de Pasqua e de Çinquagesma e los domingos; [a] más, las fiestas de dose leçiones, avnque labran, salvo el Abiento e la Septuagesma fasta la Pasqua. Disen la toda la semana de Nabidat e de Pascua e de Çinquagesma[. Mas] ala misa del ayuno non, nin la disen ala misa de la vigilia que non son en domingo.

${ }^{37}$ ssábados] ms reads: ssábados e las fiestas ayan llana mente sus biesperas. Homeoteleuton error. 
Chapter II8. Capítulo CXVIII. En quales días an de desyr 'Credo'.

En quales días disen 'Credo': el día de la Nabidat e el día de Circunçisión, dela Epiphania, e dela Pasqua, de Ascensión, e de Çinquagesma, e Santa María, todos los domingos, Invençio, Exultatio de Ssanta Crus; a más, las fiestas de Sant Juan $\mathrm{Bb}<$ autista $>$ e de todos los apostoles e euangelistas e de Todos Santos e Santa María Magdalena, e el día de san Benito e de San Batualdo, el día del Rey Bueno.

f. 68v Chapter I23. Capítulo CXXIII. De la fiesta del Cuerpo de Dios, sy vynuere enel día de Sant Iohan.

Si la fiesta del Cuerpo de Dios viniere en día de Ssant Ihohan Baptista o de Sant Pedro, complida mente se faga. E el día del Cuerpo de Dios a las biesperas ffagan comemoraçión de Sant Iohan. E el día ssiguiente fagan la ffiesta[.] Eneste ochauario cada día digan misa delas ochauas, ssy non si viniere ffiesta de doze leçiones. Mas, si la ffiesta ouiere dos missas, la primera ssea delos p<er>dones. E sy ouiere comemoraçión que aya ofiçio enel gradal, digan la los clérigos. E eneste ochauario non digan missa dela orden. Otrosí, sy alguna comulgare en casa dela abbadesa, por la puerta dela cama lyeuen el Cuerpo de Dios.

f. 69r Chapter I25. Capítulo CXXV. De cómmo sse an de partir los tiempos en cada vn anno.

Del departimiento delos tienpos. Otro día de Pascua tannen la canpana dela claustra a laudes. Non ssale ninguna de maytines. Mas el martes delas ochauas ffasta otro día de Ssanta Crus sienpre tannen la canpana del coro a laudes e a esta canpana entran ssienpre las freyras en coro. E el día de Santa Cruz entran las freyras al quarto responso. E tannen la canpana del choro e enlos días feriales entran alos sseys ssalmos. [...]

Chapter 126. Capítulo CXXVI. De cómmo an de vannar el cuerpo después que fuere ffinado, e de cómmo se an de regir.

Quando resçebimos el cuerpo, sy le an de vannar, acabado 'Sub venite sancti' e la collecta, lyeuen la al cabildo delas fynadas e vayan dos monjas de coro [a] vestir escapularios al dormitor e las cogullas encima. E quando entraren enel cabillo desnuyen las cogullas, e estén en escapularios e ayuden a vannar el cuerpo. E entanto que la vannan, el abadessa o la priora o las que estouieren rresen los psalmos; mas non la vanne la rrefytola nin la que ha de seruir al conuento. E quando la ouieren vannada, la abadessa vistale la cogulla e pongan le el velo prieto e çingan le la sobre cinta. E en tanto que este offiçio sse cunple, deue estar el conuento en carrera de Santiago, e el monje ${ }^{38}$ diga las collectas que ssuele desir, e quando las ouiere acabadas assienten se e rresen el psalterio a vielsos del vn coro e del otro ffasata que trayan el cuerpo. E desque le trayeren, acomienden le e lyeuen le ala eglesia.

${ }^{38}$ el monje] should read la monja, as in Chapter I3I. 
Chapter I27. Capítulo CXXVII. De los anyuerssarios de la orden e de los que f. 69v yasen en el coro.

Los aniuersarios dela orden e delos que yasen en el coro, ssy ffueren en domingo alas viesperas, los ffagan el lunes las missas e disen collecta por los que yasen en coro atodas oras. E quando ssueltan delas que yasen enla naue, ssi fuere en domingo non los ffagan ese día, sy non en lunes ssi non lo enbargare alguna cossa. E disen collecta por ellas quando alas oras ffasta la missa acabada. E atodos estos aniuerssarios traen ençienso[.] El domingo que parten los libros, leen en cabillo dos ssen<ten>çias: la primera 'Liçet', la segunda 'In quadragessyma'. E delas ochauas de Pascua ffasta la Asçensión, los domingos sserá la missa matinal de 'Rressurrexi', mas non digan el prefacio 'Te quidem' ssi enestos domingos viniere ffiesta de dose leçiones, la misa matinal sserá del domingo. E la ssegunda collecta 'Deus qui per', e después la del ssanto. En este tiempo non digan ala missa matinal ssy non vna All<eluy>a. E ssy la myssa matinal es del domingo digan la primera All<eluy>a. E si otra ves sse dixeire la missa, digan la ssegunda All<eluy>a. E ssi la Purificación de Santa María viniere en gomingo todas tomen agua bendita e el día de Ramos digan 'Gloria tibi domine' ala passión ${ }^{39}[\ldots]^{40}$ digan 'Dominus uobistus' el martes, e el miércoles 'Dominus vobistus' mas non 'Gloria tibi domine'. E ssy la que lee a cabillo o la que tiene collectas non las pudiere conplir, tome las la más priora o $[\ldots]^{41} \mathrm{E}$ del miércoles adelante, tome las la más juniora.

Chapter I28. Capítulo CXXVIII. De las cosas que somos tenudas a desir por 2nd col. los ffinados e en quales días.

Este es el deubdo que auemos a conplir: [a] sseys días andados del mes de otubre rresamos vn salterio por que es ese día el aniuersario del Rey Bueno, [e] las collectas 'Praesta domine' e 'Deus venie'. A trese días deste mes, aniuersario dela infante donna Blanca, e dan este día vn salterio. [ $]^{42}$ es el aniuersario del infante don Ffernando fijo del Rey Bueno, e dan çinquenta ssalmos. El día de Symon e Jude, aniuersario del arçobispo don San<cho $>$, e dan los ssiete ssalmos. A tres días andados de nouiembre, aniuersario de nuestra sennora la Reyna Buena, e dan vn ssalteryo. E otro día, por la reyna su fija, que ayuntó los rreynos, dan vn salterio. A seys días deste mes es el aniuersario dela rreyna dona Beatrys, dan vn ssalterio. $\mathrm{E}$ a quinse días andados deste mes es el aniuersario de don Ffelipe, e dan los ssiete salmos. A tres días por andar deste mes es el aniuersario dela reyna donna Vrraca e dela rreyna donna Blanca, e dan dos veses los ssiete ssalmos. A quatro días andados de disiembre es el aniuersario de donna Yssabel, e dan los ssiete

39 el día de Ramos digan 'Gloria tibi domine’ ala passión] ms reads: el día de Ramos non(erased) digan 'Gloria tibi domine' ala passión. See Chapter 79.

${ }^{40}$ Erased passage.

${ }^{4 I}$ Erased passage.

${ }^{42}$ Date missing. 
f. 70r salmos. A veyn- | A veynte días de disiembre, [dan] los ssiete ssalmos por donna María de Almenar. El primer día de [blank] es aniuesario por la Infante Ssanta [e] rresamos vn salterio. A veynte días de enero es [el] aniuersario de don Moryel e de ssu muger, dan dos pares de ssiete ssalmos. A trese días deste dicho mes [es el] aniuersario de don Alfonso ffijo del infante don Fernando, dan los ssiete ssalmos. A quinse días deste mes, aniuersario de don Manuel ffijo de don Fernando rrey de Castiella e de León. Eneste mes [es el] aniuersario del infante don Alfonso, fijo de don Alfonso, Rey de León.

\section{Chapter I29. Capítulo CXXIX. A quantos días de cada vn mes ffasen aniuersa- rio por los sennores ffinados.}

A honze días de março, aniuersario del infante don Alffonso, dan los siete ssalmos. A cinco días de abril, dan aniuersario del rey don Alfonso, que fynó en día de Viernes de la Crus, dan vn ssalterio. [A] quatro días por andar deste mes, aniuersario del rey don Sancho, dan vn ssalterio. A honze días de mayo, aniuersario del infante don Fradique, ffijo de don Fernando Rey de Castiella e de León, dan los ssiete ssalmos. A quatro días por andar deste mes, aniuersario del rey don Fernan-

2nd col. do el Ssanto, dan un ssalterio. A dos días por andar deste mes, aniuersario por el | rrey don Enrrique, ffijo del rrey don Alfonso, dan un ssalterio.

\section{Chapter 130. Capítulo CXXX. De los anyuersarios que fasen por ssenores e sennoras finados.}

A nueue días por andar al mes de jullio, aniuersario dela reyna de aragón, ffija del Rey bueno, nuestro sennor, dan los quinse salmos e los ssiete. A quatro días por andar deste mes, aniuersario del infante don Pedro, e dan cinquenta ssalmos. Otro día, el infante don Iohan, dan los ssiete ssalmos. A nueue días por andar del mes de jullio, aniuersario de donna Costança, ffija de don Alfonso, Rey de Castiella e de León, e dan çinquenta salmos. Otro día de ssant pablo, por la reyna donna María dan los ssiete ssalmos. A quatro días por andar de agosto, aniuersario del infante don Fernando, ffijo heredero de don Alfonso rrey de Castiella e de León, dan los ssiete ssalmos. A onse días andados deste mes, aniuersario del infante don Enrique, fijo de don Ffernando rrey de Castiella e de León, dan los ssiete ssalmos. A dos días de setiembre, aniuersario dela infante donna Blanca, ffija del infante don Pedro, dan los ssiete ssalmos. A nueue días deste mes, aniuersario dela Infante donna Constança, ffija del rrey de León, dan los ssiete ssalmos. Enel mes de otubre, aniuersario del rrey don Juan, ${ }^{43}$ dan vn ssalterio. El aniuersario dela infanta donna Blanca, fasen le el domingo de quasi modo e dan vn ssalteryo.

${ }^{43}$ Juan] ms reads: $\mathrm{Jn}^{\circ}$. 
Chapter I3I. Capitulo CXXXI. Delos siete psalmos de los anyuersarios de las f. 70v abbadessas.

Los ssiete ssalmos delos aniuersarios delas abbadessas e los delos lunes e del Rey bueno sson por todos quatrocientos e ssesenta e quatro. E si la monja quisiere quitar todo esto en salterios, nontan le quarenta e seys que rrese en cada anno.

\section{Chapter 133. Capítulo CXXXIII. De lo que a de ffaser el conuento quando alguna se quisyere ffinar. ${ }^{44}$}

Esto es a ssaber: que quando ffyna alguna, deue la enfermera faser entrar una crus de çenisa e poner vn ffierro dessuso e ssobre el poer la ffynada. E después vaya se la enfermera por la claustra nueua. Essi el conuento estouiere en cabillo, en lauor, o en leçión, tuste ý la tabla ala puerta, non sse[r]moniendo a ninguna parte. E ssy estouiere de parte dela leçión o enel coro, vayan la tustando ffasta la puerta dela naue. E ssi estouiere enel refitor, o enel dormitor, vayan la tustando ala puerta del cabillo ffasta la puerta del dormitor. E ssy acaesçiere quando alos matines, vayan | allá las que mandare la cantora conlas otras que non estan en coro e dos a dos, 2nd col.

o tres a tres, vayan disiendo 'Credo in deum' en manera que se oyan fasta que llequen ala defunta. E ssi oyeren tustar la tabla enel coro quando dixieren las oras de defuntis, matines, o viesperas, mande la cantora que ffinquen pocas enel coro e vaya todo el conuento ala defunta enla manera que es dicho. E ssy acaessiere quando ouiere comido el conuento, assi en quaresma commo en otro tiempo, leuanten se luego que oyan la tabla e non digan 'Tu autem domine' nin tangan la canpana, mas vayan luego ala defunta en la manera que es dicho. E quando fuere leuada al coro, tornense a comer, e la que lee ala messa comiençe ally do lo dexo. E ssy quando comiere el conuento, ssegundo oyeren tustar la tabla, non se leuante por eso, mas comman e después que ouiere comido vayan ala defunta. E ssy quando ffisieren cabillo oyeren tustar la tabla, dexen el cabillo luego e vayan dela defunta. E después que fuere leuada al coro, vayan al cabillo e comiençen do lo dexaron. E ese mismo día suelte la cantora enel cabillo. E sy acaesçiere quando dixeren las oras canónicas, fagan la cantora abreuiar las oras, saluo maitines e laudes e bviesperas, e mande que vayan algunas alla las que entendiere que se puede | escusar en coro. E después que fuere leuada la defunta al coro, aquellas que salieron del coro vayan al cabillo e comiençen las las oras de cabo; mas si acaesçiere quando a matines o a laudes o a viesperas, non las comiençe de cabo, saluo de aquel logar do las dexaron. E ssy en tiempo del ynvierno disiendo laudes oyeren tustar la tabla, non dexen la prima, mas acabada la prima, vayan luego a la defunta. E ssi quando tanxieren a collaçión oyeren tustar la tabla, dexen la campana e vayan todas a la defunta. Mas si tustaren la tabla quando leyeren a collaçión, diga la que lee 'Tu

${ }^{44}$ This rubric is misleading. The chapter has nothing to do with the 'wish to die', but rather gives instructions about how to proceed when a nun dies at the monastery. The word quisiere should probably read 'sintiere' (i.e. 'to feel' instead of 'to want'). 
autem' e la abbadessa 'Adjutorium n<ost $>$ rum' e vayan luego ala defunta. E las que essa noche perdieren la collaçión, non ffagan satiffaçión, mas otro día tomen venia en cabillo. Mas ssy en sábbado, ffasiendo el mandato, oyeren tustar la tabla, nol dexen, mas la cantora ffaga lo abreuiar lo más que se puediere e vayan luego ala defunta. E quando leuaren la defunta ala eglesia en tanto que dixieren las oras canónicas, deue saber la cantora qué disen en coro; e ssy dixeren el Euangelio o 'Te deum laudamus' o algún responsorio, deuen atender enla claustra con la deffunta, mas deuen entrar luego en coro ffasta que ssea ffenesçido. E ssy por auentura enel coro cantaren otra cosa qual quier, que non ssea euanquelio nin 'Te deum laudamus' nin responso, non sse deuen parar enla claustra con la deffunta, mas deuen entrar luego enel coro e las que estan enel coro deuen dexar lo que disen e cantar con ella ffasta que ssea acomendada la defunta, e después començar aquello que disen en aquel logar do lo dexaron. E si fenescieren el ssalteryo antes que el cuerpo 2nd col. se sotierre, di- | -gan el offiçio delos defuntos dela ora del comer ffasta la noche 'Plaçebo domino' e 'Dirige' e 'Verba mea'. E ssy fenescieren el segundo ssalterio, digan 'In loco pasque e dominus rregit me'; e ssi el terçero, digan 'Complaceat' e 'Expectans expectauy'; e del comienço dela noche ffasta otro día, digan 'Dirige', o 'In loco pascue', o 'Complaçeat', e después 'Exultabunt domino'. E si fuere de día, lea ${ }^{45}$ la edomadaria las leçiones, e ssy denoche, lea las aquella a quien la cantora lo mandare.

\section{Chapter 134. Capítulo CXXXIIII. En quales tiempos pueden tomar bendición las monjas quando fueren de camino.}

En tienpo del verano pueden tomar las monjas la bendiçión alas laudes e a todas las otras oras saluo alas conpletas. Enlos días priuados pueden tomar la bendiçión alos matines. E las que an a tomar la bendiçión vayan a grado e vueluan se aderredor e inclinen sse o tomen venia ssegundo el tiempo. E quando vynieren de camino, non sse vueluan, mas en todo tiempo tomen venia. E de aquesta guisa, ffagan las que ffueren conla abbadesa ala yda e ala venida, assy a bendiçión como a oraçión. E ssy después que ouieren tomada la bendiçión por yr camino e antes que salgan dela claustra tanxiere la canpana a alguna ora o al cabillo o a collaçión, esse día ffynan. E quando ffueren ffuera del monesterio digan las oras con ssus preçes ordenada miente. Elas que fueren delas granjas o a alguna cassa del monesterio e se viniere esse mesmo día, non tomen bendiçión. Otrosí, las que vynieren, ssy en alguna granja non allbergaren o enla villa o en otro logar non comieren, non tomen bendiçión. E la bendiçión es a desir enla bos que disen la collecta ssy non alas laudes, e alas biesperas que es del desir mas baxo. Quando la abbadesa

f. 71v ffuere en camino o viniere en verano antes de terçia | e en ynuierno, después de terçia ffasta la nona puede oyr missa o puede $1 a^{46}$ desir. Assy los días alos ayunos

${ }^{45}$ lea] ms reads: lean.

${ }^{46}$ puede la] ms reads: pueden glioa. See EO 88.I6. 
como enlas de Pasqua e de Çinquagesma e enlas de Nabidat e en los grandes ofiçios delos defunctos, assy como es costunbre enlos ayunos acostunbrados, tengan asy en verano como en inuierno, ssy non ssy alguna abbadesa las ffisiesse yantar consigo en su mon<esteri>o tan ssola miente o con algún obispo o arçobispo o lego dela ssiella del apostoligo. En los grandes ayunos enlos quales es costunbre de comer conducho quaresmal, guarden lo segundo es costunbre [e] ala messa non ffablen. E ffuera delos monesterios de ssu orden non coman carne nin grossura nin aunque sea de carne. Mas aquellas que salieren del monestero, ssy esse día non tornaren, después quando vynieren vayan [a] faser oraçión e entrando enla eglesia echen sse el agua bendita e fagan oraçión segundo el tienpo que ffuere. Ssy non fallaren el conuento enel coro, mas ssy lo fallaren non disiendo las oras, ffagan oraçión fuera del coro. Mas ssy vynieren quando dixeren las oras, luego deuen entrar e aconpannar las que cantan ssy antes dela 'Gloria' del primero del primero psalmo vynieren, e ssi después dela 'Gloria' dél, vayan al grado [a] ffaser ssatisfaçión ssy non dixeren el 'Kyrie leyson'. El ssi fallaren la puerta dela eglesia çerrada, fagan oraçión ffuera; e ssy dentro del monesterio fueren quando tanxieren la canpana de manos lauar e non fueren a vielso dela mesa, pierdan la bendiçión. E ssy ffallaren tanniendo la canpana dela mesa, non vayan ala oraçión, mas entren enel refitor. En todo tienpo quando alguna toma la bendiçión ala conpleta, sy las las monjas yasen a preçes ssobre las formas, non sse leuanten en pie nin la que da la bendiçión, mas ssy ffallaren comiendo el conuento, vayan ala oraçión e después vengan e demanden ala cellerisa, o alas que siruen, sy entrara[n] o non. E sy las mandaren entrar, digan el verso en silençio es- | -tando enclinadas ssegundo el 2nd col. conuento ssuele ffaser e digan la bendiçión non fasiendo signo de crus. Esto ssea sienpre guardado ala yantar e ala çena. E ssy vinieren quando comen las que siruen, non demanden si entran. Mas si quando comieren las que siruen, ellas tarde vinieren, non las atiendan, e ellas, otrosí, non dexen de comer magre las otras sse leuanten, nin por el conuento ssi vyniere alos beueres, nin por que tangan la canpana ala collaçión antes que se acabe. Mas si viniere quando tanxieren ala collaçión, vayan con el conuento e con ellas diseiendo la conpleta e después coman e desta guisa ffagan así si alas conpletas vinieren. E ssi después de conpletas vinieren, coman e después degan sus oras en cabillo, e assy lo cumplan aquellas que ssalieren e tomaren aquel día mesmo que salieren del monesterio, las quales deuen catar ssy pudieren que vengan ala primera rrefecçión del conuento. E es a ssaber que en qualqier delas abadías de nuestra orden, monjas o freyras de nuestra orden ý vinieren, o tengan su orden assy como en sus monesterios, mas non digan en coro salmos nin antifanas nin lecçiones nin responsorios nin oficio de edomadaria, nin vytatorio non digan fasta que la abbadesa ge lo mande. Mas ssy prioradgo o otra obediençia ouiere por ssu obediençia, ninguna cosa non faga. Mas si priora fuere, tenga el primer logar después dela priora del monesterio. 


\section{f. 72r [Cómo an de contar en latín. Centum et cetera] ${ }^{47}$}

Centum, dosentum, trecenta, quadraginta, quingenta, ssegenta, ssetuaginta, occigenta, nonaginta, mille: este es el cuento con uasa o con condiçión que termina en 'a'. Centum, ducentusm, treçentos, quadrigentus, quingentus, secentus, otiggentus, nongentus, mille: este es el cuento con condiçión o palabra que ffenesçe en 'os', e ssi fuere palabra que ffenesçe en 'as', deue sse mudar la 'o' en 'a' en todos los cuentos assi commo ssy dixese de los otros cuentos. Deçem, viginta, triginta, quadraginta, qucaginta, sexaginta, sseptuaginta, octaginta, nonaginta, centum: este cuento es de contar assy syenpre con qual quier palabra que venga, si quier fenesca en 'a', sy quier en 'os', si quier en asy. Assy commo sy dixiesemos veginte o treginta. Vasa o taurus, o vacas. Esta manera de contar es muy ffuerte de ssaber a aquel que non ssabe gramática.

\section{Chapter 135. Capítulo CXXXV. Del tiempo que ay de la $<$ Setuagésima $>$ ffasta la Pascua, cómmo se an de ordenar.}

De la Ssetuagésima ffasta la Pasqua, los domingos e las fiestas de dose leciones, el ssábbado de la Sexagésima e dela Quincagésima que diran missa de Ssanta María, e los ssábados delas quatro temporas, e el Viernes dela Crus, e la vigilia de Pasqua e de Çinquagesma, ssienpre comiençe los tratos del coro que touieren vitatorio e

2nd col. digan el vn vielso del vn coro e el otro del otro e aposadas. | Mas el acabamiento delos tractos, todo el conuento los cante. Mas 'Benedictus est domine', aquella quele començare, le torne de cabo e desy cante le todo el conuento. Mas los otros tractos, aquella que toma el canto los comiençe e todo el conuento los cante en vno. E ssy enel domingo dela Ssetuagésima o Ssexagésima o Quintagésima viniere la ffiesta de Ssanta María que sserá la misa de terçia suya, ala missa matinal digan el tracto del domingo.

\section{Chapter 136. Capítulo CXXXXVI. De los Kyrios e la Gloria e los Ssanctus e Agnus ffestivales, en quales días son a desyr.}

Esto es a ssaber: quelos Quirios e la 'Gloria in excelsis' e los Ssanctus e los Agnus ffestuales son a desir en las ffiestas generales e todas las otras fiestas en que non labramos, e el domingo de Quasi modo ha Quirios ffestuales. Mas todos los domingos de todo el anno, así commo el domingo después de Navidat en que non viene ffiesta ninguna e el otro domingo después de la circuncisión e el otro del ochavario de epiphania e todos los otros de todo el anno, sson a desir los Quirios que desimos en las ffiestas en que labramos. Otrosy, es a saber [que] quando la vigilia de Assupçión de Santa María viniere en domingo, la missa matinal ssea del domingo e la mayor sserá dela vigilia con los Quirios que ssuelen desir en los domingos. 


\section{Chapter 137. Capítulo CXXXVII. De commo ha de bendesyr el agua el abbat o el conffessor el día de Ramos.}

El domingo de Ramos, el exorçismo del agua ssea ffecho del abbad e después el abbad comiençe la terçia desí[.] ${ }^{48}$ Acabada la terçia, tomen la verga pastoral e bendiga los rramos sobre el grado del presbiterio puestos ante dela ora dela misa del ssachristán. E estas cosas acabadas, | después que el cantor ofreçiere el ramo al abbat, comiençen el antifana 'Pueri ebreorum' e luego el ssachristan con ssu conpannero e aquellos a quien fuere mandado del prior, partan los rramos alos monjes e alos nouiçios; la otra parte dela alos ffrayres legos e ala conpann<í >a e alos huespedes, ssy hi fueren[. E] en tanto acabada la sobre dicha antifana, ssea cantada la otra 'Pueri hebreorum'. Pues estas cossas sson ordenadas: commiençe el cantor el antifana 'Ocurrunt turbe' e ssalga el subdiácono con el agua bendita e ssalga el diácono con la cruss descubierta e este subdiácono ssiga el conuento por aquella orden que estan en coro, yendo delante los monjes legos assi que el abbad o el ssaçerdote domadario; ssy el abbad no fuere, ý vaya postremero, e después delos noviçios, los ffrayres legos. E asy sea fecha la proçessión tan sola mente por la claustra. Mas el prior cate que alguna cosa non conueniere ssea ffallada enla claustra en tanto que esta proçesión ssea fecha o la otra dela Purificaçión de Santa María o dela Asçensión o de Assumçión Ssante Marie es fecha por la claustra[.] Acabada la antifana 'Occurunt turbe', ssea comentada el antifana 'Collegerunt'; e en tanto que esta es cantada, ssea fecha la primera estaçión enla parte que es çerca del dormitor. Acabada esta antifana, ssiga la luego el v<ielso > 'Vnus aunt', mueuan sse los ffrayres de aquel logar, e ssea fecha la ssegunda estaçión cerca el rrefitor; mas ala rrepitiçio de aquesta -es esta: 'Quod ffaçimus'- vayan los ffrayres ala postrimera estaçión çerca la eglesia. E en cada una estaçión el diácono e el ssubdiácono ayan sus ffazes tornadas e la crus tornada | al couento, e andando, e estando el sub- 2nd col. diácono antel diácono ssea. Pero enla postrimera estaçión, escomiença el cantor el antifana 'Aue rex noster', [e] encline se el conuento ala crus, ffincados los monjes e las manos en tierra. E todos leuantados ý, desi esten tornados ala crus ffasta que ssea començada la 'Gloria laus'; e en tanto que esta antifana 'Aue rex noster' es cantada, el ssachristan trayga el atryl que él antes de terçia ouo guardado en el cabillo con el libro delos euangelios e la epistola al logar ado es a leer el euangelio del diácono. E esto es ante la puerta dela eglesia; mas çerca del fin desta ssobre dicha antifana 'Aue rex noster', el diácono déla crus al ssubdiácono e esse subdiácono, en tanto, ponga el agua bendita [de] yuso. Mas quando el diácono ffuere cubierto dela epistola, tire sse un poco del atryl e pida bendiçión del abbad. E después, tornado contra oryente, lea el Euangelio e el subdiácono esté antél con la crus e aya su ffas tornada al conuento. E leydo el diácono el Euangelio, dexe la epistola e tome la crus e el ssubdiácono tome el agua bendita. E estonçe, esté el conuento

${ }^{48}$ desí] i.e.: de sí mismo (himself). 
las fases tornadas unos a otros. Mas dos frayres deuen ser amonestados del cantor çerca el ffyn del Euangelio; [e] entre enla eglesia e çerrada la puerta esten tornadas las ffases ala processión e canten los vyelsos ssegunt son ordenados en los libros. E estos vyelsos acabados, desos ssea rretornado el primero desos vielsos, 'Gloria laus', $e^{49}$ después tornen sse a la proçesión e estén en su orden. Pues estas cosas acabadas, assy momiençe el abbad el R<esponsorio> 'Ingredient domino' e entren

f. 73r le cantando todos en la eglesia; mas | los ramos que traen entrando por el coro, echen los ssobre el grado del presbiterio. E esstos rramos tire[n] los luego dende el ssacfristán; mas del día commo puso la crus, ý finque descubierta ffasta después de conpletas. E después ssea celebrada la missa commo en fiesta de un apostol. E es a saber que alas proçesiones que sson fechas por la claustra, non conuenga ý de andar alos huespedes, nin entrar enel cabillo alos semones sy non ffuere alguna tan onrrada persona a quien deua esto ser otorgado. E aquella semana del euangelio non la rresciba ningún diácono ssegundo orden nin el ssacerdote la domada dela missa, mas aquellos a quien el cantor acomendare estos ofiçios enla tabla con consejo del abbad, pero el diácono podrá mudar el cantor enel ssábbado sy fuere me[ne]ster.

\section{Chapter I38. Capítulo CXXXVIII. De la passión del día de Ramos.}

Mas enla passión del Día de Ramos, 'Dominus uobiscum' e 'Gloria tibi domine' [es] dicho. Mas alas passiones del martes e del miércoles, 'Dominus uobiscum' es dicho; mas 'Gloria tibi domine' non es dicho. Mas el viernes, nin 'Dominus uobiscum' nin 'Gloria tibi domine' non es dicho. E quando non es dicho ala passión 'Gloria tibi domine', non sse signen los frayres signo de crus.

\section{Chapter 139. Capítulo CXXXIX. Del jueves De la cena, cómmo an de aser en este día.}

El jueves antes de Pasqua, ssea celebrada la missa después dela primera festiual 2nd col. mente commo en fiesta de vn apostol e ssin venias e | todos los frayres, así los conuersos como los monjes, todos comulgen al mayor altar ssi la muchedumbre non lo enbargare; mas el diácono tantas hostias ponga al consagrar que ese día abaste. A Ssanta Comunión, atodos los frayres, assy por el ofiçio del sygiente commo la parte dela ssanta communio pueda ser por los enfermos; mas después de la paz, el Corpus Dominus sea tomado del vaso ssobre el altar e ssea puesto sobre la patena en quella ora que es a tomar[. E] assy luego ssea tollido el panno dese vaso, e otro panno ap $<$ re $>$ sentado aquella ora del sachristán ssea puesto ennese panno; e aquel panno mudado dese ssachristán. Luego, el abbat o el que canta la misa, ençierre onrrada mente la parte dela Santa comunión que es a guardar por el otro día en el vaso que desuso diximos. E estonçe, el panno viejo acuçiosa mente ssea ssacudido

49 e] ms reads: estos e. 
enla patena e ssea quinado ssobre la pisçina, e las cenisas dél ssean echadas ennllá. E es a saber: que eneste día missa priuada non ssea cantada de ninguno sy non para comulgar los conuersos o la muchedumbre lo demandare, e eso mismo sea del día po[r] la missa de Santa María, ala que ninguno este día non comulgue, e la missa cotidiana. 


\section{Appendix 2.}

The Obituary in MS 3 of the Museo Arqueológico de Madrid ${ }^{\mathrm{I}}$

MS 3 of the Museo Arqueológico de Madrid (hereinafter Arqueológico 3) is a lavishly decorated manuscript that belonged to Las Huelgas, where it was kept until it was confiscated and taken to the museum in 1968. ${ }^{2}$ The codex contains the calendar-martyrology used by the nuns of Las Huelgas, the Rule of Saint Benedict and other Cistercian texts. Table 7 below summarizes the contents of the book.

Table 7.

Contents of manuscript Arqueológico 3

\begin{tabular}{|c|l|}
\hline fol. & \multicolumn{1}{c|}{ Content } \\
\hline $1 \mathrm{v}$ & Obituary notes (later addition). \\
\hline $2 \mathrm{r}-7 \mathrm{v}$ & Calendar. \\
\hline $8 \mathrm{r}$ & $\begin{array}{l}\text { Document on the consecration of altars and sepulchres at Las Huelgas, 1279 (later } \\
\text { addition?). }\end{array}$ \\
\hline 9r-205v & Martyrology (with obituary notes in marginal additions). \\
\hline $206 \mathrm{r}-213 \mathrm{v}$ & $\begin{array}{l}\text { Various Cistercian letters and treatises (summarized in Revilla Vielva, 1934, and } \\
\text { Montero Torres, 1997). Super exordium cisterciensis cenobii; Exordium, etc. }\end{array}$ \\
\hline $215 \mathrm{v}-297 \mathrm{r}$ & Rule of Saint Benedict. \\
\hline $297 \mathrm{r}-298 \mathrm{v}$ & $\begin{array}{l}\text { Prayers for the dead (fol. 297r-v); notes on the election of the new abbot; on the } \\
\text { commencement of the Cistercian monastery, 1098 (fol. 298); on the dedication of the } \\
\text { church (1190; fol. 298v); on the promise made by the Cistercian abbot to the bishop } \\
\text { (fol. 298v). }\end{array}$ \\
\hline
\end{tabular}

The calendar-martyrology includes the Commemoratio omnium fratrum et sororum et falimiarium defunctorum ordinid nostri (fol. 2Ir-v). Under this rubric we find a list of the abbesses of Las Huelgas up to Urraca Martínez (†127I). Below the list, the principal scribe of the manuscript left a blank space for future additions and, lower down on the folio, continued writing: "Hec non et omnium

I I thank Carmen Julia Gutiérrez and Laura Fernández Fernández for shared discussions and thoughts in our joint examination of this manuscript at the Museo Arqueológico.

${ }_{2}^{2}$ Revilla Vielva, 1934; Montero Torres, 1987; Janini, 1962; Janini, I977, no. 208, p. I82; Domínguez Bordona, I933, I, no. I.I58, fig. 4IO. 
episcoporum atque abbatum et abbatissarum defunctorum ordinis nostre...”. This indicates that the manuscript was compiled at some time between I27I and I276, that is, during the abbesship of Urraca Díaz († c. 1273/76). Later, the blank space left by the principal scribe was used by a subsequent hand to add the names of abbesses deceased between 1287 and 1340 . $^{3}$

The manuscript therefore dates from the reign of Alfonso X and was almost certainly produced in the royal scriptorium. Its lavish decoration and miniatures (which include gold and elaborate pen-work) are comparable to other Alfonsine codices compiled in the I27Os and I280s, such as the astronomical manuscript now preserved in Paris, Bibliothèque de l'Arsenal, MS 8322 (see especially fol. 27v). ${ }^{4}$ It would be logical to assume that Arqueológico 3 was offered as a gift from Alfonso X to the convent of Las Huelgas, perhaps as part of the compensation for the nuptial ceremonies of his heir, Fernando de la Cerda, in I269, or for the transfer of the sepulchre of Alfonso's mother, Queen Beatriz, from Las Huelgas to Seville in I279. Interestingly enough, fol. 8r contains a copy of the document on the consecration of the altars and sepulchres organized by Alfonso X's sister at Las Huelgas in 1279, the same year in which the body of Queen Beatriz was transferred.' This is the same document edited in Lizoain, 1987 (doc. 596), whose reliability has been doubted by certain art historians on grounds that the only known copy is from the eighteenth century; its thirteenth-century copy in Arqueológico 3 definitely confirms the authenticity of the document.

Thereafter, a secondary hand added a number of obituary notes in the margins of the pages of the martyrology (Scribe Ob-I). The earliest personage cited is Henry II of England ( $\dagger$ II8I), father of the founding queen of Las Huelgas; the latest personages are the Infanta Berenguela ( $\dagger$ I288/90) and Isabel de Molina († I292). Accordingly, Scribe Ob-I must have added the obituary notes to the martyrology at some point between 1292 and I295, given that Sancho IV's obituary note ( $\dagger$ I295) was added by a third hand. Further obituary notes added by third hands are on fol. Iv (originally blank; notes added after I300, see Table 8); fol. 2Ir: Abbesses from María Gutiérrez († I287) to María González († 1340); fol. 66v: Infanta Blanca de Portugal († I32I); fol. 7Iv: King Sancho IV († I295); fol. I48r: Abbes Berenguela López ( $†$ I295).

${ }^{3}$ Curiously, this secondary scribe also omitted, perhaps by mistake, the name of Urraca Díaz († 1276).

${ }^{4}$ On the origins and dating of Paris 8322, see Fernández Fernández, 20IO-II.

5 The hand that copied this document is not that of the principal scribe of the codex. 
The absence of Alfonso X in Arqueológico 3's obituary is difficult to explain. Was Alfonso's anniversary actually celebrated at Las Huelgas? It is hard to determine to what extent the succession crisis between Alfonso $\mathrm{X}$ and his son Sancho IV played a role in this absence. Yet it is perhaps significant that Sancho IV's obituary note is the most extensive inscription dedicated to any king in the manuscript; Sancho's obituary even surpasses the flattery of the obituary note dedicated to Alfonso VIII, the founder of the monastery.

In any case, the manuscript contains a number of errors, such as the incorrect date of the death of Fernando III, the erroneous numbering of abbesses, missing abbesses, or repeated obituary notes.

The very latest personage mentioned in the codex is Abbess María González de Agüero († I340; fol. 2Ir).

\section{Table 8.}

Obituary notes in Arqueológico 3.

The numbers in the fourth column refer to the entries on Table 6 .

\begin{tabular}{|c|c|c|c|}
\hline fol. & Obituary & Identification & HC \\
\hline $1 \mathrm{v}$ & $\begin{array}{l}\text { Octauo decimo kalendas iulij [14 June] Item comemoratio } \\
\text { illustrissimi dompni Leodouici, regis Anglie. Et dompni } \\
\text { Alleffonssi, infancis filij regis Aragonie. Et dompni } \\
\text { Ferdinandi, infancis nobilissimi. Et dompni Sancij, } \\
\text { infantis et archiepiscopi toletani. Et dompni Philippi, } \\
\text { infantis nobilissimi. Et dompni Hemanuelis infantis } \\
\text { nobilissimi, filiorum Fernandi Regis Castelle et Legionis. } \\
\text { Quinto decimo kalendas iulij [17 June] Item comemoratio } \\
\text { dompni Ferdinandus, infantis nobilissimi. Et dompni } \\
\text { Petri, infantis nobilissimi. Et dompni Jaymis, infantis } \\
\text { nobilisimi. Item nobilisime dompne Berengarie, infantisse. } \\
\text { Et dompne Beatricis, infantisse nobilissime. Et dompne } \\
\text { Alionor, nobilissime infantisse, filiorum illustrissimi } \\
\text { Alleffonssi Regis Castelle et Legionis. }\end{array}$ & 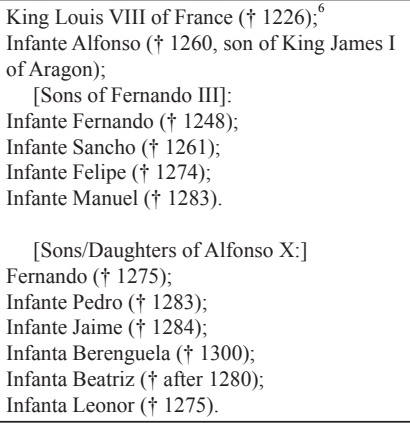 & $\begin{array}{c}30 \\
- \\
- \\
- \\
- \\
-\end{array}$ \\
\hline $9 \mathrm{r}$ & $\begin{array}{l}\text { VIGILIA NATALI DOMINI [24 January] } \\
\text { Obijt infans Hemanuel, filius illustrissimi Ferdinandi } \\
\text { Regis Castelle et Legionis. }\end{array}$ & $\begin{array}{l}\text { Infante Manuel, son of Fernando III of Castile } \\
\text { and León ( } \dagger 1283,25 \text { December) }\end{array}$ & 17 \\
\hline $16 r$ & $\begin{array}{l}\text { QVARTO NONAS IANUARIJ [2 January] } \\
\text { Obijt Nobilissima Constancia, famula dei et uirgo } \\
\text { mundissima, monaca Sancte Marie Regalis, filia illustris } \\
\text { Alleffonsus regis Castelle. }\end{array}$ & $\begin{array}{l}\text { Infanta Constanza, daughter of Alfonso VIII, } \\
\text { nun of Las Huelgas ( } \dagger 1243 \text {, January) }\end{array}$ & - \\
\hline
\end{tabular}

6 "Leodouici, regis Anglie" must be an error. It probably refers to the king of France, Louis VIII, who, incidentally, claimed the title of King of England from I216 to I217. The Cistercian Missal, MS 20324 of the Biblioteca Nacional de España, which J. Janini argues belonged to Las Huelgas (Janini and Serrano, 1969, no. I66, pp. 198-199), contains the obituary note "Obiit Ludovicus rex Francie" on 7 November (the king died on 8 November I226). 


\begin{tabular}{|c|c|c|c|}
\hline $17 \mathrm{v}$ & $\begin{array}{l}\text { NONAS IANUARIJ [5 January] } \\
\text { Obijt Inffantis Alleffonsus, filius illustris regis Legionis. }\end{array}$ & $\begin{array}{l}\text { Infante Alfonso de Molina, son of King } \\
\text { Alfonso IX of Leon, brother of Fernando III of } \\
\text { Castile and Leon ( } \dagger 1272,6 \text { January) }\end{array}$ & 18 \\
\hline $21 \mathrm{r}-\mathrm{v}$ & $\begin{array}{l}\text { III IDUS IANUARIJ [11 January] } \\
\text { [principal hand:] } \\
\text { COMMEMORATIO OMNIUM FRATRUM ET SORORUM ET } \\
\text { FALIMIARIUM DEFUNCTORUM ORDINID NOSTRI. Requiescant } \\
\text { in pace. Amen. } \\
\text { Item commemoratio domini Eugenij pape; } \\
\text { et dompne Sol huius loci abbatisse prime; } \\
\text { et dompne Marie secunde; } \\
\text { et domne Sancie tercie; } \\
\text { et dompne Marie quarte; } \\
\text { [secondary hand, in the margin:] } \\
\text { dompne Agnetis quondam abbatisse; } \\
\text { [principal hand:] } \\
\text { et dompne Eve quinte; } \\
\text { et dompne Vrrace sexte; } \\
\text { et dompne Urrace septime; } \\
\text { [third hand:] } \\
\text { dompne Marie octaue; } \\
\text { et dompne Berengarie none; } \\
\text { et domne Vrrace decime; } \\
\text { et domne Marie undecime. } \\
\text { [blank space] } \\
\text { [principal hand:] Hec non et omnium episcoporum atque } \\
\text { abbatum [21v] et abbatissarum defunctorum ordinis } \\
\text { nostre; et illustrissimi domini Allefonsi regis Castelle, et } \\
\text { uenerabilis uxoris eius regine domine Alionoris, patronum } \\
\text { et fundatorum monasterium Sancte Marie Regalis, et } \\
\text { filiorum eorumdem; nec non et serenissimi domini } \\
\text { Ferdinandi regis Castelle et Legionis et nobilissime uxoris } \\
\text { eius regine domine Beatricis; } \\
\text { [large blank space] } \\
\text { et aliorum benefactorum ordinis nostri. Requiescant in } \\
\text { pace. Amen. }\end{array}$ & 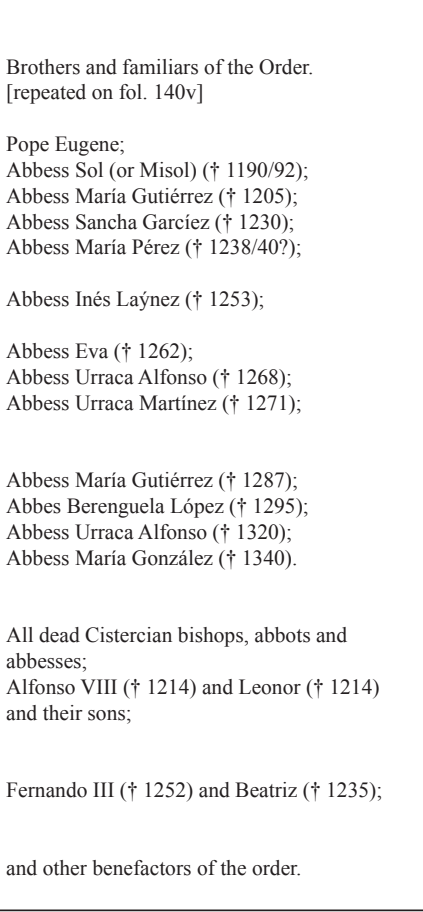 & \\
\hline $51 \mathrm{r}$ & $\begin{array}{l}\text { III IDUS MARCIJ [ } 13 \text { March] } \\
\text { Obijt dominus Alffonsus, infans Aragonie, filius domine } \\
\text { Lionor nobilissime regine. Anno domini M.CC.L.IX. }\end{array}$ & $\begin{array}{l}\text { Infante Alfonso of Aragon, son of James I of } \\
\text { Aragon and Leonor of Castile (daughter of } \\
\text { Alfonso VIII of Castile) ( } \dagger 1260,23 \text { March) }\end{array}$ & 19 \\
\hline $63 \mathrm{r}$ & $\begin{array}{l}\text { IV IDUS APRILIS [10 April] } \\
\text { Obijt dompna Sol abbatissa prima Sancte Marie Regalis. }\end{array}$ & Abbess Sol (or Misol) $(† 1190 / 92)$ & - \\
\hline $66 \mathrm{v}$ & $\begin{array}{l}\text { XV KALENDAS MAIJ [17 April] } \\
\text { Obijt Nobilisima ac illustrissima humilissima ancilla } \\
\text { Christi, Infantissa dompna Blanca, serenissimi regis } \\
\text { portugalie filia, qui fuit columpna degencium necnon } \\
\text { totius ordinis cisterciensis sustentacionem, per cuius } \\
\text { in<par>titu languescit huius cenobium. Era M.CCC.LIX. } \\
\text { [anno 1321] }\end{array}$ & $\begin{array}{l}\text { Infanta Blanca of Portugal }(\dagger 1321,15-25 \\
\text { April) }\end{array}$ & $\begin{array}{l}2, \\
35\end{array}$ \\
\hline $71 \mathrm{v}$ & $\begin{array}{l}\text { VI KALENDAS MAIJ [26 April] } \\
\text { Obijt triumphator magnificus, belliger inuictus } \\
\text { illustrissimus, memoria dignus, deo deuotus, Rex Sancius, } \\
\text { cuius marte sensit Africa, cuius leuitatem desiderauit } \\
\text { Gallia, cuius genus astiný Portugaliam, cuius zelus } \\
\text { comprehensit Aragoniam, nobilis Ilifonsi regis Castelle et } \\
\text { Legionis filius. }\end{array}$ & King Sancho IV $(† 1295,25$ April $)$ & 21 \\
\hline $80 \mathrm{r}$ & $\begin{array}{l}\text { VI IDUS MAIJ [10 May] } \\
\text { Obijt infans Fredricus, filius illustrissimi Fernandi regis } \\
\text { Castelle et Legionis. }\end{array}$ & $\begin{array}{l}\text { Infante Fadrique, son of Fernando III of Castile } \\
\text { and Leon, executed by order of his brother } \\
\text { Alfonso X († 1277) }\end{array}$ & 22 \\
\hline
\end{tabular}




\begin{tabular}{|c|c|c|c|}
\hline $91 \mathrm{v}$ & $\begin{array}{l}\text { III KALENDAS JUNIJ [ } 30 \text { May] } \\
\text { Obijt dominus Ferdinandus, deuotissimus rex Castelle et } \\
\text { Legionis. Era millesima CC.LXXX.V. [anno 1247; but } \\
\text { this date is certainly a mistake]. }\end{array}$ & $\begin{array}{l}\text { King Fernando III of Castile and Leon, 'the } \\
\text { Saint' }(\dagger 1252,30 \text { May) }\end{array}$ & 23 \\
\hline $95 \mathrm{v}$ & $\begin{array}{l}\text { VIII IDUS JUNIJ [6 June] } \\
\text { Obijt Enricus rex, filius Alffonsi regis Castelle. }\end{array}$ & King Enrique I († 1217, 6 June) & - \\
\hline $103 \mathrm{r}$ & $\begin{array}{l}\text { X KALENDAS JULIJ [22 June] } \\
\text { Obit nobilessima et uenerabilis Alienor regina Aragonie, } \\
\text { filia Alleffonsi illustri regis castelle. Era M.CC.LXXXII. } \\
\text { [anno 1244] }\end{array}$ & $\begin{array}{l}\text { Queen Leonor of Aragon, daughter of Alfon- } \\
\text { so VIII, queen consort of Aragon by virtue } \\
\text { of her marriage to King Jaime I de Aragón } \\
(\dagger 1244)\end{array}$ & 25 \\
\hline $110 \mathrm{r}$ & $\begin{array}{l}\text { V NONAS JULiJ [3 July] } \\
\text { Obijt Sancia abbatissa III Sancta Marie Regalis. Anni ab } \\
\text { incarnatione domini M.CC.XXX. [1230] }\end{array}$ & Abbess Sancha $(\dagger 1230)$ & - \\
\hline $112 \mathrm{r}$ & $\begin{array}{l}\text { NONAS JULIJ [7 July] } \\
\text { Anniversarij rex Henrricus maior Anglie secundus. Era } \\
\text { M.CC.XXVII. [anno 1189]. }\end{array}$ & King Henry II of England († 1189, 6 July) & - \\
\hline $118 v$ & $\begin{array}{l}\text { XII KALENDAS AUGUSTI [21 July] } \\
\text { Obijt dompna Vrraca abbatissa VII Sancte Marie Regalis. }\end{array}$ & Abbess Urraca Martínez $(†$ 1271) & - \\
\hline $119 \mathrm{v}$ & $\begin{array}{l}\text { X KALENDAS AUGUSTI [23 July] } \\
\text { Obijt nobilissima Constancia, famula dei, monacha Sancte } \\
\text { Marie Regalis, filia illustrissimi Allefonsi regis Castelle et } \\
\text { Legionis. Era M.CCC.XVIII. [anno 1280] }\end{array}$ & $\begin{array}{l}\text { Infanta Constanza, daughter of Alfonso X, } \\
\text { nun of Las Huelgas, died at age } 21(\dagger 1280 \text {, } \\
23 \text { July) }\end{array}$ & 28 \\
\hline $121 \mathrm{v}$ & $\begin{array}{l}\text { VI KALENDAS AUGUSTI [27 July] } \\
\text { Obijt infans Ferdinandus, primogenitus filius et heres } \\
\text { illustrissimus domini Allefonsus regis Castelle et Legionis. } \\
\text { Era M.CCC.XIII. [anno 1275] }\end{array}$ & Infante Fernando de la Cerda ( $† 1275,25$ julio) & 30 \\
\hline $129 \mathrm{v}$ & $\begin{array}{l}\text { II idus augusti [12 August] } \\
\text { Obijt dompna Eva abbatissa V Sancte Marie Regalis. }\end{array}$ & Abbes Eva $(\dagger 1262)$ & - \\
\hline $130 \mathrm{v}$ & $\begin{array}{l}\text { XIX KALENDAS SEPTEMBRIS [14 August] } \\
\text { Obijt Maria abbatissa II Sancte Marie Regalis, orate pro } \\
\text { illa. Era M.CC.XL.III. [anno 1205] }\end{array}$ & Abbess María Gutiérrez $(† 1205)$ & - \\
\hline $144 \mathrm{r}$ & $\begin{array}{l}\text { VIII IDUS SAPTEMBRIS [6 September] } \\
\text { Obijt infantissa Constancia, filia regis Legionis, monialis } \\
\text { Sancte Maria Regalis. Era millesima docentesima } \\
\text { octogesima. [anno 1242] }\end{array}$ & $\begin{array}{l}\text { Infanta Constanza, daughter of Alfonso IX de } \\
\text { León, }(\dagger 1242,7 \text { September) }\end{array}$ & 33 \\
\hline $148 \mathrm{r}$ & $\begin{array}{l}\text { XVIII KALENDAS OCTOBRIS [14 September] } \\
\text { Obijt domina Berengare, XI [correction by a third hand: } \\
\text { IX] abbatissa Sancte marie Regails. }\end{array}$ & Abbess Berengela López († 1295) & - \\
\hline $149 \mathrm{v}$ & $\begin{array}{l}\text { XV KALENDAS OCTOBRIS [17 September] } \\
\text { Anime fratrum et familiarium hec defunctorum ordine } \\
\text { nostri. R.I.P. }\end{array}$ & $\begin{array}{l}\text { Brothers and familiars of the Order. } \\
\text { [Repeated on f. } 21 r]\end{array}$ & \\
\hline $151 \mathrm{r}$ & $\begin{array}{l}\text { VII KALENDAS OCTOBRIS [ } 25 \text { September] } \\
\text { Obijt infans Ferdinandus filius regis Castelle et Legionis. }\end{array}$ & $\begin{array}{l}\text { Infante Fernando of Castile, son of Fernan- } \\
\text { do III († 1248?). }\end{array}$ & - \\
\hline $160 \mathrm{r}$ & $\begin{array}{l}\text { II NONAS OCTOBRIS [6 October] } \\
\text { Obijt Allefonsus rex gloriosus Castelle. } \\
\text { [at the bottom of the folio:] } \\
\text { Obijt illustrissimus Allefonsus rex Castelle, hedificator } \\
\text { monasterij Sancte Marie Regalis, qui potentissimum } \\
\text { regem marrochitanum campestri prelio superauit in loco } \\
\text { qui dicitur Las naua de Tolosa. Era m.CC.LII. [anno 1214] }\end{array}$ & $\begin{array}{l}\text { King Alfonso VIII, founder of the monastery } \\
(\dagger 1214,6 \text { October) }\end{array}$ & 1 \\
\hline $163 v$ & $\begin{array}{l}\text { III IDUS OCTOBRIS [13 October] } \\
\text { Obijt nobilissima ac inclita humilis ancilla Ihesu Christi } \\
\text { domina Berengeria i } \\
\text { Infantissa, monialis Sancte Marie Regalis, illustrissimi } \\
\text { domini Fernandi regis Castelle et Legionis filia. }\end{array}$ & $\begin{array}{l}\text { Infanta Berenguela, daughter of Fernando III, } \\
\text { señora of Las Huelgas ( } \dagger \text { 1288-1290) }\end{array}$ & 13 \\
\hline $164 \mathrm{r}$ & $\begin{array}{l}\text { II IDUS OCTOBRIS [14 October] } \\
\text { Obijt Insans dompnus Ferdinandus filius Alleffonsus } \\
\text { serenissimus regis Castelle. Era M.CC.XL.nona. [anno 1211] }\end{array}$ & $\begin{array}{l}\text { Infante Fernando, son of Alfonso VIII }(\dagger 1211 \text {, } \\
14 \text { October) }\end{array}$ & 3 \\
\hline
\end{tabular}




\begin{tabular}{|c|c|c|c|}
\hline $171 v$ & $\begin{array}{l}\text { V KALENDAS NOUEMBRIS [ } \mathbf{2 8} \text { October] } \\
\text { Obijt dominus Sancius, illustris archiepiscopus toletanus. }\end{array}$ & $\begin{array}{l}\text { Infante Sancho, son of Fernando III of Castile } \\
\text { and Leon, archbishop elect of Toledo }(\dagger 1261, \\
27 \text { October) }\end{array}$ & 4 \\
\hline $173 v$ & $\begin{array}{l}\text { UIGILIA OMNIUM SANCTORUM [ca. } 31 \text { October] } \\
\text { Obijt nobilissima et uenerabilis Berengaria regina Castelle } \\
\text { et Legionis, fillia Alleffonsi illustris regis Castelle. }\end{array}$ & $\begin{array}{l}\text { Queen Berenguela of Castile, daughter of } \\
\text { Alfonso VIII and Leonor. }(\dagger 1246, \\
8 \text { November) } \\
{[\text { Repeated on fol. 176v] }}\end{array}$ & 6 \\
\hline $175 \mathrm{r}$ & $\begin{array}{l}\text { IIII NONAS NOUEMBRIS [2 November] } \\
\text { Obijt Alionor, uenerabilis regina Castelle, vxor } \\
\text { senerissimum [sic] regis Castelle domnu Aldefonsi, qui } \\
\text { fuerunt fundatores huius cenobij. }\end{array}$ & $\begin{array}{l}\text { Queen Leonor, wife of Alfonso VIII, founder } \\
\text { of the Las Huelgas Monastery ( } \dagger 1214 \text {, } \\
31 \text { October) }\end{array}$ & 5 \\
\hline $176 v$ & $\begin{array}{l}\text { NONAS NOUEMBRIS [ } 5 \text { November] } \\
\text { Obijt nobilissima et uenerabilis et potens Berengaria } \\
\text { regina Castelle et Legionis, fillia Alleffonsi illustris regis } \\
\text { Castelle. }\end{array}$ & $\begin{array}{l}\text { Queen Berenguela of Castile, daughter } \\
\text { of Alfonso VIII and Leonor. }(\dagger 1246,8 \\
\text { November) } \\
{[\text { Repeated on fol. } 173 \mathrm{v}]}\end{array}$ & 6 \\
\hline $177 \mathrm{r}$ & $\begin{array}{l}\text { VIII IDUS NOUEMBRIS [6 November] } \\
\text { Obijt nobilissima et uenerabilis Beatrix regina Castelle, } \\
\text { uxor domini Ferdinandi serenissimum regis Castelle et } \\
\text { legionis, filia Philipi romanorum imperatoris. }\end{array}$ & $\begin{array}{l}\text { Queen Beatriz, wife of Fernando III }(\dagger 1235 \text {, } \\
5 \text { November) }\end{array}$ & 7 \\
\hline $178 \mathrm{r}$ & $\begin{array}{l}\text { VI IDUS NOUEMBRIS [8 November] } \\
\text { Obijt Vrraca regina uxor regis Portugalis, filia illustrissimi } \\
\text { regis Aldeffonsi de Castella. }\end{array}$ & $\begin{array}{l}\text { Queen Urraca, daughter of Alfonso VIII, } \\
\text { infanta of Castile and queen consort of } \\
\text { Portugal by virtue of her marriage to Alfonso } \\
\text { II of Portugal ( } \dagger 1220,30 \text { November); } \\
\text { [Repeated on fol. } 192 \mathrm{v}]\end{array}$ & 10 \\
\hline $182 \mathrm{r}$ & $\begin{array}{l}\text { XVII KALENDAS DECEMBRIS [15 November] } \\
\text { Obijt infans Philipus illustrissimi Ferdinan[d]i regis } \\
\text { Castelle. }\end{array}$ & $\begin{array}{l}\text { Infante Felipe of Castile, son of Fernando III, } \\
\text { archbishop elect of Seville ( } \dagger 1274, \\
28 \text { November) }\end{array}$ & 8 \\
\hline $182 \mathrm{v}$ & $\begin{array}{l}\text { XVI KALENDAS DECEMBRIS [16 November] } \\
\text { Obijt dompna Maria de Guzman abatissa IIII Sancte marie } \\
\text { Regalis. Era M.CC.LXX.V. [anno 1237] }\end{array}$ & Abbess María Pérez († 1237) & - \\
\hline $192 \mathrm{r}$ & $\begin{array}{l}\text { IIII KALENDAS DECEMBRIS [ } 28 \text { November] } \\
\text { Dompna Blanca regina Francie. }\end{array}$ & [Repeated on fol. 192v] & 10 \\
\hline $192 \mathrm{v}$ & $\begin{array}{l}\text { III KALENDAS DECEMBRIS. [ } 29 \text { November] } \\
\text { Obierunt inclite femine dompna Vrraca regina Portudalie } \\
\text { et dompna Blanca regina Francie, filie illustrissimi } \\
\text { Alleffonsi quondam regis Castelle. }\end{array}$ & $\begin{array}{l}\text { Queen Urraca, daughter of Alfonso VIII, } \\
\text { infanta of Castile and queen consort of } \\
\text { Portugal by virtue of her marriage to Alfonso } \\
\text { II of Portugal († 1220, } 30 \text { November); } \\
\text { Queen Blanca, daughter of Alfonso VIII, } \\
\text { infanta of Castile and queen consort of France } \\
\text { by virtue of her marriage to King Luis VIII } \\
\text { ( } \dagger 1252,29 \text { November) } \\
\text { [Repeated on fol. } 192 \text { r] }\end{array}$ & $\begin{array}{l}9, \\
10\end{array}$ \\
\hline $196 \mathrm{r}$ & $\begin{array}{l}\text { NONAS DECEMBRIS [5 December] } \\
\text { Obijt dompna Helisabet monialis filia inclita infantis } \\
\text { domini Allefonsi de Molina. }\end{array}$ & $\begin{array}{l}\text { Isabel de Molina, daughter of Alfonso } \\
\text { Fernández, bastard son of Alfonso X. († 1292) }\end{array}$ & 11 \\
\hline $204 \mathrm{r}$ & $\begin{array}{l}\text { XIII KALENDAS IANUARIJ [20 December] } \\
\text { Obijt dompna Urraca abbadessa VI. }\end{array}$ & Abbess Urraca Alfonso $(\dagger 1268)$ & - \\
\hline
\end{tabular}




\section{Table 9.}

Abbesses mentioned in Arqueológico 3. The dates in the left-hand column relate to the abbesses' documentation as reported in Gutiérrez, 2014.

\begin{tabular}{|c|c|c|c|}
\hline \multicolumn{2}{|r|}{ Abbesses documented in Las Huelgas } & \multirow{2}{*}{\begin{tabular}{l}
\multicolumn{1}{c}{ List on fol. 21r } \\
$\begin{array}{l}\text { Sol huius loci abbatisse } \\
\text { prime }\end{array}$
\end{tabular}} & \multirow{2}{*}{$\begin{array}{l}\text { Marginal notes added to the Martyrology } \\
\text { fol. 63r: Sol abbatissa prima }\end{array}$} \\
\hline 1 & \begin{tabular}{|l} 
Sol (or Misol) \\
$1187-1190 / 92$ \\
\end{tabular} & & \\
\hline 2 & $\begin{array}{l}\text { María Gutiérrez } \\
1190 / 92-1205 / 07\end{array}$ & Marie secunde & $\begin{array}{l}\text { fol. 130v: Maria abbatissa II } \\
\text { [anno 1205] }\end{array}$ \\
\hline \multirow[t]{2}{*}{3} & $\begin{array}{l}\text { Sancha Garcíez } \\
1205 / 07-1230\end{array}$ & Sancie tercie & $\begin{array}{l}\text { fol. 110r: Sancia abbatissa III } \\
\text { [anno 1230] }\end{array}$ \\
\hline & \multicolumn{3}{|c|}{ Between 1230 and 1232 there was no abbess at the convent. } \\
\hline 4 & $\begin{array}{l}\text { María Pérez de Guzmán } \\
1232-1238 / 40 ?\end{array}$ & Marie quarte & $\begin{array}{l}\text { fol. 182v: Maria de Guzman abatissa IIII } \\
\text { [anno 1237] }\end{array}$ \\
\hline 5 & $\begin{array}{l}\text { Inés Laýnez } \\
1240-1253\end{array}$ & $\begin{array}{l}\text { Agnetis, quondam } \\
\text { abbatisse } \\
\text { [marginal add.] }\end{array}$ & - \\
\hline 6 & $\begin{array}{l}\text { Elvira Fernández } \\
1254-1261 \text { [excommunicated] }\end{array}$ & - & - \\
\hline 7 & $\begin{array}{l}\text { Eva } \\
1261-1262\end{array}$ & Eve quinte & fol. 129v: Eva abbatissa $\mathrm{V}$ \\
\hline 8 & $\begin{array}{l}\text { Urraca Alfonso } \\
1263-1268\end{array}$ & Vrrace sexte & fol. 204r: Urraca abbadessa VI \\
\hline 9 & $\begin{array}{l}\text { Urraca Martínez } \\
1268 / 70-1271\end{array}$ & Urrace septime & fol. 118v: Vrraca abbatissa VII \\
\hline 10 & $\begin{array}{l}\text { Urraca Díaz } \\
1272-1273 / 76\end{array}$ & - & - \\
\hline 11 & $\begin{array}{l}\text { María Gutiérrez } \\
1273 / 76-1287\end{array}$ & $\begin{array}{l}\text { Marie octaue } \\
\text { [latter add.] }\end{array}$ & - \\
\hline 12 & $\begin{array}{l}\text { Berenguela López } \\
1288-1295\end{array}$ & $\begin{array}{l}\text { Berengarie none } \\
\text { [latter add. }]\end{array}$ & $\begin{array}{l}\text { fol. 148r: Berengare, XI [correction by a third } \\
\text { hand: IX] abbatissa }\end{array}$ \\
\hline 13 & $\begin{array}{l}\text { Urraca Alfonso } \\
1296-1320\end{array}$ & $\begin{array}{l}\text { Vrrace decime } \\
\text { [latter add.] }\end{array}$ & - \\
\hline 14 & $\begin{array}{l}\text { María González Agüero } \\
1321-1340\end{array}$ & $\begin{array}{l}\text { Marie undecime } \\
\text { [latter add.] }\end{array}$ & - \\
\hline
\end{tabular}

